Preprint submitted to Quaternary Geochronology chlorine-36, aluminum-26, helium-3, carbon-14

\title{
Cosmogenic Nuclide Systematics and the CRONUScalc Program
}

\author{
Shasta M. Marrero ${ }^{\mathrm{a}, \mathrm{b}}$, Fred M. Phillips ${ }^{\mathrm{b}}$, Brian Borchers ${ }^{\mathrm{c}}$, Nathaniel \\ Lifton $^{\mathrm{d}}$, Robert Aumer ${ }^{\mathrm{e}, \mathrm{c}}$, Greg Balco ${ }^{\mathrm{f}}$ \\ ${ }^{a}$ Corresponding author; University of Edinburgh, School of Geosciences, Drummond \\ Street, Edinburgh, EH8 9XP, UK \\ ${ }^{b}$ New Mexico Tech, Earth 83 Environmental Science Dept., Socorro, NM, 87801, USA \\ ${ }^{c}$ New Mexico Tech, Department of Mathematics, Socorro, NM, 87801, USA \\ ${ }^{d}$ Purdue University, West Lafayette, IN, USA \\ ${ }^{e}$ Current position: BENTEK Energy, 32045 Castle Court, Ste. 200, Evergreen, CO \\ 80439, USA \\ ${ }^{f}$ Berkeley Geochronology Center, Berkeley, CA 94709, USA
}

\begin{abstract}
As cosmogenic nuclide applications continue to expand, the need for a common basis for calculation becomes increasingly important. In order to accurately compare between results from different nuclides, a single method of calculation is necessary. Calculators exist in numerous forms with none matching the needs of the CRONUS-Earth project to provide a simple and consistent method to interpret data from most commonly used cosmogenic nuclides. A new program written for this purpose, CRONUScalc, is presented here. This unified code presents a method applicable to ${ }^{10} \mathrm{Be},{ }^{26} \mathrm{Al},{ }^{36} \mathrm{Cl},{ }^{3} \mathrm{He}$, and ${ }^{14} \mathrm{C}$, with ${ }^{21} \mathrm{Ne}$ in testing. The base code predicts the concentration of a sample at a particular depth for a particular time in the past, which can be used for many applications. The multi-purpose code already includes functions for calculating surface exposure age for a single sample or for a depth profile containing multiple samples. The code is available under the GNU General Public License agreement and can be downloaded and modified to deal with specific atypical scenarios.
\end{abstract}

Keywords: cosmogenic nuclide, exposure age calculator, beryllium-10, 


\section{Introduction}

The CRONUS-Earth Project, funded by the U.S. National Science Foundation, is intended to improve many aspects of cosmogenic isotope use and help create a consistent, accurate use of the technique within the community. It functioned in collaboration with CRONUS-EU, a similarly motivated group in Europe funded by the European Commission. One important part of that project is the creation of a code that can consistently perform necessary calculations for different scaling schemes and that is applicable to many of the commonly used nuclides $\left({ }^{10} \mathrm{Be},{ }^{26} \mathrm{Al},{ }^{36} \mathrm{Cl},{ }^{3} \mathrm{He},{ }^{14} \mathrm{C}\right)$. The program presented here, called CRONUScalc, is a joint effort by the CRONUS Project to incorporate all major contemporary advances in the understanding of cosmogenic-nuclide production and to treat all the commonly used nuclides in an internally consistent fashion. This calculator directly incorporates much of the format and function of the ${ }^{26} \mathrm{Al} /{ }^{10} \mathrm{Be}$ code by Balco et al. (2008), but it extends the functionality beyond ${ }^{26} \mathrm{Al} /{ }^{10} \mathrm{Be}$ as well as introducing other new features. The new CRONUScalc code keeps the original modular format, but has updated the code with functions to perform production/accumulation calculations, calibrations, and surface and depth profile exposure ages and erosion rates.

The base code of CRONUScalc predicts the cosmogenic nuclide concentration in a sample (of either finite or point thickness) at a given depth at a particular time in the past. This function allows great versatility in earth science applications. CRONUScalc can be used to predict concentrations of a suite of nuclides for a variety of purposes. The code is published under the GNU General Public License, version 2 terms. The basic code can be modified to output many different parameters and can be downloaded (https://bitbucket.org/cronusearth/cronus-calc) and modified to suit a user's particular needs. The code repository is open to user contributions, allowing for sharing and future growth of the program. The version of the program described in this paper is marked online as Version 2.0 in the downloadable repository.

The code has been used to create two specific calculators to address the common need to calculate surface exposure ages from unknown samples. The two calculators that are included with the program are a single-sample surface exposure age calculator and a multi-sample depth-profile calculator. Additional functions in the code are designed to calibrate production rates, test alternative scaling frameworks, and determine erosion rates. 
The fundamental theory and assumptions that have gone into the code are described in this paper. This paper matches the CRONUScalc downloadable version 2.0 available in the repository. There are significant new features in CRONUScalc as compared to previous calculators, including a more accurate method of integration through time and depth, updated geomagnetic history, newly produced calibration data sets, updated and calibrated muon production model, and the ability to calculate exposure ages for single samples at depth or perform a calibration.

\section{CRONUScalc Program Systematics}

The complete set of equations and fundamental theory behind the code can be found in Appendix A and will be useful for those new to the topic or interested in particular details because Appendix A systematically documents all the equations used in CRONUScalc, without need for the reader to refer back to numerous prior publications. The sections contained in the main body of the paper are designed to provide a general cosmogenic user with a summary of the systematics and relevant publications, focusing on the new research developments compared to the code described in Balco et al. (2008). A standard reference that describes the equations for production of cosmogenic nuclides is Gosse \& Phillips (2001). The equations given in that paper have provided the baseline for numerous applications of cosmogenic nuclides. CRONUScalc is an implementation of equations from Gosse \& Phillips (2001) and from newer sources, as described in each section.

\subsection{Production Equations}

\subsubsection{Spallation}

Cosmogenic-nuclide production from spallation, defined for this purpose as the interaction of a high-energy particle with a target nucleus producing a cosmogenic nuclide as a product of the reaction, follows a well-established exponential decrease with depth. At the surface, spallation is typically the dominant production mechanism. All the nuclides discussed in this paper are produced through at least one spallation pathway. The formula for the instantaneous production rate from spallation $\left(P_{s, m}\right)$ is (Gosse \& Phillips, 2001; Schimmelpfennig et al., 2008):

$$
P_{\mathrm{s}, \mathrm{m}}(Z)=S_{T} \sum S_{e l, s} P_{\mathrm{m}, \mathrm{k}}(0) C_{\mathrm{k}} \exp \left(-\frac{Z}{\Lambda_{\mathrm{f}, \mathrm{e}}}\right)
$$


where $P_{\mathrm{m}, \mathrm{k}}$ is the modern sea-level, high-latitude production rate of species $\mathrm{m}$ by spallation of element $\mathrm{k}$ at 2010 solar modulation (atoms $\mathrm{g}^{-1} \mathrm{a}^{-1}$ ); $S_{T}$ is the topographic shielding factor (unitless); $S_{e l, s}$ is the geographical scaling factor for spallation reactions for the particular reaction of interest, which varies temporally due to fluctuations in the geomagnetic field or solar magnetic field (unitless); $C_{\mathrm{k}}$ is the concentration of the element $\mathrm{k}$ (atoms $\mathrm{g}^{-1}$ $\mathrm{a}^{-1}$ ); and $\Lambda_{\mathrm{f}, \mathrm{e}}$ is the effective attenuation length for the spallogenic reactions (applies to fast neutrons and spallogenic protons) $\left(\mathrm{g} \mathrm{cm}^{-2}\right)$. The production is summed for all target elements $\mathrm{k}$ that produce nuclide $\mathrm{m}$ to give the total spallation production rate.

\subsubsection{Epithermal and Thermal Neutrons}

Low-energy cosmogenic nuclide production, including that from thermal and epithermal neutrons, does not follow a simple exponential pattern with depth due to the atmosphere-ground interface effects. Low-energy neutrons produced in the upper $\sim 50 \mathrm{~cm}$ of rock tend to diffuse upward out of the rock and into the atmosphere, resulting in a reduction of the flux as the rock surface is approached. Phillips et al. (2001) analytically solved the neutronflux differential equation across the land/atmosphere interface to obtain the appropriate production equations.

The production of cosmogenic nuclides via the low-energy pathway is dependent on the neutron flux, which is, in turn, dependent on the composition of the rock. In order to calculate production from this pathway using a universal parameter, the value $P_{f}(0)$ is calibrated instead of any parameter dependent on composition. The $P_{f}(0)$ parameter is the production rate of epithermal neutrons from fast neutrons in the air just above the surface. This parameter can be used in conjunction with the sample-specific composition to calculate the applicable production rates.

Cosmogenic nuclide production via low-energy neutrons is implemented as described in Gosse and Phillips (2001), except for a small modification to the calculation of muon-induced neutrons (discussed in Section 2.1.3). In several cases, small typos in Gosse and Phillips (2001) were also corrected (see the appendix for the corrected equations). Low-energy production is currently only implemented for ${ }^{36} \mathrm{Cl}$, but could be modified by advanced users to apply to other nuclides with low-energy production pathways, such as ${ }^{3} \mathrm{He}$. 


\subsubsection{Muons}

Although muons make up a large portion of the incoming cosmic-ray flux at the earth's surface, the low interaction rate means that they penetrate more deeply into the subsurface than neutrons. Muon contributions to total cosmogenic nuclide production are typically small at the surface, but become important at depth (Stone et al., 1998). Accurate calculation of muogenic production is thus important for sampling sites with large erosion rates or samples at depth.

Early calculators employed an exponential approximation for production from muons reactions according to Stone et al. (1998). Balco et al. (2008) implemented a newer model by Heisinger et al. (2002b,a) that calculates the production from muon reactions using physical parameters determined from laboratory irradiation experiments. Braucher et al. (2003) used a deep core to provide evidence that the parameters specified by Heisinger et al. (2002a,b) overestimated actual ${ }^{10}$ Be production by fast muons by approximately a factor of two. This was supported by additional profile data measured by Braucher et al. (2011) and by Kim \& Englert (2004), as well as reanalysis of previously published deep profile data by Braucher et al. (2013).

Rather than using parameters estimated from laboratory muon irradiations, the CRONUS-Earth Project has adopted values calibrated from nuclideconcentration profiles at carefully selected sites (Fig 1 in Phillips et al., 2015; Marrero, 2012; Borchers et al., 2015). A 30-m deep quartzite core from Antarctica has allowed the calibration of muon production parameters for ${ }^{26} \mathrm{Al}$ and ${ }^{10} \mathrm{Be}$ (Fig 1 in Phillips et al., 2015). For ${ }^{36} \mathrm{Cl}$, previously published data sets (Evans, 2001; Stone et al., 1998) collected from quarry profiles were used to reparameterize the muon model for cosmogenic ${ }^{36} \mathrm{Cl}$ production from muons on Ca and K (Marrero, 2012). A CRONUS-Earth depth profile was not measured for ${ }^{14} \mathrm{C}$, and ${ }^{14} \mathrm{C}$ profiles measured by other investigators (Kim et al., 2007; Lupker et al., 2013, 2015) have shown problems with distinguishing slow-muon production from production by muogenic neutrons, therefore at present CRONUScalc uses the values from Heisinger et al. (2002a,b) for ${ }^{14} \mathrm{C}$. This may result in less accuracy for the calculation of muogenic ${ }^{14} \mathrm{C}$ production than for other nuclides, but ongoing investigations (Lupker et al., 2013, 2015) may yield improved parameter values in the near future.

Nuclide production by fast muon reactions $\left(P_{\mu, \text { fast }}\right)$ is described by Equation 2 (Heisinger et al., 2002b). The parameter $\sigma_{0}$ was selected as the calibration parameter for the production of nuclides by muon reactions, as dis- 
cussed in (Fig 1 in Phillips et al., 2015). This was mainly because it is the only nuclide-dependent parameter in the fast production equation. However, direct calibration of the $\sigma_{0}$ parameter also eliminates any dependence on the accuracy of the conversion from $\sigma_{190}$ (the parameter measured in the laboratory irradiation experiments) to $\sigma_{0}$ (see Equation B.27, from Equation 14 in Heisinger et al. (2002b)).

$$
P_{\mu, f a s t}=S_{T} \phi_{\mu, t o t a l}(\mathrm{Z}) \beta(Z)(\bar{E}(Z))^{\alpha} \sigma_{0} \mathrm{~N}_{t, i}
$$

Where the factor $\beta(Z)$ is a function of the mean total muon energy and is shown in Equation B.25 and $\bar{E}$ is defined as the mean muon energy at a given depth $\mathrm{Z}$ and is shown in Equation B.26. $\phi_{\mu, t o t a l}$ is the total muon flux at the site, as calculated by the same equations used to calculate the fluxes for the Lifton et al. (2014) scaling framework. $\mathrm{N}_{t, i}$ is the number density of the atoms in the target element (in units of at $/ \mathrm{g}$ ). This value is a constant for each nuclide unless the composition of the target changes, as it does for ${ }^{36} \mathrm{Cl} . \quad \alpha$ is an energy-dependent coefficient that parameterizes the energy dependence of the cross-section $(\sigma)$ on muon energy. Experimental results permit values for $\alpha$ between 0.75 and $>1.0$ (Heisinger et al., 2002b) so the CRONUS-Earth Project chose a value of $\alpha=1.0$. By assuming that $\alpha$ equals one, $\beta$ will also be equal to one.

Nuclide production by slow negative muon capture $\left(P_{\mu-}\right)$ is described by Equation 3, originally from Charalambus (1971) and discussed in detail for ${ }^{36} \mathrm{Cl}$ by Stone et al. (1998). The production rate depends on the stopping rate of negative muons $\left(\phi_{\mu-}\right)$ as well as the nuclide-dependent factors $\left(f_{i, C}, f_{i, D}\right.$, $\left.f_{i}^{*}\right) . \phi_{\mu-}$ is derived from the muon flux calculated by the same equations used in Lifton et al. (2014). $f_{i, D}$ is the fraction of muons stopped by element $\mathrm{k}$ and absorbed by the nucleus before decay of the muon. $f_{i, C}$, the compound factor, represents the fraction of the muons that are captured by a target element (as opposed to the other elements present) within the bulk rock. The formula for the compound factor (Equation E.40) is taken from Charalambus (1971) and the values are consistent with those used by Heisinger et al. (2002a).

$$
P_{\mu-}=S_{T} \phi_{\mu-}(Z) f_{i, C} f_{i, D} f_{i}^{*}
$$

The remaining parameter, $f_{i}^{*}$, the particle emission channel probability, is the probability that the excited nucleus of the target atom will emit the proper particle to result in transformation to the nuclide of interest. Heisinger et al. (2002a) experimentally determined $f_{i}^{*}$ values for the production of ${ }^{26} \mathrm{Al}$ 
(from $\mathrm{Si}$ ), ${ }^{10} \mathrm{Be}$ and ${ }^{14} \mathrm{C}$ (from $\mathrm{O}$ ), and ${ }^{36} \mathrm{Cl}$ (from $\mathrm{K}$ and $\mathrm{Ca}$ ), but these values tend to overestimate nuclide concentrations measured in depth profiles in the same fashion as for fast muon production (Fig 1 in Phillips et al., 2015; Braucher et al., 2011). The production parameters for slow negative muon capture, $f_{i}^{*}$, were calibrated by fitting to the measured CRONUS-Earth profile for for ${ }^{10} \mathrm{Be}$ and ${ }^{26} \mathrm{Al}$ and by fitting to previously published profiles for ${ }^{36} \mathrm{Cl}$, as previously discussed.

The muon-capture reactions can release neutrons that later participate in neutron-capture reactions (muon-induced neutrons). Instead of assuming an exponential decrease in muon production with depth to calculate this flux, as most previous calculators do, the new muon module described above is used to calculate production with depth. The muon code calculates the negative muon stopping rate $\left(\phi_{\mu-}(\mathrm{Z})\right)$ and total muon flux $\left(\phi_{\mu f}(Z)\right)$ terms at a given depth for the calculation of the production rate of muon-induced neutrons (Equation 4). This muon-induced neutron production rate is used in the thermal and epithermal neutron flux equations (Equations B.30 and B.34), which are ultimately used to determine the production rate via the low-energy neutron pathway.

$$
P_{n, \mu}(\mathrm{Z})=Y_{s} \phi_{\mu-}(Z)+5.8 \times 10^{-6} \phi_{\mu f}(Z),
$$

where $Y_{s}$ is the average neutron yield per stopped negative muon (FabrykaMartin, 1988).

\subsubsection{Radiogenic Production}

Radiogenic production in this context refers to the generation of lowenergy neutrons by reactions related to the radioactive decay or spontaneous fission of $\mathrm{U}$ or $\mathrm{Th}$, and the subsequent absorption of those neutrons to produce nuclides of interest, principally ${ }^{36} \mathrm{Cl}$. Although ${ }^{3} \mathrm{He}$ is also produced from $\mathrm{Li}$ in this manner (Lal, 1987; Dunai et al., 2007), only ${ }^{36} \mathrm{Cl}$ radiogenic subtraction is incorporated into the program and the discussion below focuses on ${ }^{36} \mathrm{Cl}$ for that reason. The radiogenic low-energy neutron flux is assumed to be in equilibrium with the concentrations of uranium (U) and thorium (Th) in the rock. This component is quantified using measured concentrations of U and Th and the method described in Fabryka-Martin (1988), which is based on the formulations developed by Feige et al. (1968). These equations are shown in Appendix B.5.

The quantification of the bulk rock properties requires fundamental nuclear properties for each element. The original table of these properties pre- 
sented in Fabryka-Martin (1988) has now been corrected and updated using the information in Mughabghab (2006) and Schimmelpfennig et al. (2009).

A table of nuclear properties for all the elements considered in CRONUScalc is shown in Table 1.

In most studies, the rocks (not the exposure age) are sufficiently old that the assumption of equilibrium is reasonable. Even for younger features, such as a newly-erupted basalt, the assumption of equilibrium is reasonable due to equilibration with the uranium and thorium concentrations prior to eruption, so long as the magma did not undergo differentiation or mixing that significantly changed its $\mathrm{U}$ and $\mathrm{Th}$ contents less that $\sim 0.5$ Ma prior to sampling. The alternative is to allow production from radiogenic sources to begin at the exposure age (or any rock formation age). This difference in assumption is small for most ${ }^{36} \mathrm{Cl}$ samples and no data set currently exists to differentiate between the two assumptions. This assumption is only significant for young samples with high chlorine contents $(>50 \%$ production from $\mathrm{Cl}$ ) or significant $\mathrm{U}$ or $\mathrm{Th}$.

\subsection{Calibration Technique}

The production rates incorporated into the CRONUScalc code are the results from CRONUS-Earth Project calibrations. The calibration data set compiled by CRONUS-Earth includes a large number of sites representing a large range of latitudes, longitudes, and elevations. Ideal sites should have little uncertainty in the sample parameters (e.g. erosion rate, elevation, shielding, independent age constraints, etc.). The sites were divided into two categories based on the quality of the site, with the sites that came closest to fitting the criteria above placed into the 'primary calibration data set'. Additional sites with independent age constraints, but not meeting the strict criteria for primary sites, were placed into the 'secondary data set'. These samples are independent of the primary calibration data set and therefore can be used to assess the final calibrated parameters.

The calibration method, data set details including references, and the spallation calibration results for all nuclides are discussed in detail in Borchers et al. (2015). Additionally, some details of the ${ }^{10} \mathrm{Be}$ and ${ }^{26} \mathrm{Al}$ muon calibration can be found in Phillips et al. (2015) and the full chlorine-36 calibration can be found in Marrero (2012); Marrero et al. (2015). 


\begin{tabular}{|c|c|c|c|c|c|c|c|c|c|c|c|c|c|c|c|c|c|c|c|c|c|c|}
\hline 2 & I & 呑 & $£$ & ?ִ & $\underset{ن}{\stackrel{8}{0}}$ & @ִ & & 文 & & 5 & 尽 & $\begin{array}{l}0 \\
0 \\
0 \\
0\end{array}$ & $\stackrel{\tilde{i}}{\hat{i}}$ & $\begin{array}{l}\infty \\
\sim \\
i \\
\end{array} \mid$ & 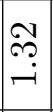 & $\stackrel{\stackrel{2}{Q}}{\stackrel{0}{0}}$ & $\underset{\forall}{\vec{t}}$ & $\begin{array}{l}\infty \\
\dot{10} \\
\dot{0}\end{array}$ & $\stackrel{\sim}{\sim}$ & $\underset{\leftrightarrow}{\stackrel{0}{0}}$ & $\mid$\begin{tabular}{c}
$\infty$ \\
\hdashline \\
0 \\
0
\end{tabular} & 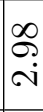 \\
\hline & I & $\infty$ & -1 & 0 & $\beth$ & $\stackrel{\mathcal{V}}{-}$ & & & $\stackrel{12}{-1}$ & $\stackrel{\Omega}{-}$ & จิ & $\approx$ & 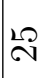 & $\stackrel{\bullet}{\sim}$ & $\stackrel{1}{-1}$ & S & ชิ & $\overrightarrow{0}$ & $\delta$ & 尺 & $\infty$ & $\stackrel{\sim}{\sim}$ \\
\hline & I & 0 & Lك & $\sim$ & $\sqrt{c}$ & - & & $\sim$ & & & -1 & $\curvearrowright$ & $\neg$ & $\stackrel{20}{-}$ & 0 & 0 & 0 & 0 & 0 & 0 & $\begin{array}{l}0 \\
0\end{array}$ & \\
\hline & I & 0 & 0 & $\begin{array}{l}\vec{\sigma} \\
\dot{0} \\
\dot{0} \\
-1\end{array}$ & 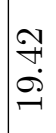 & 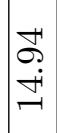 & 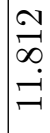 & 㑒 & & 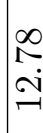 & 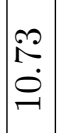 & חִ & 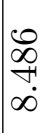 & 范 & $\left|\begin{array}{c}0 \\
0 \\
0 \\
-1\end{array}\right|$ & $\begin{array}{l}\infty \\
0 \\
\dot{1} \\
\dot{1} \\
\Sigma\end{array}$ & $\mid \begin{array}{c}\overrightarrow{1} \\
\Xi \\
\dot{+}\end{array}$ & 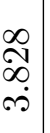 & $\begin{array}{l}\mathscr{A} \\
\text { î. } \\
\text { ì }\end{array} \mid$ & $\begin{array}{l}\vec{S} \\
\stackrel{S}{2} \\
\stackrel{i}{N}\end{array}$ & $\begin{array}{l}\vec{P} \\
\stackrel{1}{p} \\
\dot{\infty}\end{array}$ & 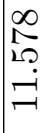 \\
\hline & & $\begin{array}{l}\Omega \\
\stackrel{\Omega}{0} \\
0 \\
\dot{0}\end{array}$ & 0 & $\stackrel{\infty}{\stackrel{\infty}{0}}$ & $\begin{array}{l}\infty \\
0 \\
0\end{array}$ & $\begin{array}{l}0 \\
\sim \\
\sim\end{array}$ & & ֶ. & 0 & & 0 & 0 & 0 & 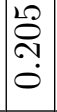 & 0 & $\mid \begin{array}{r}\tilde{a} \\
\stackrel{\sigma}{-}\end{array}$ & 0 & 0 & 0 & 0 & $\begin{array}{l}\dot{0} \\
\dot{\sigma}\end{array}$ & $\stackrel{0}{0}$ \\
\hline & & 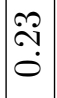 & 0 & $\stackrel{10}{\stackrel{10}{0}}$ & & $\mid \begin{array}{l}\infty \\
20\end{array}$ & & : & 0 & & 0 & 0 & 0 & 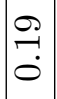 & 0 & 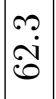 & 0 & 0 & 0 & 0 & & \\
\hline$\omega^{2}$ & I & $\begin{array}{l}\text { 定 } \\
\text { i⿱ }\end{array}$ & If & $\prod_{i 0}^{0}$ & 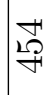 & ְְׁ? & $\underset{\neg}{\stackrel{f}{*}}$ & $\begin{array}{l}10 \\
\stackrel{20}{7}\end{array}$ & $\underset{f}{f}$ & $\stackrel{\leftrightarrow}{\dddot{F}}$ & $\mid \begin{array}{l}\mathscr{2} \\
\stackrel{\leftrightarrow}{+}\end{array}$ & $\begin{array}{l}1 \\
0 \\
0\end{array}$ & 露 & 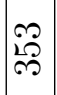 & 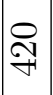 & $\mid \begin{array}{l}\hat{2} \\
\text { i⿱ }\end{array}$ & 0 & 0 & 0 & 0 & $\begin{array}{l}\infty \\
10 \\
10\end{array}$ & $\stackrel{\circ}{\circ}$ \\
\hline-1 & 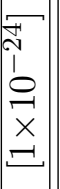 & $\mid \begin{array}{l}2 \\
\tilde{0} \\
\mathscr{0} \\
\tilde{\delta} \\
\delta \\
0 \\
0\end{array}$ & 0 & $\begin{array}{l}\infty \\
\stackrel{\infty}{8} \\
0 \\
0\end{array}$ & 孚 & \begin{tabular}{l}
$\infty$ \\
\hdashline \\
0 \\
0 \\
0
\end{tabular} & $\stackrel{\sim}{\check{0}}$ & $\begin{array}{l}0 \\
\infty \\
0 \\
0\end{array}$ & & - & $\mid \begin{array}{l}\stackrel{2}{\sim} \\
\stackrel{\leftrightarrow}{2} \\
\stackrel{\sigma}{0}\end{array}$ & r. & $\stackrel{4}{\stackrel{3}{9}}$ & 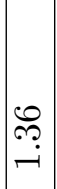 & $\begin{array}{l}2 \\
\infty \\
\dot{0} \\
\ddot{-}\end{array}$ & $\stackrel{\Re}{\mathscr{P}}$ & 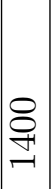 & 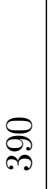 & $\stackrel{N}{N}$ & $\begin{array}{l}\mathscr{2} \\
\dot{\infty} \\
\infty\end{array}$ & $\stackrel{0}{0}$ & $\stackrel{\bullet}{\bullet}$ \\
\hline . & 2 & $\mid \begin{array}{l}\dot{1} \\
\dot{8} \\
0 \\
\dot{0}\end{array}$ & 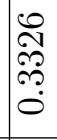 & 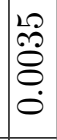 & $\begin{array}{l}1 \\
\Sigma \\
0 \\
0\end{array}$ & $\begin{array}{l}0 \\
0 \\
0 \\
8 \\
0 \\
0\end{array}$ & 常 & $\stackrel{F}{\check{I}}$ & بـ & ㄱ. & $\stackrel{\leftrightarrow}{\stackrel{\leftrightarrow}{\leftrightarrow}}$ & $\underset{f}{\not{0}}$ & 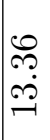 & $\begin{array}{l}0 \\
\llcorner \\
\sim \\
\sim \\
\end{array}$ & & $\hat{\mathscr{0}}$ & $\mid \begin{array}{c}0 \\
+ \\
\mathscr{8} \\
\mathscr{8}\end{array}$ & $\begin{array}{l}8 \\
0 \\
10 \\
\\
\end{array}$ & & $\stackrel{\overparen{P}}{r}$ & & S. \\
\hline $\begin{array}{c}\tilde{u} \\
\tilde{u} \\
0^{2}\end{array}$ & 2 & $\mid \begin{array}{l}\overrightarrow{0} \\
\kappa \\
\dot{r}\end{array}$ & 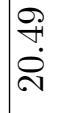 & ז' & \begin{tabular}{c}
$\infty$ \\
\hdashline \\
\hdashline \\
$\infty$ \\
$\infty$
\end{tabular} & $\begin{array}{l}\underset{H}{f} \\
\stackrel{\leftrightarrow}{*}\end{array}$ & & & & 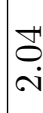 & & $\underset{+}{\stackrel{g}{+}}$ & 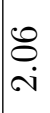 & 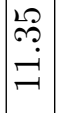 & $\begin{array}{l}\infty \\
10 \\
-10\end{array}$ & $\mid \begin{array}{r}\tilde{N} \\
\stackrel{\forall}{*}\end{array}$ & $\begin{array}{l}\infty \\
\infty \\
\infty\end{array}$ & $\stackrel{\mathbb{N}}{\sim}$ & $\left|\begin{array}{l}\infty \\
0 \\
0 \\
0\end{array}\right|$ & 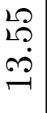 & & $\begin{array}{l}\infty \\
\infty \\
\infty \\
\infty\end{array}$ \\
\hline is & 1 & 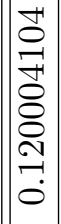 & - & 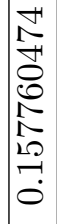 & 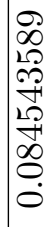 & 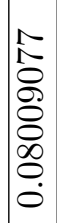 & 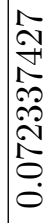 & $\begin{array}{l}10 \\
1 \\
0 \\
0 \\
10 \\
20 \\
0 \\
0 \\
0 \\
0\end{array}$ & 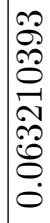 & 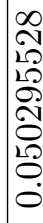 & 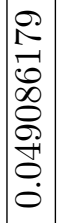 & 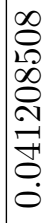 & 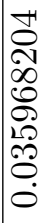 & 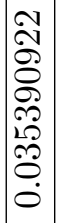 & 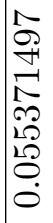 & 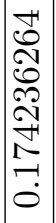 & 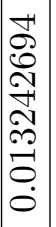 & 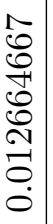 & $\mid \begin{array}{c}\mathfrak{2} \\
2 \\
\infty \\
\infty \\
1 \\
\infty \\
2 \\
0 \\
8 \\
0 \\
0 \\
0\end{array}$ & 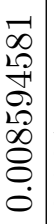 & & 文 \\
\hline$\dot{\leftarrow}$ & $\begin{array}{l}\overrightarrow{0} \\
\dot{\varepsilon} \\
0 \\
0\end{array}$ & $\stackrel{0}{-1}$ & 官 & 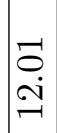 & 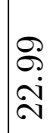 & $\begin{array}{l}\vec{\sim} \\
\stackrel{\sim}{\sim}\end{array}$ & $\begin{array}{l}\infty \\
\stackrel{\infty}{0} \\
\stackrel{\leftrightarrow}{N}\end{array}$ & 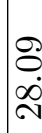 & 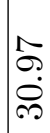 & $\vec{\rho}$ & $\mid \begin{array}{c}\infty \\
0 \\
\dot{0} \\
\stackrel{\gamma}{1}\end{array}$ & $\begin{array}{l}\stackrel{N}{\infty} \\
\stackrel{N}{\forall}\end{array}$ & $\frac{\vec{\sigma}}{\dot{\sigma}}$ & $\begin{array}{l}20 \\
\infty \\
20 \\
20 \\
20\end{array}$ & $\begin{array}{l}10 \\
10 \\
10 \\
\end{array}$ & $\mid \begin{array}{c}\vec{\infty} \\
\dot{0} \\
0\end{array}$ & 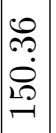 & 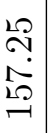 & $\left|\begin{array}{c}m \\
\infty \\
\infty \\
\mathscr{2} \\
\cdots\end{array}\right|$ & $\begin{array}{l}\overrightarrow{0} \\
\dot{N} \\
\stackrel{2}{N}\end{array}$ & & $\begin{array}{l}\text { O } \\
\text { î } \\
\text { î }\end{array}$ \\
\hline & 1 & 0 & & J & & $\Sigma$ & & & & & & $\dot{\mathrm{E}}=$ & & 哇 & & $\varphi$ & $\vec{n}$ & $\mho$ & & & $\ddot{\exists}$ & \\
\hline
\end{tabular}

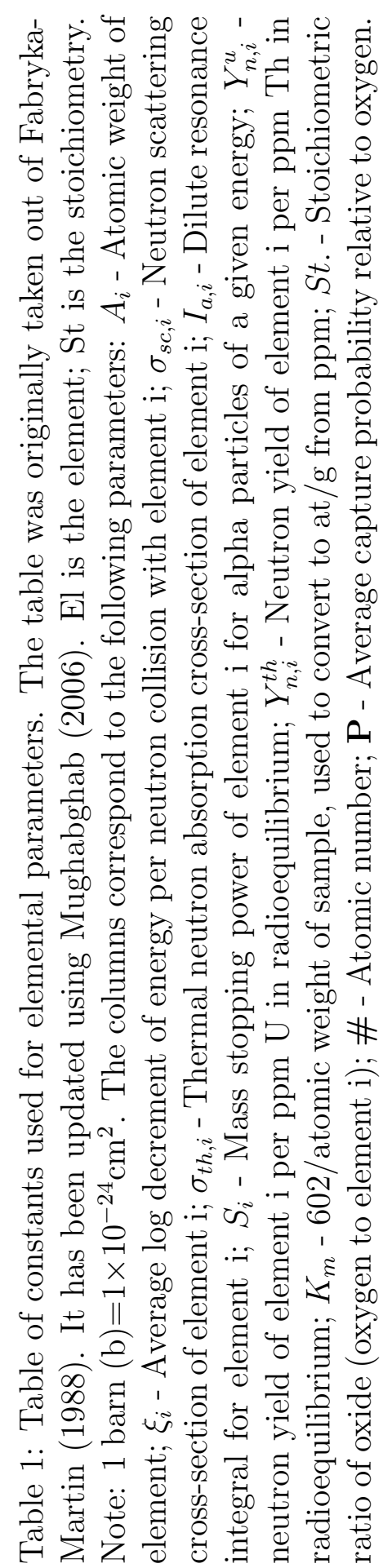




\subsection{Production Rate Scaling}

Cosmogenic nuclide scaling applies the physics governing the modulation of the cosmic-ray flux by atmospheric mass and the terrestrial and solar magnetic fields to provide production rates as a function of location and exposure time. Numerous scaling frameworks have been proposed in order to correct for latitude, elevation, atmospheric pressure anomalies, dipole and non-dipole geomagnetic field changes, and solar modulation. CRONUScalc implements seven scaling frameworks, as summarized in Table 2. This includes the original model by Lal (1991), further developed by Stone (2000) (referred to as St), that was based on cosmic-ray emulsion data and some neutron monitor data. A version of the Lal/Stone scaling accounting for geomagnetic field variations is also included (Lm). CRONUScalc includes the neutron-monitor-based models of Dunai (Du) (Dunai, 2000, 2001a), Lifton (Li) (Lifton et al., 2005), and Desilets (De) (Desilets \& Zreda, 2003; Desilets et al., 2006b). Finally, CRONUScalc implements two new models based on Lifton et al. (2014). The Lifton-Sato-Dunai (LSD, denoted SF herein) scaling framework (Lifton et al., 2014) does not rely on empirical fitting to a set of measured data points, but instead is based on analytical fits to physics-based modeling, and has been tested against measured atmospheric secondary nucleon and muon energy spectra.

The energy spectrum of the cosmic-ray flux produced by the LSD framework provides information that is available neither from the traditional Lal (St) scaling, nor neutron-monitor based scaling (Du, Li, De). This, in turn, allows the production rates of cosmogenic nuclides to be calculated by integrating the energy-dependent excitation function with the calculated particle energy spectrum. This is termed "nuclide-dependent scaling" because it results in a separate scaling factor for each nuclide, rather than a single scaling factor applicable to all nuclides, as the previous methods did. In the case of ${ }^{36} \mathrm{Cl}$, for example, this results in six nuclide-dependent scaling factors, including four high-energy scaling factors to scale the spallation reactions (K, Ca, $\mathrm{Ti}$, and $\mathrm{Fe}$ ) and one generalized spallation reaction to scale the low-energy reactions. Due to the derivation from the high-energy flux, the low-energy pathways cannot be scaled using the incoming low-energy neutron flux. (Note that since ${ }^{36} \mathrm{Cl}$ is commonly measured in rocks of varying compositions, each reaction has to be individually weighted by the concentration of the target element in the rock, unlike nuclides such as ${ }^{10} \mathrm{Be}$ or ${ }^{26} \mathrm{Al}$ that are commonly measured in minerals of constant composition, such as quartz). In all of the other scaling frameworks, the nuclide-dependent scaling factors still appear in 
the code, but all are set equal to the single scaling factor produced by the selected scaling framework. This nuclide-dependent scaling framework (LSDn, denoted SA herein) is the default on the online interface due to its favorable calibration results (see Borchers et al. 2015) and the possibility for future incorporation of updates to the excitation functions and other physics-based research. For all the details of the scaling frameworks themselves, please see the original papers (cited in Table 2); for details of implementation, please see the description in Balco et al. (2008) and Lifton et al. (2014).

In CRONUScalc, the geomagnetic history is consistent across all scaling frameworks, even though each model uses the history in a slightly different manner. This information is available in the code and can be modified directly if a different geomagnetic history is necessary. References for the currently implemented geomagnetic history can be found in Table 3, with relevant details in Lifton et al. (2014). The calculator is flexible, allowing knowledgeable users to modify the code to incorporate alternative geomagnetic models.

Although the various paleomagnetic reconstructions are in broad agreement, there are considerable differences for certain time intervals, indicating some uncertainty with regard to the accuracy of each reconstruction. In addition, each reconstruction contains internal uncertainties stemming from uncertainties in the measurements and chronology. We do not attempt to propagate these uncertainties into the CRONUScalc ages. This is partly due to the difficulty of quantifying the unknown errors in each reconstruction (for example, the assumed constant geomagnetic field of the St model is also clearly in error, but how does one quantify the magnitude and propagate it into the resultant age?). When considering the entire CRONUS-Earth secondary calibration data set (Borchers et al., 2015), the difference between the average normalized Lal-Stone (St; constant geomagnetic field) ages and the Lal (1991) (Lm; time-varying field) ages is only $0.4 \%$, and increases to $1.8 \%$ for the same comparison at the high-elevation, low-latitude Breque, Peru, site. However, due to the approximately sinusoidal dipole variation over the exposure time of a significant number of the calibration sites, these comparisons may still underestimate the differences when sample exposure is integrated over longer time spans in which the time-integrated effects might not cancel (<ca. $100 \mathrm{ka}$ ). Considering the difficulty of quantifying this uncertainty and propagating it, and the minimal effect the effort would have on age uncertainties for a majority of samples, we have neglected it. We acknowledge that for older or younger samples especially at low latitude, the 


\begin{tabular}{|c|c|c|}
\hline Abbr. & Reference & Description \\
\hline St & $\begin{array}{l}\text { Lal (1991); Stone } \\
(2000)\end{array}$ & $\begin{array}{l}\text { Time-independent (constant production rate). Based on two } \\
\text { different types of neutron reaction counting methods (photo- } \\
\text { graphic emulsions and neutron monitors). Scaling factor inputs } \\
\text { are geographic latitude and atmospheric pressure, based on the } \\
\text { Stone (2000) modification. }\end{array}$ \\
\hline Lm & $\begin{array}{l}\text { Lal (1991); Nishi- } \\
\text { izumi et al. (1989) }\end{array}$ & $\begin{array}{l}\text { Time-dependent version of St based on time-variation in the } \\
\text { dipole magnetic field intensity, as formulated by Nishiizumi } \\
\text { et al. (1989). }\end{array}$ \\
\hline $\mathrm{Li}$ & $\begin{array}{l}\text { Lifton et al. (2005, } \\
2008)\end{array}$ & $\begin{array}{l}\text { Time-dependent model based on neutron monitor measure- } \\
\text { ments and incorporating dipole and non-dipole magnetic field } \\
\text { fluctuations and solar modulation. The scaling factor is based } \\
\text { on actual atmospheric pressure, solar modulation, and a cutoff } \\
\text { rigidity calculated using trajectory tracing. }\end{array}$ \\
\hline $\mathrm{Du}$ & $\begin{array}{l}\text { Dunai } \\
\text { 2001a,b) }\end{array}$ & $\begin{array}{l}\text { Time-dependent model based on neutron monitor measure- } \\
\text { ments and incorporating dipole and non-dipole magnetic field } \\
\text { fluctuations. The scaling factor is based on an analytically cal- } \\
\text { culated cutoff rigidity and atmospheric pressure. A long-term } \\
\text { mean for solar modulation is used in this model. }\end{array}$ \\
\hline$\overline{\mathrm{De}}$ & $\begin{array}{l}\text { Desilets et al. } \\
\text { (2006b); Desilets } \\
\text { \& Zreda }(2003)\end{array}$ & $\begin{array}{l}\text { Time-dependent model based on neutron monitor measure- } \\
\text { ments and incorporating dipole and non-dipole magnetic field } \\
\text { fluctuations. The scaling factor is based on a cutoff rigidity } \\
\text { calculated using trajectory tracing and the actual atmospheric } \\
\text { pressure. }\end{array}$ \\
\hline $\begin{array}{l}\text { LSD } \\
\text { (Sf) }\end{array}$ & $\begin{array}{lll}\text { Lifton } & \text { et } & \text { al. } \\
(2014) & & \end{array}$ & $\begin{array}{l}\text { Time-dependent model based on equations from a nuclear } \\
\text { physics model and incorporating dipole and non-dipole mag- } \\
\text { netic field fluctuations and solar modulation. The scaling factor } \\
\text { is based on actual atmospheric pressure, solar modulation, and } \\
\text { a cutoff rigidity calculated using trajectory tracing. The total } \\
\text { flux (protons+neutrons) is used to scale all reactions. }\end{array}$ \\
\hline $\begin{array}{l}\text { LSDn } \\
\text { (Sa) }\end{array}$ & $\begin{array}{lll}\text { Lifton et } & \text { al. } \\
(2014) & & \end{array}$ & $\begin{array}{l}\text { Time-dependent model based on equations from a nuclear } \\
\text { physics model and incorporating dipole and non-dipole mag- } \\
\text { netic field fluctuations and solar modulation. The scaling } \\
\text { factor is based on actual atmospheric pressure, solar modu- } \\
\text { lation, and a cutoff rigidity calculated using trajectory trac- } \\
\text { ing. Nuclide-dependent scaling is implemented by incorporating } \\
\text { cross-sections for the different reactions. }\end{array}$ \\
\hline
\end{tabular}

Table 2: Table of scaling frameworks, including abbreviations, original references, and a brief description of each model. 


\begin{tabular}{|l|l|l|}
\hline Time period (kyr) & Model name & Reference \\
\hline $3-7 \mathrm{ka}$ & CALS7k & Korte \& Constable (2005) \\
\hline 7-18ka & GLOPIS-75 & Laj et al. (2004) \\
\hline $18 \mathrm{ka}-2 \mathrm{Ma}$ & PADM2M & Ziegler et al. (2011) \\
\hline
\end{tabular}

Table 3: Geomagnetic history used in all the scaling frameworks.

effect might be larger and we hope that quantification will be addressed in future research. The geomagnetic models used may also include systematic spatial or temporal biases that may be resolved with further research.

While CRONUScalc offers seven different spallation scaling frameworks, it uses only one muon scaling model. Muons were not natively scaled in any of the original models, so we use the energy-dependent Lifton et al. (2014) muon model to scale the muon flux.

A new input to the code is the "year collected" that allows the scaling frameworks to more precisely account for the time of exposure. In previous calibrations, the independent age constraints have been listed as "before present." For radiocarbon analyses, this is actually "years before 1950." The calibrations have been updated accordingly and now list independent ages as "years before 2010" and the exposure age calculation routines in CRONUScalc now integrate production through the collection year. For most samples, this is not a critical change, but with the advent of very highprecision cosmogenic ages on very young samples (e.g. Schaefer et al. 2009), it will eliminate the need for ad-hoc corrections for sample date. This capability will only become more important through time. The sample is assumed to have been processed shortly after collection or to have been stored where continued production and decay would be insignificant.

\subsection{Attenuation Length}

The apparent attenuation length, the attenuation length with respect to a flat surface with no topographic shielding, quantifies the depth distribution of the production by neutron spallation. When the apparent attenuation length is adjusted to account for the dip of the sample surface and any topographic shielding, the result is the effective attenuation length, $\Lambda_{f, e}$. The effective attenuation length is the parameter that should be used in calculations pertaining to production from a particular sample.

The effective attenuation length is an input parameter for each sample. The web-based user interface automatically calculates the effective attenua- 


\begin{tabular}{|l|l|l|l|l|l|l|l|l|}
\hline Depth/Cut. Rig. & $\mathbf{1 1 0 0}$ & $\mathbf{1 0 0 0}$ & $\mathbf{9 0 0}$ & $\mathbf{8 0 0}$ & $\mathbf{7 0 0}$ & $\mathbf{6 0 0}$ & $\mathbf{5 0 0}$ & $\mathbf{4 0 0}$ \\
\hline $\mathbf{0}$ & 151 & 152 & 153 & 154 & 155 & 158 & 163 & 172 \\
\hline $\mathbf{4}$ & 152 & 152 & 154 & 156 & 159 & 164 & 171 & 185 \\
\hline $\mathbf{8}$ & 156 & 159 & 161 & 164 & 168 & 175 & 185 & 204 \\
\hline $\mathbf{1 2}$ & 162 & 165 & 168 & 171 & 176 & 184 & 196 & 218 \\
\hline $\mathbf{1 6}$ & 168 & 170 & 172 & 177 & 182 & 191 & 204 & 228 \\
\hline $\mathbf{2 0}$ & 169 & 171 & 174 & 179 & 184 & 192 & 206 & 231 \\
\hline
\end{tabular}

Table 4: The table used for the interpolation of attenuation lengths based on the given atmospheric depth (top row, in units of $\mathrm{g} / \mathrm{cm}^{2}$ ) and cutoff rigidity (first column, in units of GV). Values based on those obtained using the spreadsheet that accompanied Sato et al. (2008), but include the additional $11.1 \%$ correction discussed in the text.

tion length if it is not provided. For use in the raw code where attenuation length is not automatically calculated, there is a function (attenuationlengthnormal.m) to calculate the parameter at a given location (latitude, longitude, elevation) and pressure of a sample. The attenuation-length model in CRONUScalc is based on atmospheric attenuation lengths calculated from the PARMA model of Sato et al. (2008), which is an analytical model for estimating cosmic-ray spectra in the atmosphere. The attenuation lengths are interpolated from the values given in Table 4 using the vertical cutoff rigidity and atmospheric depth of the site.

The interpolated attenuation lengths have been adjusted upward by $11.1 \%$ to account for systematic differences between atmospheric and lithospheric attenuation. This adjustment is based on the approximate relation:

$$
\frac{\lambda_{f, r o c k}}{\lambda_{f, \text { atm }}}=\left(\frac{A_{\text {rock }}}{A_{\text {atm }}}\right)^{1 / 3}
$$

where $\mathrm{A}_{\text {rock }}$ and $\mathrm{A}_{\text {atm }}$ are the average atomic weights of the rock and atmosphere, respectively. The average atomic weight of the atmosphere was taken to be $14.68 \mathrm{~g} \mathrm{~mole}^{-1}$ and that of average rock $20.40 \mathrm{~g} \mathrm{~mole} \mathrm{e}^{-1}$. (We note that any changes in the chemical composition of the atmosphere over the time scale of interest for application of cosmogenic-nuclide surface chronology are too small to affect the attenuation length.) This relation is derived from the following simple considerations.

The macroscopic cross-sectional area of the atoms in a gram of matter scales as the product of the number of atoms of each element in the volume 
multiplied by the average cross-sectional area of the atoms. Assuming that atomic nuclei are spheres of constant density, and that each nucleus is made up of spheres of uniform mass and diameter (protons and neutrons), the radius of each atom will scale by the atomic weight to the one-third power (Friedlander et al., 1981). The cross-sectional area will then scale as the square of the radius. The product of these is the average atomic crosssection to the two-thirds power. The number of atoms per gram will scale by Avogadro's number divided by the average atomic weight. Therefore, the macroscopic cross-sectional area of substance i (rock or atmosphere), per gram, will scale as follows:

$$
\text { Area }_{i} \propto \frac{N_{A} A_{i}^{2 / 3}}{A_{i}}=\frac{N_{A}}{A_{i}^{1 / 3}}
$$

where $\mathrm{N}_{A}$ is Avogadro's number. The apparent attenuation length is the inverse of the macroscopic area per gram. When the ratios of the attenuation lengths for rock and atmosphere are taken, Equation 5 results. (John Stone, personal communication, 14 February 2012).

The attenuation length will also vary as a function of lithology. The average atomic weight of common lithologies varies from $19.8 \mathrm{~g} \mathrm{~mole}^{-1}$ for quartzite to $21.5 \mathrm{~g} \mathrm{~mole}^{-1}$ for ultramafic rocks. However, the maximum difference between the attenuation length calculated for any lithology and that for the mean atomic weight (averaged over all lithologies) is $<2 \%$. This is insignificant and hence CRONUScalc does not compute attenuation lengths on a lithology-specific basis. There is some modeling evidence to suggest that nuclide-dependent attenuation lengths may be needed in the future (Argento et al., 2014), something the calculator is already equipped to accommodate because attenuation length is a sample input.

Figure 1 shows the dependence of the modeled effective attenuation length on elevation and latitude. For samples with large topographic shielding corrections, these values should be adjusted to account for horizon obstructions.

The final attenuation lengths overlap with the range of values presented by Dunai (2000) from 121 to $>170 \mathrm{~g} / \mathrm{cm}^{2}$, with the range for most samples falling between 150-190 g/ $\mathrm{cm}^{2}$ (see Figure 1). Although the results are in the same range as commonly assumed values of $160-170 \mathrm{~g} \mathrm{~cm}^{-2}$ (Gosse \& Phillips, 2001; Dunai, 2010), a significant difference in age between the use of the two different attenuation lengths (CRONUS-predicted value vs $170 \mathrm{~g} \mathrm{~cm}^{-2}$ ) is possible for samples with high erosion rate, very long exposure times, or at 


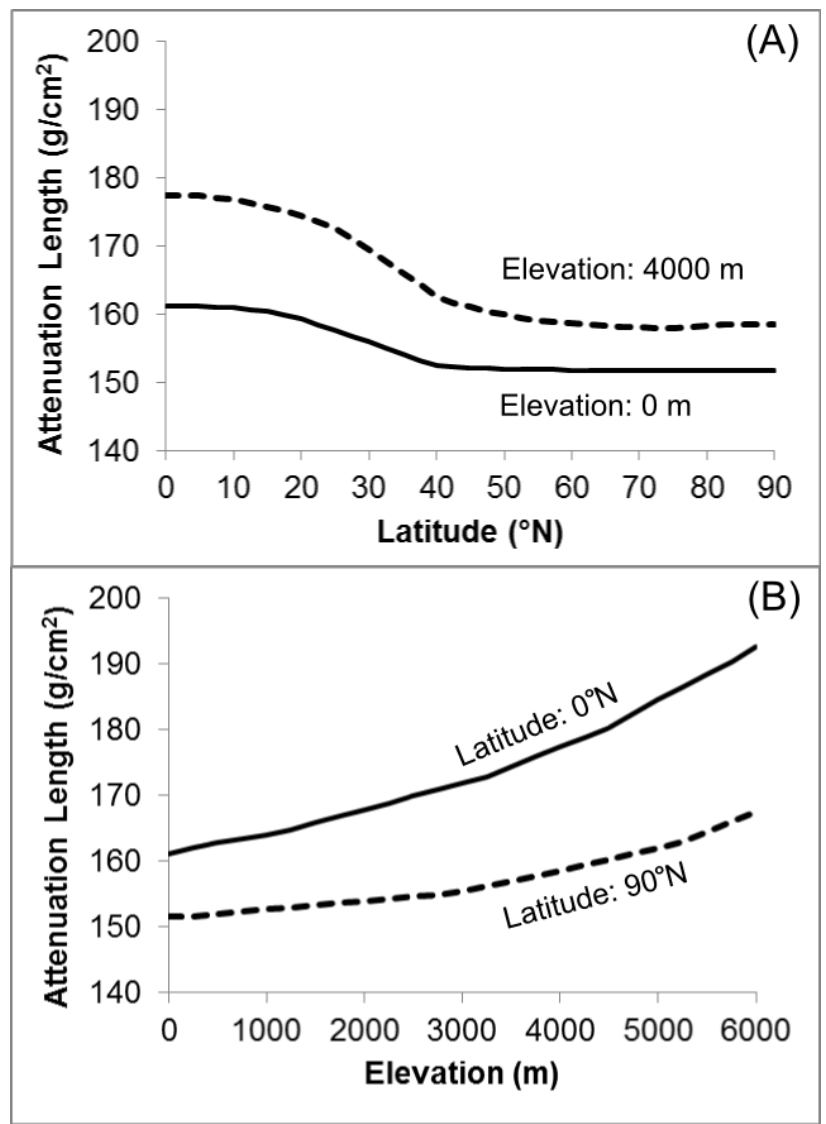

Figure 1: The change in effective attenuation length for a flat surface at various elevations (A), shown for both zero and $90^{\circ} \mathrm{N}$ latitude, and effective attenuation length at various latitudes (B), shown for elevations of 0 and $4000 \mathrm{~m}$. 
significant depth. In order to test the magnitude of this effect, we predicted ${ }^{10} \mathrm{Be}$ concentrations using the CRONUScalc modeled attenuation length of $153 \mathrm{~g} / \mathrm{cm}^{2}$ (corresponding to $40^{\circ} \mathrm{N}$ at sea level) for artificial samples for a range of ages and erosion rates. The resulting ages were then determined using an attenuation length of $170 \mathrm{~g} / \mathrm{cm}^{2}$. The results (Figure 2, B.6) show that the attenuation length change from $153 \mathrm{~g} / \mathrm{cm}^{2}$ to $170 \mathrm{~g} / \mathrm{cm}^{2}$ results in up to a $2 \%$ difference on the $20 \mathrm{ka}$ age for erosion rates up to $10 \mathrm{~mm} / \mathrm{kyr}$. The difference is considerably larger for faster eroding samples with longer exposure times, or alternately samples at depth, with differences of almost $50 \%$ for 300 ka exposure times with erosion rates of $10 \mathrm{~mm} / \mathrm{kyr}$. However, for most surface samples with modest or low erosion rates, this difference is relatively small. When depth profiles are available, the attenuation length should still be one of the fitted parameters to ensure the most accurate value (e.g. Braucher et al. 2013). Use of the surface shielding calculator to estimate attenuation lengths for depth profiles or very high erosion rates should be approached with caution.

Given the physics-based derivation of the new attenuation length model, the new attenuation lengths are implemented as the default in the online calculator interface. However, as this parameter is an input for each sample, the choice of attenuation length is ultimately left to the user. The final model for attenuation length is included as its own function in the code repository (see the Function Appendix in the supplementary materials). A separate shielding calculator has been developed to simplify the calculation of the topographic shielding factor as well as the appropriate effective attenuation length. The attenuation length model accounts for the latitude and elevation of a sample. If shielding information is included, the effective attenuation length is modified accordingly. A link to the shielding calculator is available on the calculators homepage (http://web1.ittc.ku.edu:8888/.

\subsection{Accumulation}

Instantaneous production rates, such as those described above, must be integrated in both time and thickness in order to calculate the production in a real sample. In many common solutions, this is done analytically or with additional multiplicative factors to account for the finite thickness of a sample. In the CRONUScalc program, this integration is done numerically, which is more accurate for depth integrations and makes it simple to incorporate time-dependent scaling and varying production rates. 


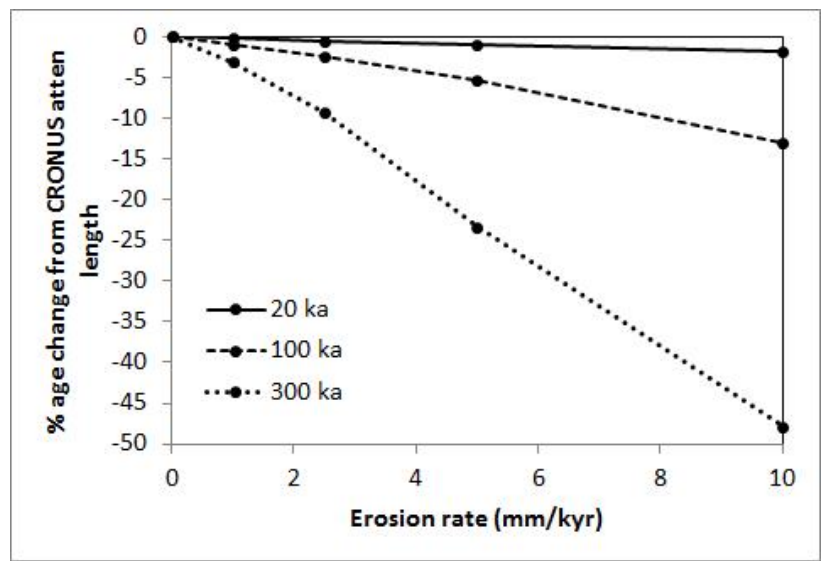

Figure 2: Change in ages due to change in attenuation length from the original CRONUS-calculated value $\left(153 \mathrm{~g} / \mathrm{cm}^{2}\right)$ to $170 \mathrm{~g} / \mathrm{cm}^{2}$, compared over a range of erosion rates $(0,1,2.5,5$, and $10 \mathrm{~mm} / \mathrm{kyr})$ and three different exposure ages $(20,100$, and $300 \mathrm{ka})$.

For a given age, an appropriate time step, $\Delta \mathrm{t}$, is found such that the erosion rate is small for that period and the changes in time-dependent production rates are not too large. Although larger time steps may be appropriate for some samples or scaling methods, the time step default is set to 100 years in order to maintain time-step errors below $0.4 \%$ for all sample types, as calculated assuming the correct age is the age produced using a time step of 1 year.

The sample begins at depth and the cosmogenic inventory within the sample is tracked during its migration to the surface. For each time step, the current scaling factors and production rates are found for the sample. The inventory accounts for the decay of all previously produced nuclide inventory (the first term in Equation 7) as well as the production and decay of the nuclide during the current time step (second term in Equation 7).

$$
N_{\text {tot }}=N_{\text {prev }} e^{-\lambda \Delta t}+P_{\text {tot }} * f_{\text {decay }}
$$

where $N_{\text {tot }}$ is the total inventory in the sample up to the current time step; $N_{\text {prev }}$ is the inventory from all previous time steps; $\lambda$ is the decay constant for the nuclide; $P_{\text {tot }}$ is the instantaneous production rate of the nuclide from all mechanisms; and $f_{\text {decay }}$ is the decay factor (Equation 8) that accounts for the fact that a small amount of the nuclide produced at the beginning of the 
time period will have decayed by the end of the period.

$$
f_{\text {decay }}=\frac{1-e^{-\lambda \Delta t}}{\lambda}
$$

After the nuclide is produced, the samples are "eroded" by updating the depths for the sample by using the erosion rate and the time step, as shown in Equation 9.

$$
D_{\text {new }}=D_{\text {previous }}-\Delta t * \epsilon
$$

where $D_{\text {new }}$ is the new depth, $D_{\text {prev }}$ is the previous sample depth, and $\epsilon$ is the erosion rate of the surface.

These steps are repeated from $t=$ (year sampled)-age, with the sample at depth, until t is equal to the year sampled, when the sample reaches the surface. The inventory is then returned by the module and used in any number of other functions, such as surface or depth-profile calculators, or simply returned to the user.

\section{Considerations Specific to Individual Cosmogenic Nuclides}

While the in-situ cosmogenic nuclides share many similarities in terms of production pathways, they are each produced by a different combination of pathways and there are other individual issues that need to be addressed. In the following sections, the specific pathways for production, uncertainties, and other issues are documented for each of the major four code modules representing five nuclides.

Each nuclide is produced by one or more of the pathways discussed in the previous section. The most common reactions are shown in Table 5 for common nuclides and their common target minerals.

Inputs required by CRONUScalc vary, but the inputs common to all nuclides include location (latitude, longitude, elevation/pressure), sample parameters (thickness, bulk density, depth, and attenuation length), site parameters (topographic shielding, erosion rate, year collected), and chemical parameters (cosmogenic nuclide concentration). Additional inputs are necessary for some nuclides to account for production through low-energy neutron pathways (composition, water content). For all nuclides, the required cosmogenic nuclide concentration is assumed to incorporate any blank corrections, as these vary from lab to lab and therefore cannot be standardized to be included in the program. 


\begin{tabular}{|c|c|}
\hline Nuclide & Reaction \\
\hline${ }^{3} \mathrm{He}$ & $\begin{array}{l}\text { Spallation: O, Mg, Si, Ca, Fe, Al } \\
{ }^{6} \mathrm{Li}(\mathrm{n}, \alpha)^{3} \mathrm{He}\end{array}$ \\
\hline${ }^{10} \mathrm{Be}$ & $\begin{array}{l}{ }^{16} \mathrm{O}(\mathrm{n}, 4 \mathrm{p} 3 \mathrm{n}){ }^{10} \mathrm{Be} \\
{ }^{28} \mathrm{Si}(\mathrm{n}, \mathrm{x})^{10} \mathrm{Be} \\
{ }^{16} \mathrm{O}\left(\mu^{-}, \alpha \mathrm{pn}\right){ }^{10} \mathrm{Be} \\
{ }^{28} \mathrm{Si}\left(\mu^{-}, \mathrm{x}\right){ }^{10} \mathrm{Be}\end{array}$ \\
\hline${ }^{14} \mathrm{C}$ & $\begin{array}{l}{ }^{16} \mathrm{O}\left(\mu^{-}, 2 \mathrm{p}\right){ }^{14} \mathrm{C} \\
{ }^{16} \mathrm{O}(\mathrm{n}, 2 \mathrm{pn}){ }^{14} \mathrm{C} \\
{ }^{17} \mathrm{O}(\mathrm{n}, \alpha){ }^{14} \mathrm{C} \\
{ }^{28} \mathrm{Si}(\mathrm{n}, \mathrm{x}){ }^{14} \mathrm{C}\end{array}$ \\
\hline${ }^{26} \mathrm{Al}$ & $\begin{array}{l}{ }^{28} \mathrm{Si}(\mathrm{n}, 2 \mathrm{pn}){ }^{26} \mathrm{Al} \\
{ }^{28} \mathrm{Si}\left(\mu^{-}, 2 \mathrm{n}\right){ }^{26} \mathrm{Al}\end{array}$ \\
\hline${ }^{36} \mathrm{Cl}$ & $\begin{array}{l}{ }^{40} \mathrm{Ca}(\mathrm{n}, 2 \mathrm{n} 3 \mathrm{p}){ }^{36} \mathrm{Cl} \\
{ }^{39} \mathrm{~K}\left(\mu^{-}, \mathrm{p} 2 \mathrm{n}\right){ }^{36} \mathrm{Cl} \\
{ }^{40} \mathrm{Ca}\left(\mu^{-}, \alpha\right){ }^{36} \mathrm{Cl} \\
{ }^{35} \mathrm{Cl}(\mathrm{n}, \gamma){ }^{36} \mathrm{Cl} \\
{ }^{39} \mathrm{~K}(\mathrm{n}, \alpha){ }^{36} \mathrm{Cl} \\
\mathrm{Fe}(\mathrm{n}, \mathrm{x}){ }^{36} \mathrm{Cl} \\
\mathrm{Ti}(\mathrm{n}, \mathrm{x}){ }^{36} \mathrm{Cl}\end{array}$ \\
\hline
\end{tabular}

Table 5: Common reactions producing in-situ terrestrial cosmogenic nuclides (Gosse \& Phillips, 2001). The symbolism is as follows for the X(a,b)Y reaction: $\mathrm{X}$ is the target element, a is the particle interacting with the target, $\mathrm{b}$ is emitted during the reaction, and $\mathrm{Y}$ is the final nuclide product. " $\mathrm{x}$ " in the second place inside the parentheses indicates a reaction for which several different combinations of emitted particles are possible. Reactions are only shown for the pathways discussed in the paper. For beryllium, aluminum, and carbon, only those reactions possible in a quartz target mineral are shown. 


\subsection{Aluminum-26 and Beryllium-10}

${ }^{10} \mathrm{Be}$ is the most commonly used cosmogenic nuclide. ${ }^{26} \mathrm{Al}$ is also produced in quartz and is commonly processed in the same samples as ${ }^{10} \mathrm{Be}$. Both nuclides are produced in quartz through only two mechanisms: spallation and muogenic production. Muogenic production of ${ }^{10} \mathrm{Be}$ and ${ }^{26} \mathrm{Al}$ accounts for only $\sim 1.5 \%$ and $\sim 2 \%$ of total surface SLHL production, respectively, as calculated using CRONUScalc. CRONUScalc employs the currently accepted half-life and AMS standard values for ${ }^{10} \mathrm{Be}$ (Nishiizumi et al., 2007; Korschinek et al., 2010; Chmeleff et al., 2010). The online interface performs automatic renormalization for all ${ }^{10} \mathrm{Be}$ and ${ }^{26} \mathrm{Al}$ concentrations based on the standards selected by the user. The interface passes this information to the underlying raw CRONUScalc program, which assumes the concentration is normalized to 07KNSTD for ${ }^{10} \mathrm{Be}$ and KNSTD for ${ }^{26} \mathrm{Al}$. For discussions concerning these normalizations, see Balco et al. (2008) and Nishiizumi et al. (2007).

When ${ }^{26} \mathrm{Al}$ and ${ }^{10} \mathrm{Be}$ are both being analyzed for a particular sample, they can be processed in the same quartz split. The code operates in a fashion similar to that of Balco et al. (2008) in that it allows any given sample to be associated with data from either ${ }^{10} \mathrm{Be}$ or ${ }^{26} \mathrm{Al}$, or both nuclides. The production rates for both nuclides have only been determined reliably in quartz, so this is the only mineral target supported by CRONUScalc at this time.

Additional information, such as erosion rate or burial history, can be determined if more than one nuclide is analyzed in a sample (Bierman, 1994; Granger \& Muzikar, 2001). The common Al/Be pair is frequently used for these investigations. CRONUScalc does not currently provide figures for the paired interpretation if ${ }^{10} \mathrm{Be}$ and ${ }^{26} \mathrm{Al}$, but these capabilities could be added by an advanced user following the method described in Granger \& Muzikar (2001); Granger (2006).

For information on the production rates used in the calculator, see the CRONUS-Earth spallation production rate calibration paper (Borchers et al., 2015) or the summary paper (Phillips et al., 2015).

\subsection{Chlorine-36}

Cosmogenic ${ }^{36} \mathrm{Cl}$ is produced by a wide range of pathways that have been discussed in the production systematics section. The main three pathways are spallation ( $\mathrm{Ca}, \mathrm{K}, \mathrm{Ti}, \mathrm{Fe})$, low-energy neutron absorption $(\mathrm{Cl})$, and muogenic production ( $\mathrm{Ca}, \mathrm{K}, \mathrm{Ti}, \mathrm{Fe}$ ). Note that we include the production of ${ }^{36} \mathrm{Cl}$ 
by relatively low-energy neutrons (down to approximately $3 \mathrm{MeV}$ ) by the reaction ${ }^{39} \mathrm{~K}(\mathrm{n}, \alpha){ }^{36} \mathrm{Cl}$ in the "spallation" category, using the cross-section of Reedy (2013), since this energy is still well above the epithermal level.

Previous studies have resulted in production-rate estimates that differ from each other by up to $40 \%$. One goal of the CRONUS-Earth project was to resolve these uncertainties (Marrero, 2012; Marrero et al., 2015, this volume, submitted). For spallation production rates, only CRONUS-Earth mineral separate data is used in the calibration and the resulting production rates fit the independent secondary data set very well (see evaluation of the secondary ${ }^{36} \mathrm{Cl}$ data set in Borchers et al. (2015)). For the low-energy neutron production pathway, however, there are additional unknown complicating factors, potentially water content or other site-specific parameters, which influenced the $P_{f}(0)$ calibration. A more complete discussion of calibration results and factors affecting ${ }^{36} \mathrm{Cl}$ production can be found in Marrero et al. (2015), but the resulting value for $P_{f}(0)$ fits the secondary data set well and is used in CRONUScalc until additional ${ }^{36} \mathrm{Cl}$ calibrations can be performed. The $P_{f}(0)$ value that was obtained during the CRONUS-Earth calibration has a larger uncertainty (about $20 \%$ ) than the other ${ }^{36} \mathrm{Cl}$ production parameters. Ideally, ${ }^{36} \mathrm{Cl}$ should be measured on low-chlorine mineral separates to eliminate the uncertainty associated with this pathway (cf. Schimmelpfennig et al. 2009). Analysis of low-chlorine mineral separates should help to keep ${ }^{36} \mathrm{Cl}$ ages to a similar level of uncertainty as other nuclides.

It is important to note that the predicted nuclide concentrations are more sensitive to certain parameters than others. For example, hydrogen is the most effective moderator of neutron energy (Fabryka-Martin, 1988), and thus the amount of water in a sample can strongly affect the magnitude of the low-energy neutron flux and consequently influence the production of ${ }^{36} \mathrm{Cl}$ through the low-energy pathway. The importance of water was evaluated theoretically by Dep et al. (1994) and experimentally substantiated by Dunai et al. (2014), indicating that the presence of hydrogen can significantly influence production. There is some evidence to indicate that the water content of the surrounding landscape may also affect the low-energy neutron flux (Zreda et al., 2008). The sensitivity of sample age to water in the current calculator is included in the sensitivity study in Section 5.2.

Chlorine-36 dating requires compositional parameters that most cosmogenic nuclides do not. The code allows for the input of both "mineral target" and "bulk-rock" compositions. The bulk-rock analysis permits the calculation of the neutron-transport parameters. If a mineral separate has been used 
for the analysis, the target-element concentrations (comprehensively, $\mathrm{K}, \mathrm{Ca}$, $\mathrm{Ti}, \mathrm{Fe}$, and $\mathrm{Cl}$ ) are also needed for the sample on which the measurement was performed. The bulk-rock composition includes data on trace-elements, such as boron and uranium, that are needed for the appropriate calculation of neutron-absorption properties of the rock and radiogenic subtraction. For samples with low $\mathrm{Cl}$ content and high concentrations of $\mathrm{K}$ and/or $\mathrm{Ca}$, the full range of trace element analyses may be superfluous. Given a complete analysis of a rock sample, CRONUScalc calculates the percentage of the production originating from low-energy neutron absorption by $\mathrm{Cl}$, spallation on $\mathrm{Ca}$ and $\mathrm{K}$, and muons. This can be used to determine whether chemical analysis of elements that modulate the low-energy neutron flux are needed for every sample.

Isotope Dilution Mass Spectrometry (IDMS) is a standard method for highly accurate elemental and isotopic analysis. In cosmogenic-nuclide applications it is commonly used for analysis of ${ }^{36} \mathrm{Cl}$ and elemental $\mathrm{Cl}$. The process includes adding a "spike" of known isotope ratio that has been enriched in one of the stable chlorine isotopes, either ${ }^{35} \mathrm{Cl}$ or ${ }^{37} \mathrm{Cl}$. In either case, the ratios of ${ }^{36} \mathrm{Cl} /{ }^{35} \mathrm{Cl}$ and ${ }^{35} \mathrm{Cl} /{ }^{37} \mathrm{Cl}$ are measured by the accelerator mass spectrometer. The stable chloride concentration and the ${ }^{36} \mathrm{Cl}$ concentration of the rock can both be back-calculated using the ratios from the accelerator and the recorded spike and sample masses from sample preparation. The process is described in detail in Desilets et al. (2006a).

When using IDMS for chlorine, there is a correlation between the uncertainties in stable chloride concentration and the uncertainties on ${ }^{36} \mathrm{Cl}$ concentration because they both depend on the same isotope ratios. In order to produce the correct uncertainties from raw laboratory results, a set of additional codes were created to handle this calculation. This code is external to the main CRONUScalc program, but is distributed with the code. It is designed to assist the user in calculating the correct concentrations of ${ }^{36} \mathrm{Cl}$ and $\mathrm{Cl}$ and correctly assigning their uncertainties for samples reported as ${ }^{36} \mathrm{Cl} /$ total $\mathrm{Cl}$ and ${ }^{35} \mathrm{Cl} /{ }^{37} \mathrm{Cl}$ by AMS. A linearized uncertainty method was used to calculate the stable chlorine concentration (spiketoconc.m). However, the traditional error propagation does not work for low-Cl samples due to the non-linear response in this range, so uncertainties are calculated using a Monte Carlo method (spiketoconcmc.m). In the Monte Carlo code, the uncertainty in the stable chlorine concentration is calculated 10,000 times using the nominal inputs (spike mass, sample mass, spike concentration, etc.) and a random uncertainty. The random quantity added to the nominal value 
of the parameter is normally distributed with a mean of 0 and standard deviation equal to the uncertainty in the parameter. For samples with high chlorine concentrations, the Monte Carlo result is essentially the same as the linearized approximations; however, at low chlorine concentrations, the uncertainties can be a significant percentage of the total concentration $(>90 \%)$.

\subsection{Carbon-14}

Production of in-situ cosmogenic ${ }^{14} \mathrm{C}$ is primarily from the spallation of oxygen, but also other elements including Mg, Al, and Si (Dunai, 2010). Unlike ${ }^{10} \mathrm{Be}$, muons contribute significantly (15-20\%) to the cosmogenic production at the surface and increasingly at depth. Quartz is the only mineral phase in which ${ }^{14} \mathrm{C}$ is commonly measured, although it is possible to measure it in other minerals as well (Handwerger et al., 1999; Dunai, 2010). Carbon14 has a short half-life and therefore reaches secular equilibrium between production and decay relatively quickly ( 25-30 kyr) (Lifton et al., 2001). Due to these factors, ${ }^{14} \mathrm{C}$ is well-suited for short-term erosion rate studies using multiple nuclides and young burial-history studies (Dunai, 2010).

In situ ${ }^{14} \mathrm{C}$ is extracted from quartz typically by stepped combustion/ dissolution (e.g. Lifton et al., 2001; Pigati et al., 2010; Goehring et al., 2014) or stepped combustion (Hippe et al., 2014). Reproducibility of intercomparison materials is typically ca. $5 \%$ among labs (Jull et al., 2013), but occasional discrepancies on replicate analyses have been as much as $5-10 \%$ in the past (Borchers et al. 2015). As a result, in situ ${ }^{14} \mathrm{C}$ production rates have tended to exhibit somewhat greater uncertainties than other nuclides, although the situation is improving as extraction techniques continue to advance.

In CRONUScalc, only the production of ${ }^{14} \mathrm{C}$ in quartz by spallation and by muons is available. This should provide adequate functionality for the majority of ${ }^{14} \mathrm{C}$ users. For information on the ${ }^{14} \mathrm{C}$ production rates used in the calculator, see the CRONUS-Earth spallation production rate calibration paper (Borchers et al., 2015).

\subsection{Helium-3}

Cosmogenic ${ }^{3} \mathrm{He}$ is produced primarily by spallation reactions on most elements present in a rock $(\mathrm{Mg}, \mathrm{Si}, \mathrm{Fe})$, but also through low-energy neutron absorption by lithium (Li) (Dunai et al., 2007). Moderate amounts of Li (50-200 ppm) can cause a significant amount of production to originate from cosmogenic thermal neutrons, affecting neighboring (and potentially Li-free) mineral phases (Dunai et al., 2007). Even in relatively low-Li samples (1 
ppm), radiogenic production can be important in rocks where the formation age of the rock is much greater than the exposure age of the sample (Lal, 1987; Farley et al., 2006; Dunai et al., 2007). There is currently no evidence of significant contribution to production via muon reactions (Kurz, 1986; Dunai, 2010). The most commonly used minerals are pyroxene and olivine, however ${ }^{3} \mathrm{He}$ has been measured in other mineral phases (e.g. apatite, zircon, biotite, titanite, kyanite, and hornblende) (Amidon \& Farley, 2012; Amidon et al., 2009; Amidon \& Farley, 2010; Farley et al., 2006; Amidon et al., 2008). When evaluating ${ }^{3} \mathrm{He}$ data, the inherited (magmatic) component must be subtracted from the measured concentration in order to include only the cosmogenically produced ${ }^{3} \mathrm{He}$ in the dating. This is done through methods that vary by lab (Kurz, 1986; Cerling, 1990; Blard \& Pik, 2008; Blard \& Farley, 2008; Williams et al., 2005). The input needed for CRONUScalc is the cosmogenic concentration of ${ }^{3} \mathrm{He}$ in units of atoms per gram. CRONUScalc assumes that any corrections for blanks or inherited component have already been performed.

Currently, CRONUScalc only incorporates spallation production for ${ }^{3} \mathrm{He}$. The spallation production rate is currently calibrated from a combined data set consisting of olivine and pyroxene samples from the compilation by Goehring et al. (2010b). The publication includes both official CRONUS data and high-quality external data sets. Individual sites were determined to be either primary or secondary data sets based on quality of the independent age control and other site parameters. For information on the ${ }^{3} \mathrm{He}$ calibration, see Borchers et al. (2015).

Recommended use of the calculator is currently limited to olivine and pyroxene due to the limitations of the calibration data set. For pyroxene and olivine derived from basalt and xenoliths, Li concentrations are typically very low $(<5 \mathrm{ppm})$ so the presence of cosmogenic or radiogenic ${ }^{3} \mathrm{He}$ from low-energy neutrons should be negligible (Dunai et al., 2007). The lithium low-energy pathway needs to be considered for minerals in rocks that are more evolved than primitive basalts and generally for rocks whose geological age is much larger than the exposure age (Dunai et al., 2007; Lal, 1987). Until this pathway is incorporated into the program, users are cautioned to limit the use to low-Li samples.

The calculation of the low-energy production pathway is complicated by the large number of additional parameters that would be needed (e.g. grain size of target minerals, complete major and trace element composition of the host rock, water content) (Dunai et al., 2007). The calculator is already 
designed to take the mineral phase as an input and a thermal neutron component could be added by adapting the low-energy production calculations already in place for ${ }^{36} \mathrm{Cl}$. This would increase the applicability of CRONUScalc to helium samples with higher Li contents and ultimately allow inclusion of other mineralogies.

\section{CRONUScalc Calculators}

The program written to perform a range of cosmogenic nuclide calculations is named "CRONUScalc." It is written in the MATLAB programming language, but can also be run under open-source Octave. The program is available under the GNU General Public License agreement and can be accessed and downloaded at: https://bitbucket.org/cronusearth/ cronus-calc. In the repository, users can upload their own files alongside the main code in order to share new features or functions using CRONUScalc.

The program is organized by scaling model, with folders containing code to perform various calculations. The core functions (Section 4.1) and the functions common to all nuclides are contained in the production folder. Additional folders are available for surface sample dating (surfacecalc), depth profile dating (profilecalc), and calibration of production rates (calib, muoncalib, pfzero).

\subsection{Core Functionality}

The code is designed to predict concentration at a particular depth for the specified nuclide. This is done using a function called prednxx, where XX represents the desired nuclide (i.e. predN36 calculates production of ${ }^{36} \mathrm{Cl}$ ). There are a few preliminary code modules necessary to build the inputs required for the main code. These include creating constants for physical parameters (physpars), calculating scaling factors (scalefacsXX), organizing the input sample parameters (sampparsXX), and computing sampledependent parameters that are needed for later calculations (compparsXX). These are not discussed in detail here, but can be found in the Function Appendix in the Supplementary Materials and will be available online for download with the code. PredNXX uses all this preliminary information in order to predict concentrations of the nuclide. This is summarized in Figure 3 for the ${ }^{10} \mathrm{Be}$ code. 


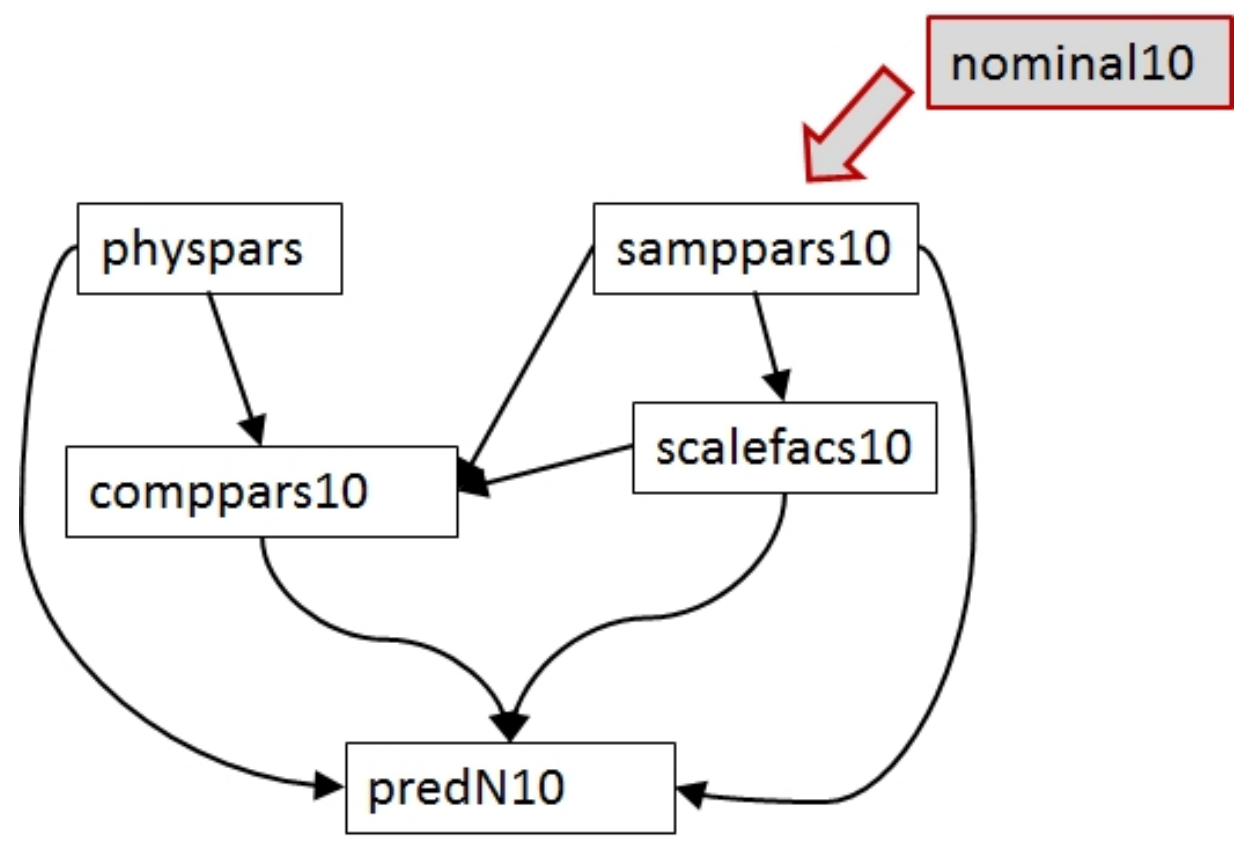

Figure 3: Data flow diagram showing the relationship between different parts of the code for a ${ }^{10} \mathrm{Be}$ sample. Inputs include the nominal inputs (nominal10) and the uncertainties on each of those inputs (uncerts10, not shown). Other code pieces (physpars, samppars10, comppars10, and scalefacs10) set up the correct variables for the upper-level code pieces. predN10 predicts the concentration for a given age and depth. 


\subsection{Features}

This program has several differences as compared to previous calculators. The CRONUScalc program is designed to work for all the commonly used nuclides, including ${ }^{10} \mathrm{Be},{ }^{26} \mathrm{Al},{ }^{3} \mathrm{He},{ }^{36} \mathrm{Cl}$, and ${ }^{14} \mathrm{C}$, with ${ }^{21} \mathrm{Ne}$ in testing. The modular nature of the program means that the scaling frameworks are applied in an identical manner to each nuclide, avoiding possible inconsistencies from errors in coding or using two different calculators for cross-nuclide comparisons. The addition of a new scaling framework by Lifton et al. (2014) allows for a physics-based calculation of the incoming cosmic-ray flux as well as nuclide-dependent scaling frameworks that incorporate the individual nuclide reaction cross-sections. This calculator has an easy input structure so that samples can be copied from spreadsheets and allows the user to run multiple samples simultaneously. This is one of the only calculators to allow the user to specify uncertainties on all input parameters and propagate those to the resulting exposure age. Finally, this program does not require any proprietary software because it can be run on either MATLAB or Octave, the latter being open-source.

CRONUScalc is able to calculate production and accumulation for any given sample as well as perform calibrations and calculate surface sample and depth-profile exposure ages. This calculator provides both surface sample and depth-profile dating abilities based on the same underlying code. Included in the surface calculator is the ability to date a single sample at depth. The code does not currently calculate burial ages.

Other new features that are not clearly visible in the upper levels of the program are the new integration method and the newly calibrated Heisinger muon production formulation. Some previous calculators relied on analytical solutions to integrate over depth by incorporating a 'thickness correction factor'. In this program, a numerical depth integration is performed, which removes approximations necessary in the analytical solution. This results in a more accurate inventory of accumulated nuclide in the sample as well as the ability to easily modify the code to look at multiple time periods with varying erosion rates. The new muon production is scaled using Lifton et al. (2014), and includes new production rate parameters calibrated from deep profiles for ${ }^{10} \mathrm{Be},{ }^{26} \mathrm{Al}$, and ${ }^{36} \mathrm{Cl}$ (for both $\mathrm{Ca}$ and $\mathrm{K}$ ).

Finally, although this paper discusses primarily the code behind the program, there is an online interface for the surface calculator, and other small tools such as the topographic shielding calculator, available to the public with no need to directly manipulate the code (http://web1.ittc.ku.edu: 
8888/). This simplifies the process and makes the technique available to a much broader range of users. Instructions for use of the interface calculators will be maintained online.

\section{Surface Sample Calculator}

The Balco et al. (2008) calculator put the Al/Be cosmogenic nuclide community on a consistent platform by providing a reliable tool for consistent ${ }^{10} \mathrm{Be}$ and ${ }^{26} \mathrm{Al}$ exposure age calculations. However, this did not apply to any other nuclides and the code did not allow the user to fully propagate uncertainties on all input parameters. CRONUScalc extends this idea to include multi-nuclide capability, full propagation of uncertainties, and the ability to work with single samples at depth.

Using the equations given in the previous sections, we can compute the rate of production of a cosmogenic nuclide at any depth within the subsurface at any point in the past. This production rate varies over time due to time-dependent scaling as well as varying due to changes in depth caused by erosion or aggradation. While the nuclide is accumulating it is also continuing to decay - the radioactive decay rate must be subtracted from the production rate. The time-dependent production rate can be numerically integrated over time in order to predict the concentration of the cosmogenic nuclide at a specific depth after a specified exposure history. By averaging the accumulated production at depths throughout the thickness of a sample, we can predict the average concentration of the cosmogenic nuclide as a function of the exposure age of the sample.

\subsection{Computing the Exposure Age or Erosion Rate}

To compute the exposure age of a sample, we begin by checking for saturation. This is done by computing the sample-specific saturation concentration by predicting the accumulated concentration in the sample assuming an exposure time of at least six half-lives, incorporating time-dependent production rates and ending in the sample collection year, and using all other user-provided inputs (see Section 3 for a list of inputs). If the measured concentration of the cosmogenic nuclide is close to or exceeds the saturation concentration ( $95 \%$ or more), then it is not possible to determine an exposure age for the sample because the sample is effectively saturated. If not, then we use the bisection method to find an age at which the predicted concentration matches the measured concentration of the nuclide. A similar 
method is applied in order to determine erosion rate for a sample when either an independent age is supplied or equilibrium with erosion rate can be assumed.

\subsection{Input Uncertainties and Derivatives}

The computed exposure age for a sample depends on a number of sample parameters in addition to the measured nuclide concentration, including its thickness and density, the assumed erosion rate, the assumed atmospheric pressure at the exposure site, etc. For each of these parameters, we compute the derivative of the exposure age with respect to the parameter by finite difference approximation. If the user supplies uncertainties for these parameters, then these derivatives are employed to propagate the uncertainties in the parameters into an uncertainty on the computed exposure age, using first order Taylor series expansion (Bevington \& Robinson, 1992).

The code allows for detailed quantification of the uncertainties associated with a sample. The commonly reported uncertainty, that from only the AMS analysis, represents the minimum uncertainty in the age of an unknown sample. There are uncertainties in the other measurements (chemical concentrations, field measurements, etc.), production rates, scaling, and laboratory processing. CRONUScalc allows an uncertainty to be assigned to each of the input parameters, a feature that is unavailable in other single-sample surface exposure age calculators. This idea was addressed in the multi-sample depth-profile calculator using Monte Carlo methods presented by Hidy et al. (2010), but is treated more systematically here using derivatives. In a manner similar to that employed by Balco et al. (2008), CRONUScalc distinguishes between analytical (internal) uncertainty, which is calculated by propagating uncertainties on every input parameter in uncertsXX, and total uncertainty, which is calculated by fully propagating the production-rate uncertainty and combining it with the analytical uncertainty. Although statistically-based uncertainties on the production rate parameters were not possible (Borchers et al., 2015), an alternative method to assess the uncertainty on this parameter was used in an attempt to provide a more complete uncertainty estimate.

The uncertainty associated with the nuclide production rate (i.e., the uncertainty added to the analytical uncertainty to give the total uncertainty) is based on a comparison of the deviations of the calculated ages for the secondary data set with the independent (and assumed correct) ages for those samples. In essence, the uncertainty associated with the production rate was increased until the average standard deviation of the calculated ages matched 
the spread of the deviations of the calculated ages from the independent ages. This empirical estimation of the additional uncertainty assumes that the residuals between the calculated ages and the independent ages averages zero and has a normal distribution. The actual distribution of residuals only marginally supports this assumption. The most significant sources of the additional uncertainty (not accounted for by the assigned analytical or other measurement uncertainties) are the following four. (1) Underestimation of the actual analytical uncertainties. Jull et al. (2013) have presented evidence that laboratory-reported uncertainties generally underestimate, sometimes by significant amounts, the actual spread of the cosmogenic-nuclide analytical data. (2) Errors in spatial scaling. Regularities in the residuals as a function of location and elevation give clues that even the best scaling models may not completely predict the global pattern of nuclide production (Phillips et al., 2015). (3) Errors in the assigned independent ages for the primary calibration data sites. Although sites with very well constrained ages were used, they cannot be guaranteed to all be completely accurate. (4) Sitespecific factors. Assumptions regarding factors such as snow cover, lack of covering deposits in the past, and erosion rates may have been in error for some sites. In summary, the additional uncertainty that is specified for the production-rate terms incorporates all sources of uncertainty or bias that are not included in the reported laboratory analytical uncertainties. It reflects the likelihood that a single, randomly selected, high-quality, cosmogenicnuclide age will correspond to an independently determined exposure age for the same material, empirically assessed using the CRONUS-Earth secondary data sets. Full details on the method, assumptions, and the uncertainty sources incorporated into the production-rate uncertainty are discussed in Phillips et al. (2015).

It is important to differentiate between the two reported uncertainty types (analytical and total). For example, analytical uncertainties alone are likely to underestimate realistic uncertainties when comparing to other dating techniques or comparing widely geographically or temporally separated cosmogenic samples. On the other hand, the total uncertainty may overestimate uncertainties when comparing between groups of samples from a single geographic location where uncertainties are not independent (e.g. in certain cases, production rate uncertainties are unimportant for relative chronology at a single site) (Dunai, 2010; Balco et al., 2008). Comparisons between nuclides can be complicated by the use of different calibration data sets and production models, so it may be necessary to use the external uncertainties 
to compare between samples from different nuclides located at the same site (Balco et al., 2008). Both uncertainties are reported, allowing the user to determine which is the most appropriate for each particular study. The user is encouraged to report all inputs, including assigned uncertainties, and note the type of uncertainty used in analyses.

A sensitivity analysis was performed in order to determine which inputs and their uncertainties have a significant effect on the sample exposure age. The results of the sensitivity analysis are presented in Figure 4. It is based on a random selection of the ${ }^{36} \mathrm{Cl}$ primary and secondary calibration samples (see Marrero (2012) for details), although similar results were seen for ${ }^{10} \mathrm{Be}$ samples. The results presented are merely intended to be representative and will vary from sample to sample. Sensitivities are only given for standard environmental parameters that are applicable for all nuclides. Chlorine-36 uncertainties are also sensitive to sample chemical composition. This topic is dealt with separately for ${ }^{36} \mathrm{Cl}$ in Marrero et al. (2015).

Based on this sensitivity analysis, there are some uncertainties that are insignificant. For example, realistic uncertainties on longitude and latitude are not important when compared to uncertainties on the concentration. Other variables that realistically do not require uncertainties include shielding and year collected. On the other hand, relatively large and potentially biased uncertainties are expected on parameters such as erosion rate and water content because these require estimation and some knowledge of the site and can rarely be precisely calculated.

When comparing different nuclide results, especially those from different sites, all uncertainties must be assessed in a consistent manner. The uncertainties from scaling and methodological considerations become primary issues. The interlaboratory studies associated with the CRONUS project (Jull et al., 2011, 2013; Vermeesch et al., 2012; Schaefer et al., 2014; Blard et al., 2014) were designed to address the uncertainties that arise solely from different processing techniques and accelerator measurements. These results were used to incorporate realistic uncertainty into the nuclide concentrations used for calibration (see Phillips et al. 2015 for details). 


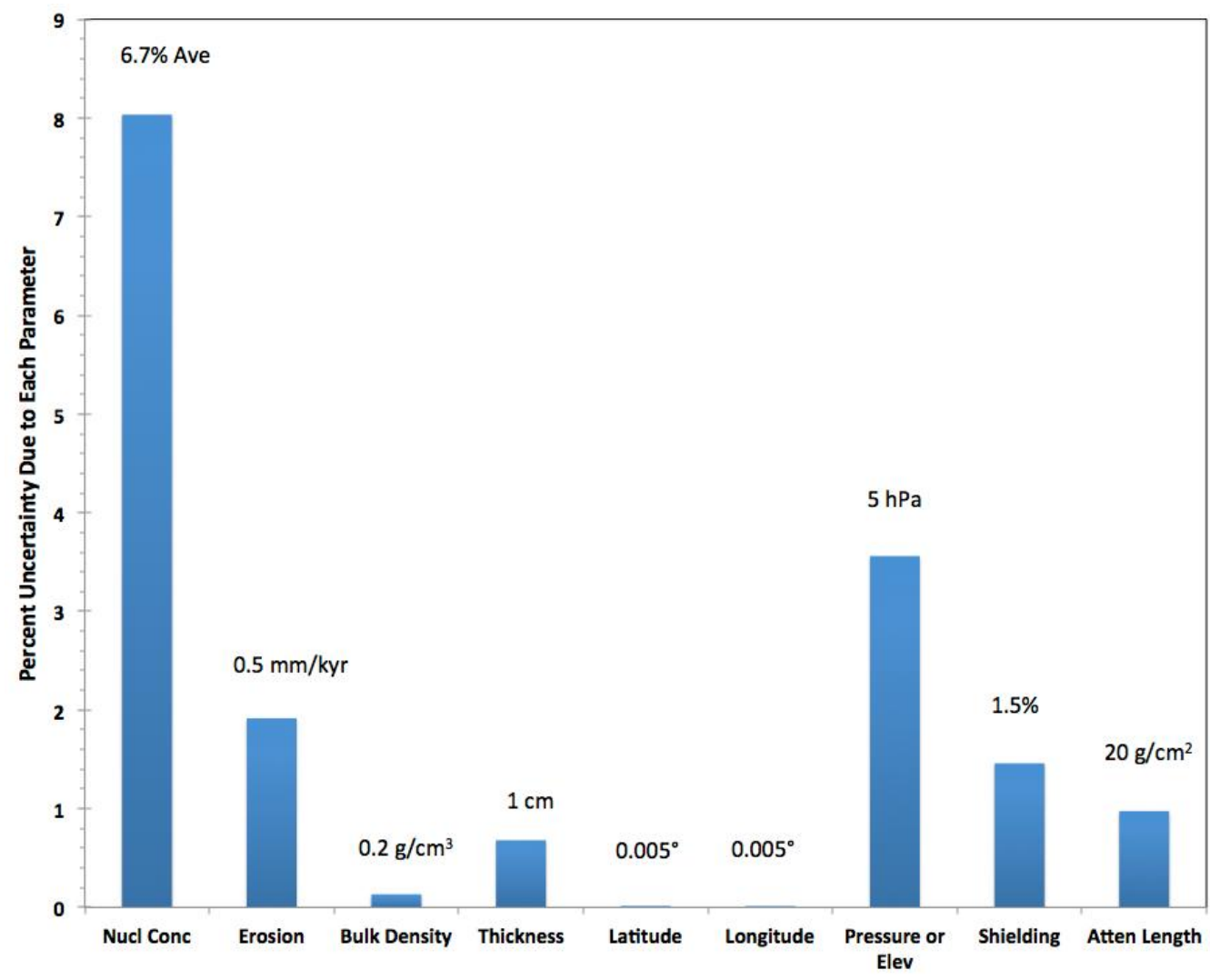

Figure 4: Amount of uncertainty (as a percentage of the final calculated age) contributed by conservative uncertainties assigned to individual sample parameters. The analysis presents the average of the propagated uncertainties for 15 primary and secondary ${ }^{36} \mathrm{Cl}$ calibration samples (Marrero, 2012; Marrero et al., 2015). The values above each bar give the assigned uncertainty in the parameter. 


\section{Depth-Profile Calculator}

The depth profile calculation is formulated as a Bayesian inverse problem. This approach has several advantages. First, unlike using a classical statistics approach to parameter estimation, the Bayesian approach treats unknown parameters as random variables. Doing so allows the resulting fitted parameters to be reported as expected values, accompanied by a probability distribution. Second, this approach allows the user to submit prior information or expert knowledge, influencing the solution. The selection of an informative prior distribution for parameters will strongly bias the resulting posterior distribution. Therefore the responsible user is obligated to report the effect that different priors have on their solution. Third, from a computational standpoint, the method presented in this section is not susceptible to the convergence failures that iterative line-search solvers can encounter in certain cases.

The inputs to the depth profile code are the same as those for the surface calculator, with several additional parameters required only for the profile calculation. The new parameters include maximum and minimum values for erosion rate, exposure age, and inheritance. In addition to erosion rate bounds, a value for total maximum erosion (positive or negative) can be used to additionally constrain the final results, which can be useful as total erosion can sometimes be easier to determine in the field. Some parameters common to the surface calculator, such as depth to top of sample and attenuation length, become more significant in the depth profiles than they were for surface samples. These parameters are both user inputs (i.e. the calculator assumes these are known parameters), although the uncertainties in these parameters have the potential to increase the uncertainty in the calculated age of the profile. One initial sensitivity test on a profile indicated that reasonable uncertainties on attenuation length were relatively insignificant, although reasonable uncertainties on bulk density measurements could result in up to $5 \%$ change in nominal age. For details on other parameters, see the sensitivity study results in Section 5.2. The depth profile calculator does not explicitly incorporate uncertainties on input parameters other than nuclide concentration.

Performing the depth profile calculation requires the simultaneous estimation of three parameters: age (t), erosion rate $(\epsilon)$, and inheritance (inh). The steps necessary for the computations are summarized here. First, an evenly spaced, 3-dimensional grid over the parameters of age, erosion rate, 
and inheritance is created. Note that the spacing is consistent only within each dimension and the parameter range for each is specified by the user. Second, the misfit $\chi^{2}$ value is calculated at each node (each age, erosion rate, and inheritance point) using Equation 10.

$$
\chi_{t, \epsilon, i n h}^{2}=\sum_{i}^{n}\left(\frac{x_{i}}{\sigma_{i}}\right)^{2}
$$

where

$$
x_{i}=\text { ConcPred }_{t, \epsilon, i n h}-\text { ConcMeas }_{i}
$$

Next, the approximated $\chi^{2}$ hyper-surface is transformed into a likelihood surface using Equation 11.

$$
L(\mathbf{x} \mid \boldsymbol{\theta})=\prod_{i=1}^{n}\left(\frac{1}{\sqrt{2 \pi \sigma_{i}}}\right) \cdot \exp \left(-\frac{\chi_{t, \epsilon, i n h}^{2}}{2}\right) .
$$

Finally, to calculate the joint posterior from the likelihood we use Bayes rule, shown in Equation 12.

$$
p(\boldsymbol{\theta} \mid \mathbf{x})=\frac{L(\mathbf{x} \mid \boldsymbol{\theta}) \pi(\boldsymbol{\theta})}{\int_{-\infty}^{\infty} L(\mathbf{x} \mid \boldsymbol{\theta}) \pi(\boldsymbol{\theta}) d \boldsymbol{\theta}},
$$

where $\pi(\boldsymbol{\theta})$ is the joint prior distribution set by the user on the following parameters: age, erosion rate, and inheritance. A trapezoidal integration scheme is used to calculate the denominator, leaving the joint posterior density, $p(\boldsymbol{\theta} \mid \mathbf{x})$.

When assigning uncertainties to a solution, it is important to determine if any multiple interactions exist between erosion rate, age, and inheritance. To display these interactions, the calculator produces 3 pairwise 2-D contour plots of the joint posterior distribution with contours of $68 \%$ and $95 \%$ regions of probability. For example, integrating $p(\boldsymbol{\theta} \mid \mathbf{x})$ over inheritance gives the probability distribution given by $p(\epsilon, t \mid \mathbf{x})$. This effectively marginalizes the joint posterior over one of the three parameters. An example of the resulting 2-D contour plots are shown in Figure 5, along with the predicted versus measured profile plot.

The best-fitting solution is the lowest chi-squared value over the entire three-dimensional grid. This is called the maximum a posterior (MAP) solution. In the 2-D pairwise plots, the MAP solution and the apparent 2-D bestfit solution do not always coincide due to the interaction of the parameters 

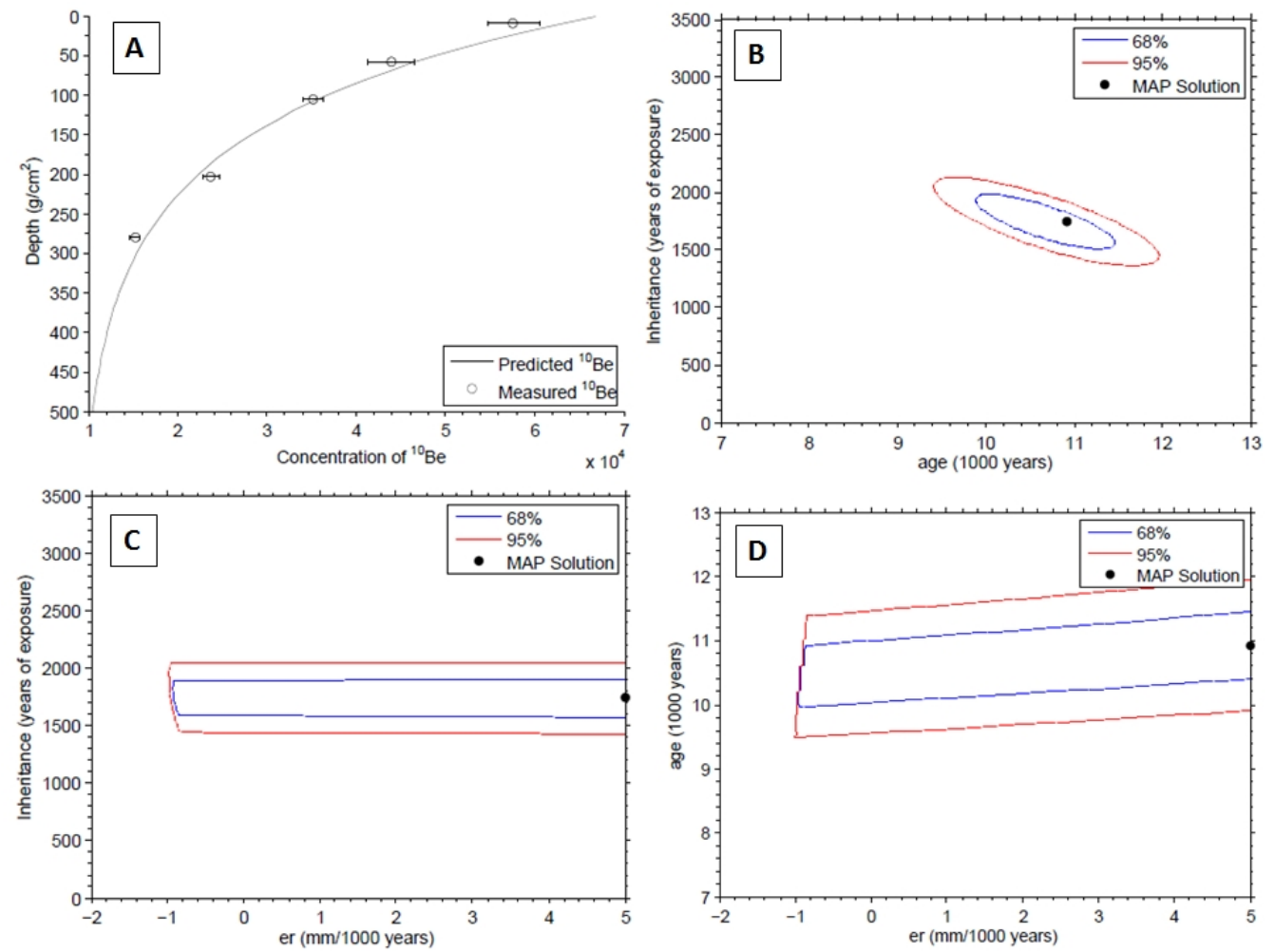

Figure 5: Example of the profile and pairwise plots produced by the depth profile calculator. The example is a ${ }^{10} \mathrm{Be}$ profile published by Goehring et al. (2010a) and used as an example in Aumer (2010). MAP solution is the best-fitting 3-D solution. $68 \%$ and $95 \%$ contours are the confidence intervals for the chi-squared values. (A) Figure shows the measured data and the predicted profile with depth; (B) Figure shows the confidence intervals for the plot of the inheritance and age; (C) Figure shows the confidence intervals for the plot of the inheritance and erosion rate; (D) Figure shows the confidence intervals for the plot of the age and erosion rate. 
with the third dimension. The direct calculation of posterior probabilities eliminates the need for Monte Carlo, as was used by Hidy et al. (2010). In contrast to Hidy et al. (2010), this code also computes a posterior probability distribution, allowing for an assessment of the probability of the resulting age being within particular age bounds. While there are other mathematical methods or spreadsheets available for calculating depth profiles (Braucher et al., 2009; Hein et al., 2009; Schaller et al., 2009), we discuss CRONUScalc in relation to Hidy et al. (2010) because of its similar format and explicit distribution for use as a depth profile calculator.

\section{Discussion and Cautions}

\subsection{Atmosphere and Elevation Relationships}

The relevant inputs are both elevation and atmospheric pressure for the sample. Elevation, which is more easily measured and can be found on a topographic map even after sampling, is the traditional input for these codes. The additional pressure input is necessary because it is the more accurate measure of the sample location in the atmosphere. If the user does not specify a site pressure, the online user interface automatically estimates the pressure using the ERA40 Reanalysis data set. The ERA40 reanalysis is a synthesis of comprehensive global observations and analyses over a 45 year period, as discussed in Uppala et al. (2005). This pressure calculation module is available with the code and pressure is a required input (not automatically calculated) within the raw code. The production-rate calibrations were all done using pressures determined from ERA40 and it is recommended that this conversion be used unless there is a specific reason to suspect a significantly different pressure relationship over the sample exposure period. ERA40 functions in Antarctica so no separate atmosphere relationship is required.

Uncertainty in the sample pressure is a significant contributor to sample uncertainty. The uncertainty associated with the pressure based on uncertainties in elevation is quite small $(<1 \mathrm{hPa}$ for elevation uncertainties up to $15 \mathrm{~m}$ ). This results in only a small amount of total uncertainty on the sample age $(<1 \%)$. A more realistic source of uncertainty associated with pressure is the difference between the current pressure and the average pressure over the exposure time of the sample. The pressure history through time is not a factor that can be accurately calculated. Our assumption that the pressure has remained relatively constant through time adds additional uncertainty. Based on the maximum differences observed between corresponding grid cells 
in the NCEP/NCAR and ERA40 (Uppala et al., 2005) reanalyses, we have added a conservative uncertainty of $5 \mathrm{hPa}$ to the CRONUS-Earth samples to account for this and this addition results in uncertainties of $2-5 \%$ for most samples.

\subsection{Uncertainties Due to Scaling}

Not all scaling frameworks fit the calibration data equally well. For each nuclide, a single data set was used to produce a production rate for each combination of scaling framework and nuclide. Because of its favorable analytical precision and accuracy, relative simplicity of its production mechanisms, and the large number of analyses, the nuclide best suited to evaluating the adequacy of scaling frameworks is ${ }^{10} \mathrm{Be}$. This topic is discussed more fully in Borchers et al. (2015) and Phillips et al. (2015), but is briefly summarized here. The average absolute error, by site averages, of the predicted vs. measured concentrations for the neutron-monitor-based scaling methods (Lifton, Dunai, Desilets) varied from 15.7 to $18.1 \%$. Those for the scaling methods based on more direct measures of spallation reactions (Lal-based and LSD) varied from 8.5 to $9.7 \%$. The second group is clearly more accurate. Although within this group the LSD-flux based model gave the best fit, the differences are so small that no clear preference is evident. In the following discussion of scaling uncertainty, the neutron-monitor based scaling methods were not considered due to the poor fit to the data set.

A second issue associated with scaling is the uncertainty from determining the scaling factor at a new location that is not a calibration site. The basis for estimating this contribution to the total age uncertainty is weak. The best basis available is found by comparing the fit of the primary CRONUSEarth ${ }^{10} \mathrm{Be}$ data set (to which the production rates were calibrated) to the fit of the secondary data set (which is independent of the primary data set) in Borchers et al. (2015). For the best-fitting scaling framework (LSD-flux based), the average absolute error was $5.4 \%$ for the primary data set, compared to $8.5 \%$ for the secondary data set. The difference between these two uncertainties could be interpreted to suggest that error in predicting scaling at non-calibration sites contributes about $3 \%$ to the total age uncertainty. However, the following factors must be considered: (1) the source of the variability cannot be assigned strictly to scaling and could, in fact, be due to other issues, such as the production rate calibration (2) samples were assigned to the secondary data set because they were weaker than those in the primary one due to factors such as less well constrained exposure histories, 
and therefore there are undoubtedly factors in addition to scaling uncertainty contributing to their larger scatter, and (3) error in scaling clearly contributes to the $5 \%$ scatter obtained for the primary data set, giving a contribution to the uncertainty from scaling that is not accounted for in the comparison. Factors (1) and (2) contribute to a decrease in scaling uncertainty while factor (3) contributes to an increase in uncertainty. The balance between these cannot at present be known, but likely the error in scaling, on average, contributes significantly less than $3 \%$ to the total age uncertainty.

The original CRONUS-Earth production-rate calibration was not able to calculate statistical uncertainties on the production rate parameters (Borchers et al., 2015). Instead, the CRONUS-Earth Project employed an empirical method for estimating production-rate uncertainty based on the secondary data set (Phillips et al., 2015). The empirical method does not break out the contribution to that uncertainty from scaling alone, but it does incorporate that source of uncertainty into the production-rate uncertainty recommendation. This inferred production-rate uncertainty is propagated along with other parameter uncertainties in CRONUScalc to provide the total uncertainty on a sample. Additional insight into scaling uncertainty can be obtained from the "leave-one-out cross-validation exercise" in Borchers et al. (2015).

\subsection{Limitations of CRONUScalc}

Although CRONUScalc has new capabilities not previously available in other calculators, there are some limitations to the program. CRONUScalc was designed to provide the most accurate model for a wide range of samples, meaning that approximations were avoided in most cases unless they could be shown not to increase uncertainty or error. The incorporation of more physics-based modeling into the program has substantially increased the calculation time for each sample. The online interface minimizes this problem by emailing the user with results, original inputs, and all data necessary to recreate the graphs prior to their deletion from the server so no further contact with the website is required. While samples are running, the user is provided a link that shows current progress on submitted samples. The use of email avoids browser timeout problems and decreases the dependence on a reliable internet connection. Emails and all sample data, except usage statistics on general location and nuclide, are automatically deleted every 24 hours from the server to protect anonymity. 
The current program only process one scaling model at a time for each sample. While it can be instructive to examine outputs from multiple scaling models, the addition of two new scaling models, for a total of seven, makes this time-prohibitive given the new framework. By allowing multiple samples to be submitted simultaneously, users can still perform the scaling comparisons by submitting samples more than once with a different scaling model selection.

\subsection{Expected Changes in Performance Due to New Scientific Content}

Comparisons to results from other similar cosmogenic calculators do not serve to show that CRONUScalc functions as expected for two main reasons. First, differences in the calibration data sets used by each program lead to very different results. Second, CRONUScalc has a different set of assumptions, parameters, and implementations than other programs, leading to results that differ by more than rounding error from the other programs, even when identical calibration data sets are used. Fundamentally, differences between the various programs are expected and this makes it impossible to prove the accuracy of CRONUScalc by obtaining the same results as those produced by other programs. The main differences are discussed later in this section.

However, in the very simplest case where there is only spallogenic production and we assume a time-independent production rate, it is possible to compare results from our code with the analytical solution given by equation 4.11 in Dunai (2010). The ${ }^{3} \mathrm{He}$ calculator was tested against analytically predicted concentrations for sample ages varying between 0.001-7000 ka and erosion rates of 0,1 , and $10 \mathrm{~mm} / \mathrm{kyr}$. At the highest erosion rates, the oldest samples were saturated. For all unsaturated samples, the differences between the analytically produced concentrations and the CRONUScalc solution were less than $0.005 \%$, with most several orders of magnitude smaller. The results are presented in Appendix D. The agreement between CRONUScalc and analytical solutions indicates that the CRONUScalc numerical integration performs well over a variety of erosion rates and ages. CRONUScalc results for other nuclides cannot be directly compared to analytical solutions due to the complex muon model and other new features, but the underlying age integration will be as accurate as demonstrated for ${ }^{3} \mathrm{He}$, because of the shared numerical integration code.

The section below highlights the new scientific content in CRONUScalc that is most likely to contribute to differences in performance when compared 
to other similar calculators. This section does not discuss the features of other calculators, but reiterates the key scientific content present in CRONUScalc and the situations that may yield major differences.

The addition of a new pair of scaling models (flux-based and nuclidedependent models from Lifton et al. (2014)) provides a flexible, physicsbased model for scaling production rates, but it also introduces the possibility for differences that vary by location and elevation when compared to results from other scaling models available in CRONUScalc or other programs. Lifton et al. (2014) contains a more detailed discussion of differences between resulting scaling factors, including the effects of solar modulation and the updated geomagnetic history.

CRONUScalc allows the user to specify an uncertainty for each parameter in the input. In addition to those analytical uncertainties, the productionrate uncertainty is propagated through to produce a total uncertainty for each sample (see Sections 5.2 and 7.2). Although the added flexibility to include an uncertainty on each input is useful, especially for older samples where fewer parameters were accurately reported, the CRONUScalc uncertainties will likely be different from those reported by other available calculators.

CRONUScalc muon production follows the Heisinger model, but uses CRONUS-Earth calibrated muon production rates (Fig 1 in Phillips et al., 2015) and is scaled using Lifton et al. (2014). In the fast muon formulation, CRONUScalc assumes a value for $\alpha$ (the parameter that defines how the cross-section scales with muon energy) equals one (see Section 2.1.3). This has a small effect on the elevation dependence on production rates when compared to models that use the value of $\alpha$ equal to 0.75 reported in the original paper (Heisinger et al., 2002b).

As discussed in Section 3.4, CRONUScalc only includes the spallation pathway for ${ }^{3} \mathrm{He}$ production calculations. This may be appropriate for some samples, but users are cautioned to check the composition of samples to confirm that this is true. Even moderate to low concentrations of lithium (Li) in a sample can potentially contribute significant production via thermal neutron production, which is not accounted for in this model.

CRONUScalc calculations for ${ }^{36} \mathrm{Cl}$ are more complex than for other nuclides, introducing more possible contributors to differences when comparing results from other programs. CRONUScalc includes ${ }^{36} \mathrm{Cl}$ production from both fast and slow muons. For samples with higher chlorine concentrations, an updated set of elemental parameters (Table 1) may make significant differences in calculated sample results, especially for samples high in boron. 
Finally, CRONUScalc assumes that the ${ }^{36} \mathrm{Cl}$ concentration is in equilibrium with the radiogenic and nucleogenic production rates in order to calculate the radiogenic subtraction (only significant for samples high in Th or U). This is unimportant for rocks with very old formation ages, but it is less clear whether this is appropriate for rocks where the formation age is equal to the exposure age. For example, based on available data for basalts, it is unclear if radiogenic production should begin at eruption or if it is in equilibrium prior to that time. Additional research is required to distinguish between these two models.

\section{Conclusion}

The CRONUScalc program, designed to predict sample concentrations at a particular depth, is intended to be versatile and work quickly for the largest number of possible applications without sacrificing accuracy. The program's abilities to calculate surface and depth-profile exposure ages, calculate erosion rates, and perform calibrations offer many options to the user. However, the code is available under a public license, so advanced users can modify the code to work for unusual scenarios. The new features, including a new scaling framework that performs nuclide-dependent scaling and a more accurate integration method, provide an internally consistent option for cosmogenic nuclide modeling. While the code can be adapted to many different functions, an online calculator with a simple interface has been designed for surface and depth-profile exposure age calculation (http://web1.ittc.ku.edu:8888/) in order to remove any necessity of a Matlab license or knowledge of coding and make the code easily available to the general cosmogenic isotope user community.

All the previous CRONUScalc versions will be archived in the online code repository and available for calculation of previously published results.

\section{Acknowledgments}

This research was supported by the National Science Foundation through the Cosmic-Ray-Produced Nuclides on Earth (CRONUS-Earth) Project through grant EAR-0345949. We would like to thank all the members of the CRONUSEarth and CRONUS-EU Projects for their input. This manuscript benefited from three thorough reviews by P. Vermeesch, R. Braucher, and an anonymous reviewer. 


\section{Appendix A. Production Models}

The sections below describe the fundamental theory behind the code. This appendix is provided to summarize the systematics of the program without referring back to numerous previous publications. See the main text for summaries of the key developments of CRONUScalc.

\section{Appendix A.1. Cosmic Rays}

Cosmic rays originate primarily from Milky Way galaxy supernova, but also from the sun and other energetic phenomena (Dunai, 2010; Gaisser, 1990; Gosse \& Phillips, 2001; Pigati \& Lifton, 2004). The main cosmogenic particles reaching the atmosphere are protons ( $87 \%$ of the cosmic-ray flux), with a smaller portion of the comic-ray flux composed of alpha particles (12\%) and other heavier nuclei (1\%) (Dunai, 2010). These incoming particles have a wide range of energies, with typical energies ranging from a few $\mathrm{MeV}$ to $10^{20} \mathrm{eV}$ (Dunai, 2010). Over long periods (10 Ma), the integrated cosmicray flux has been shown to be constant (to within 10\%) when averaged over 500 kyr timescales, with the uncertainties becoming larger (up to $30 \%$ or more) when averaged over timescales of hundreds of thousands to millions of years (Wieler et al., 2013).

As incoming cosmic-ray particles reach the top of the atmosphere, they interact with the earth's magnetic field. Only particles with sufficiently high energy and the correct trajectory will actually reach the earth's surface. This control on the magnitude of the cosmic-ray flux is quantified by means of the cutoff rigidity. The rigidity of a particle $(R)$ is given by Equation A.1. In the equation for rigidity, $p$ is the particle momentum, $c$ is the speed of light, and $e$ is the particle charge.

$$
R=p c / e
$$

The vertical cutoff rigidity, the minimum threshold for the particle energy necessary in order to penetrate the field on a path normal to the magnetic field, is the standard parameter used to organize the effect of the dipole field on the cosmic-ray flux as a function of location on the surface of the earth (Dunai, 2010; Gosse \& Phillips, 2001; Lifton et al., 2005). The cutoff rigidities are related to geomagnetic latitude, having very low values near the poles ( $>58^{\circ}$ at sea level), resulting in admittance of essentially all cosmic-ray particles, and increasing towards the equator (Lifton et al., 2005). 
The complexity of the paths of cosmic-ray particles due to interaction of looping trajectories with the solid earth results in an area where there are both allowed and forbidden trajectories in an alternating pattern known as the penumbra (Hillas, 1972). In order to determine where this region is and its effects on the cosmic-ray flux, reverse particle tracking (or trajectory tracing) can be performed for particles within $20 \mathrm{~km}$ of the earth's surface to determine the effective vertical cutoff rigidity of a location (Shea \& Smart, 1983; Dunai, 2010; Lifton et al., 2005). The effective vertical cutoff rigidity is used in scaling frameworks to parameterize the cosmic-ray flux of a site. Additional detail is given in the scaling section, Appendix C.

After the primary cosmic-ray particles reach the top of the atmosphere, they interact with atmospheric particles and create a cascade of secondary particles. As these secondary particles are produced and the cascade propagates through the atmosphere, several trends are apparent: the energy of the secondary particles decreases, the total flux of particles decreases, and the flux becomes dominated by neutrons due to the ionization losses of protons (Dunai, 2010). During these reactions, muons are also produced due to secondary reactions by energetic incoming particles high in the atmosphere (Eidelman, 2004). Unlike the hadronic component of the flux, the muonic flux increases and then reaches a plateau as the cascade moves down through the atmosphere because muons do not interact as strongly as neutrons and are lost very slowly through ionization (Gaisser, 1990). At the earth's surface, muons comprise the majority of the particles in the incoming cosmic-ray flux (Lal, 1988), but contribute less to surface production than do neutrons due to their lower propensity for nuclear interactions.

The energy spectrum of the neutrons that reach the earth's surface determines the rate of cosmogenic-nuclide-producing reactions. The neutrons, which compose $98 \%$ of the nucleonic flux at the earth's surface (Dunai, 2010), have peaks in the energy spectrum at $100 \mathrm{MeV}, 1-10 \mathrm{MeV}$, and $<1 \mathrm{eV}$ (Dunai, 2010; Goldhagen et al., 2002). The neutron energies discussed in this paper will be categorized as high $(>10 \mathrm{MeV})$, fast $(0.1$ to $10 \mathrm{MeV})$, epithermal $(0.5 \mathrm{eV}$ to $0.1 \mathrm{MeV})$, and thermal $(<0.5 \mathrm{eV})$. While these conventions follow other papers in the field (Gosse \& Phillips, 2001; Schimmelpfennig et al., 2008), there are no consistent classifications and the actual energies associated with the categories may vary in other publications (Dunai, 2010). 


\section{Appendix B. Production Equations}

The production equations for CRONUScalc are provided here. The details below are discussed in general terms for production of any nuclide, designated ' $k$ ', while details specific to a particular nuclide are discussed in later sections.

\section{Appendix B.1. Spallation}

Spallation refers to the emission of a large number of nucleons (relative to the original mass of the nucleus) when an atomic nucleus interacts closely with a high-energy particle. In some cases (e.g. ${ }^{3} \mathrm{He}$ ) a cosmogenic nuclide of interest may be one of the ejected particles. More commonly, (e.g. ${ }^{26} \mathrm{Al}$ ), it is the remainder of the target nucleus. Cosmogenic-nuclide production from spallation follows a well-established exponential decrease with depth. At the surface, spallation is typically the dominant production mechanism. All the nuclides discussed in this paper are produced through at least one spallation pathway. The formula for the instantaneous production rate from spallation $\left(P_{s, m}\right)$ is (Gosse \& Phillips, 2001; Schimmelpfennig et al., 2008):

$$
P_{\mathrm{s}, \mathrm{m}}(Z)=S_{T} \sum S_{e l, s} P_{\mathrm{m}, \mathrm{k}}(0) C_{\mathrm{k}} \exp \left(-\frac{Z}{\Lambda_{\mathrm{f}, \mathrm{e}}}\right)
$$

where $P_{\mathrm{m}, \mathrm{k}}$ is the sea-level, high-latitude production rate of species $\mathrm{m}$ by spallation of element $\mathrm{k}$ (atoms $\mathrm{g}^{-1} \mathrm{a}^{-1} ; S_{T}$ is the topographic shielding factor (unitless); $S_{e l, s}$ is the geographical scaling factor for spallation reactions for the particular reaction of interest, including temporal variation in the production rate due to fluctuations in the geomagnetic field or solar magnetic field (unitless); $C_{\mathrm{k}}$ is the concentration of the element $\mathrm{k}$ (atoms $\mathrm{g}^{-1} \mathrm{a}^{-1}$ ); and $\Lambda_{\mathrm{f}, \mathrm{e}}$ is the effective attenuation length for fast neutrons $\left(\mathrm{g} \mathrm{cm}^{-2}\right)$. The production is summed for all target elements $\mathrm{k}$ that produce nuclide $\mathrm{m}$ to give the total spallation production rate.

\section{Appendix B.1.1. Attenuation Length}

The particle attenuation length is the passage length through a medium required to attenuate the original intensity of a collimated beam of particles by a factor of $e^{-1}$ (Gosse \& Phillips, 2001). This value varies depending on the type of particle (proton, neutron, muon) and the associated energy level (fast, thermal, epithermal, etc.). For neutrons, the main factor is the energy level, with higher energy particles penetrating further into the subsurface 
than lower energy particles. The apparent attenuation length, $\lambda_{f, e}$, is the flux-weighted integral of the particle attenuation length over the entire sky.

The apparent attenuation length is an important parameter because it quantifies the depth distribution of the production by neutron spallation. The apparent attenuation length is defined with respect to a flat sample with no topographic shielding. When the apparent attenuation length is adjusted to account for the dip of the sample surface and any topographic shielding, the result is the effective attenuation length, $\Lambda_{f, e}$. The effective attenuation length is the parameter that should be used in calculations pertaining to production from a particular sample.

Typically, as the topographic shielding increases, the effective attenuation length increases (Dunne et al., 1999). The spectrum of neutron energy varies depending on the azimuth angle. The highest energy cosmic rays are vertically incident upon the sample and the flux is dominated by these rays (Dorman et al., 1999, in Dunai 2010). As the incident angle decreases going from vertical to horizontal, the intensity of the cosmic rays decreases due to the longer transport paths through the atmosphere (Dunai, 2010). The equation for this change in intensity is shown in Equation B.2. As topography typically blocks out only cosmic rays near the horizon, the average energy of the remaining cosmic rays increases. The sample dip also contributes to a change in the effective attenuation length and shielding, as described in Dunne et al. (1999).

$$
I(\theta)=I_{0} \sin ^{m} \theta,
$$

where $\mathrm{I}$ is the particle beam intensity and $\theta$ is the inclination angle from the vertical. The exponent $\mathrm{m}$, which is dependent on both energy and particle type, has been experimentally fit in several papers with significant differences in the results, as discussed in Dunai (2010). The most commonly cited value is $2.3 \pm 0.5$ from Nishiizumi et al. (1989), although Lal (1958) also gives a value of 2.3. However, Conversi and Rothwell (1954), cited by Lal, give a value of $2.1 \pm 0.3$ for $60 \mathrm{MeV}$ nucleons $(2.6 \pm 0.2$ for $750 \mathrm{MeV})$. In other studies, values of $2.5 \pm 0.5$ to $3.0 \pm 0.5$ (Barford and Davis, 1952), $3.5 \pm$ 1.2 (Heidbreder et al., 1971), and 2.65 (Masarik et al., 2000) have also been provided. Using Sato's PARMA model, the exponent is ca. 2.8 for neutrons (calculated for neutrons $>100 \mathrm{MeV}$, at solar minimum, $200 \mathrm{~m}$ altitude, $\mathrm{R}_{c}$ $=0 \mathrm{GV})$. The corresponding result for protons of similar energies is on the order of 3-3.5. Comparisons between this value and those reported in other 
studies must be considered with carefully because the energy ranges of the measurements are potentially quite different. Muons follow a similar trend, although the exponent in this case is 2 (Eidelman, 2004) or about 3.5 using the PARMA model. CRONUScalc does not use this formulation, however, and calculates the apparent attenuation length by interpolating from the values in Table 4, which were obtained using the spreadsheet published with Sato et al. (2008) and the adjustments described in the text.

The effective attenuation length depends on the sample location as well as the dip and shielding. The values for real samples vary from approximately 150-190 $\mathrm{g} / \mathrm{cm}^{2}$, which overlaps with the measured values for the apparent attenuation length, $\Lambda_{f}$, for fast nucleonic particles, which range from 121 to $>170 \mathrm{~g} / \mathrm{cm}^{2}$ (Dunai, 2000). Some recent studies for Be use a value of 177 (Farber et al., 2008; Schimmelpfennig et al., 2008). In addition to the dependence of the effective attenuation length on topographic shielding, it also depends on site cutoff rigidity and elevation, due to the dependence of the particle penetration length on particle energy. Samples from lower elevation and lower latitude will have longer attenuation lengths because of the increasing hardness of the neutron energy spectrum.

The attenuation-length model in CRONUScalc is based on atmospheric attenuation lengths calculated from the PARMA model of Sato et al. (2008). These are adjusted upward by $11.1 \%$ to account for systematic differences between atmospheric and lithospheric attenuation. See Section 2.4 for the complete derivation of the CRONUScalc attenuation length model. The data for the comparison of synthetic sample ages using different attenuation length models are presented here (B.6).

\section{Appendix B.2. Epithermal Neutrons}

Low-energy cosmogenic nuclide production, including that from thermal and epithermal neutrons, does not follow a simple exponential pattern with depth due to the atmosphere-ground interface effects. Due to the large crosssection of nitrogen for absorption of low-energy neutrons, the flux of cosmogenic thermal and epithermal neutrons in equilibrium with air is much less than that in equilibrium with rock. Low-energy neutrons produced in the upper $\sim 50 \mathrm{~cm}$ of rock therefore tend to diffuse upward out of the rock and into the atmosphere, resulting in a reduction of the flux as the rock surface is approached (see Figure B.6). Phillips et al. (2001) analytically solved the neutron-flux differential equation across the land/atmosphere interface to 


\begin{tabular}{|l|l|l|l|}
\hline $\begin{array}{l}\text { Erosion } \\
(\mathrm{mm} / \mathrm{kyr})\end{array}$ & $\begin{array}{l}\text { Be conc } \\
\text { (at/g) }\end{array}$ & $\begin{array}{l}153 \mathrm{~g} / \mathrm{cm}^{2} \\
\text { Age } \\
\text { ka) }\end{array}$ & $\begin{array}{l}170 \mathrm{~g} / \mathrm{cm}^{2} \\
\text { Age } \\
(\mathrm{ka})\end{array}$ \\
\hline \hline 0 & 73513 & 20.0 & 20.0 \\
\hline 0 & 360327 & 100.0 & 100.0 \\
\hline 0 & 1029138 & 300.0 & 300.0 \\
\hline 1 & 72154 & 20.0 & 20.0 \\
\hline 1 & 328482 & 100.0 & 99.1 \\
\hline 1 & 789962 & 300.0 & 290.8 \\
\hline 2.5 & 70156 & 20.0 & 19.9 \\
\hline 2.5 & 287378 & 100.0 & 97.6 \\
\hline 2.5 & 558968 & 300.0 & 272.2 \\
\hline 5 & 66974 & 20.0 & 19.8 \\
\hline 5 & 233598 & 100.0 & 94.7 \\
\hline 5 & 354648 & 300.0 & 230.2 \\
\hline 10 & 61176 & 20.0 & 19.6 \\
\hline 10 & 163166 & 100.0 & 86.9 \\
\hline 10 & 195499 & 300.0 & 156.6 \\
\hline
\end{tabular}

Table B.6: Summary of comparison of exposure ages using two different attenuation lengths for a variety of erosion rates. Sample parameters assumed in the calculations for CRONUScalc were: 40 deg latitude, 0 deg longitude, $0 \mathrm{~m}$ elevation, thickness of $0.001 \mathrm{~cm}$, shielding of 1 , density of $2.65 \mathrm{~g} / \mathrm{cm}^{3}$, collection date of 2014 AD. 
obtain the equations below. These, in turn, were combined with the formulations for muon-induced neutron production by Gosse and Phillips (2001) to obtain the complete equations for epithermal production.

The general form for the equation for the production of the cosmogenic nuclide of interest from epithermal neutrons is shown in Equation B.3. The epithermal neutron attenuation length $\left(\Lambda_{\text {eth,ss }}\right.$, Equation B.4) accounts for both moderation and absorption of epithermal neutrons and parameterizes the effective depth of penetration of the epithermal neutron flux (Gosse \& Phillips, 2001).

$$
P_{e t h, s s, m}=\frac{f_{e t h, s s, m}}{\Lambda_{e t h, s s}} \Phi_{e t h, s s, t o t a l}(Z)\left(1-p\left(E_{t h}\right)_{s s}\right),
$$

where $f_{e t h, s s, m}$ is the fraction of epithermal neutrons absorbed that are taken up by target element $\mathrm{k}$ to produce nuclide $\mathrm{m}$ (eqn E.15); $\Phi_{\text {eth,ss,total }}$ is the epithermal neutron flux (eqn B.8).

$$
\Lambda_{e t h, s s}=\left[\bar{\xi}_{b u l k}\left(I_{e f f, s s}+\Sigma_{s c, s s}\right)\right]^{-1}=\Sigma_{e t h, s s}^{-1},
$$

where $\xi_{\text {bulk }}^{-}$is the average macroscopic log decrement energy loss per neutron collision in the subsurface (eqn E.28); $I_{e f f, s s}$ is the macroscopic resonance integral for absorption of epithermal neutrons in the subsurface (eqn E.16); $\Sigma_{s c, s s}$ is the macroscopic neutron scattering cross-section in the subsurface (Equation E.27).

The distribution of epithermal neutrons in the subsurface can be described by Equation B.5. The epithermal neutrons are assumed to be produced entirely from the moderation of both spallation and evaporation neutrons and are assumed to be in equilibrium with the high-energy flux (Gosse \& Phillips, 2001).

$$
D_{e t h, s s} \frac{d^{2} \Phi_{e t h, s s}}{d Z^{2}}=\frac{\Phi_{e t h, s s}}{\Lambda_{e t h, s s}}-R_{e t h, s s} P_{f},
$$

where the diffusion coefficient for epithermal neutrons in the subsurface $\left(D_{\text {eth,ss }}\right)$ is defined in Equation E.9, with the corresponding parameter in the atmosphere, defined in Equation E.10; $R_{e t h, s s}$ is the normalization factor for the epithermal neutron production rate (eqn E.25); $P_{f}$ is the production rate of epithermal neutrons from fast neutrons, with the value at the surface represented as $P_{f}(0)$, which is a calibrated production rate parameter for ${ }^{36} \mathrm{Cl}$. 
The observed subsurface, epithermal neutron flux, $\Phi_{e t h, s s}$, at a particular point is the balance of exponential production with depth against the loss of neutrons through diffusion at the rock/air interface as well as loss through absorption and moderation. The hypothetical epithermal neutron flux in the subsurface assuming that there is no boundary (all material is the same as the subsurface) is indicated by $\Phi_{e t h, s s}^{*}$ and is given in Equation B.6. The difference between the hypothetical equilibrium flux in the air $\left(\Phi_{e t h, a}^{*}\right)$ and the hypothetical equilibrium flux in the subsurface $\left(\Phi_{e t h, s s}^{*}\right)$ is $\Delta \Phi_{e t h, s s}^{*}$. The physical cause of the difference between the fluxes (no interface vs interface) is the effect of diffusion. This is shown mathematically in Equation B.7 and graphically in Figure B.6.

$$
\begin{gathered}
\Phi_{e t h, s s}^{*}(Z)=P_{f}(0) \frac{R_{e t h, s s}}{\sum_{e t h, s s}-D_{e t h, s s} / \Lambda_{f, e}^{2}} \\
\Delta \Phi_{e t h, s s}^{*}=\Phi_{e t h, a}^{*}-\Phi_{e t h, s s}^{*}=-\Delta \Phi_{e t h, a}^{*}
\end{gathered}
$$

For the purposes of this initial solution, photodisintegration and other neutron-producing interactions are neglected. The diffusion-like behavior of low-energy neutrons means that the diffusion equation, in addition to the production equations, must be solved in order to predict the appropriate amount of cosmogenic nuclide from this type of production. The solution to the coupled differential equations (originally solved in Phillips et al. (2001)) yields Equation B.8.

$$
\Phi_{e t h, s s}=S_{T} S_{e l, s} \Phi_{e t h, s s}^{*} \exp \left(-\frac{Z}{\Lambda_{f, e}}\right)+(F \Delta \Phi)_{e t h, s s}^{*} \exp \left(-\frac{|Z|}{L_{e t h, s s}}\right),
$$

where the physical meaning of the $(F \Delta \Phi)_{\text {eth,ss }}^{*}$ term (Equation B.9) is the difference between the actual observed flux (with an interface present) and the flux that would be observed at the surface $(\mathrm{Z}=0)$ if all materials were the same as those in the subsurface. This can also be formulated for the air, as seen in Equation E.12. $L_{\text {eth,ss }}$ (eqn E.19) is the diffusion length for epithermal neutrons in the subsurface and the corresponding parameter in the atmosphere, $L_{e t h, a}$, is shown in Equation E.20. $S_{e l, s}$ is the scaling factor for spallation reactions, as the flux is derived from the high-energy component. 


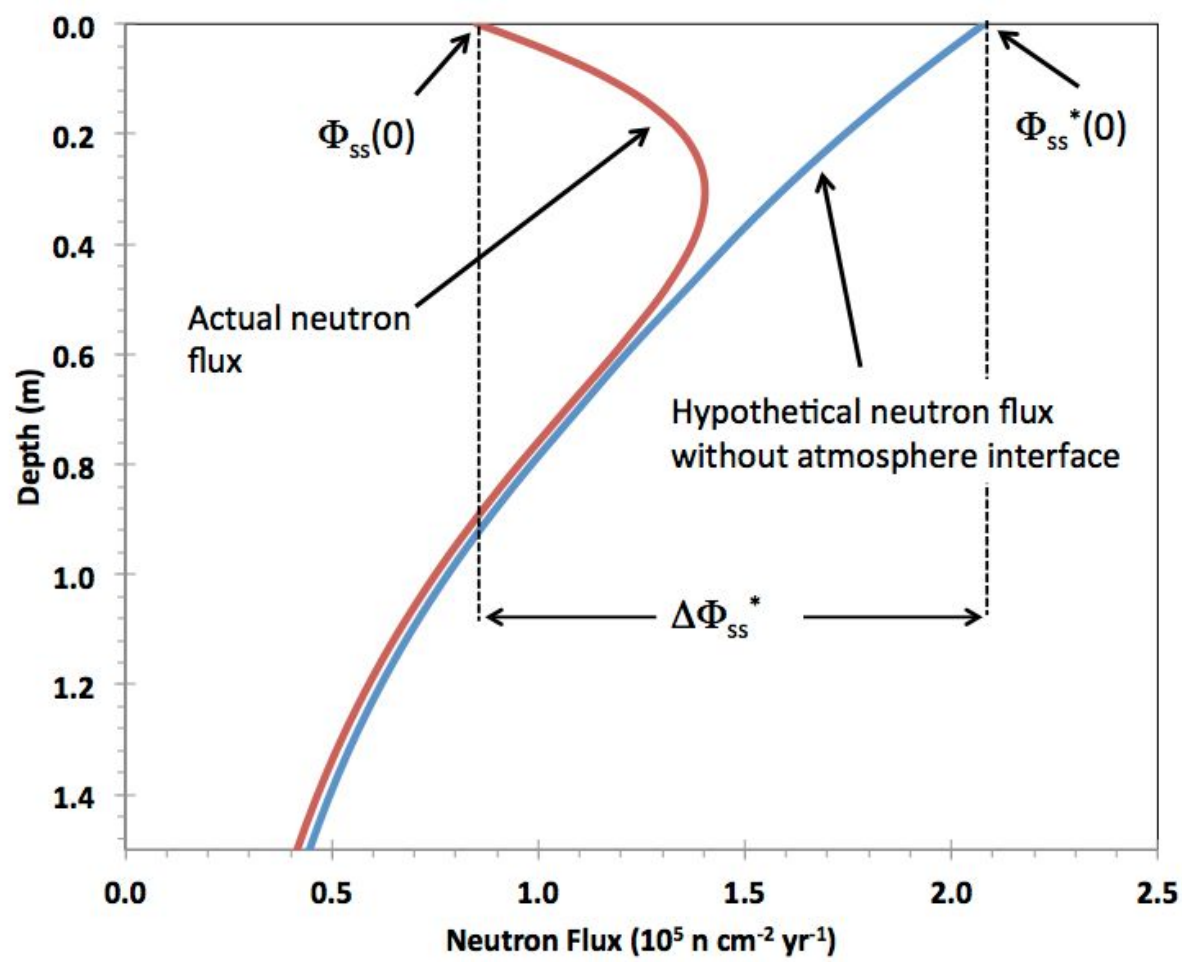

Figure B.6: Thermal-neutron flux profile calculated for standard granite from Fabryka-Martin (1988), illustrating the physical meaning of the terms $\Phi_{s s}(0)$, $\Phi_{s s}^{*}(0)$, and $\Delta \Phi_{s s}^{*}$. The physical meaning is equivalent for both thermal and epithermal neutron fluxes. 


$$
(F \Delta \Phi)_{e t h, s s}^{*}=\frac{\Delta \Phi_{e t h, s s}^{*} D_{e t h, a} / L_{e t h, a}-\Delta \Phi_{e t h, a}^{* *} D_{e t h, s s} / \Lambda_{f, e}}{D_{e t h, a} / L_{e t h, a}+D_{e t h, s s} / L_{e t h, s s}},
$$

where:

$$
\Delta \Phi_{e t h, a}^{* *}=\Delta \Phi_{e t h, s s}^{*}-\frac{D_{e t h, a}}{D_{e t h, s s}} \Phi_{e t h, a}^{*}
$$

\section{Appendix B.3. Thermal Neutrons}

Cosmogenic thermal neutrons are produced as a result of the moderation of cosmogenic epithermal neutrons (in other words, cosmogenic epithermal neutrons lose energy through collisions with atoms in the subsurface and end up as thermal neutrons, having only the ambient energy imparted by ordinary thermal vibration). The source term for thermal-neutron production is therefore the epithermal neutron distribution with depth. The production equations for thermal neutron pathways are analogous to those for epithermal neutrons. In the general production equation, the form is very similar with many parameters being replaced by ones specific for thermal neutrons instead of epithermal neutrons. The production rate $\left(P_{t h, m}\right)$ for thermal neutrons is shown in Equation B.11 (Gosse \& Phillips, 2001).

$$
P_{t h, s s, m}=\frac{f_{t h, s s, m}}{\Lambda_{t h, s s}} \Phi_{t h, s s, t o t a l}(Z),
$$

where $f_{t h, s s, m}$ is the fraction of absorbed thermal neutrons that are taken up by element $\mathrm{k}$ to produce nuclide $\mathrm{m}$ (eqn E.32); $\Phi_{t h, s s, t o t a l}$ is the thermal neutron flux (eqn B.13); and $\Lambda_{t h, s s}$ is the effective thermal neutron attenuation length (Equation E.33).

The distribution for thermal neutrons in the subsurface (Equation B.12) is also similar to that of epithermal neutrons, except that the thermal neutron source is assumed to be only neutrons moderated from the epithermal energy range.

$$
\begin{array}{r}
D_{t h, s s} \frac{d^{2} \Phi_{t h, s s}}{d Z^{2}}=\frac{\Phi_{t h, s s}}{\Lambda_{t h, s s}}-R_{t h, s s} \frac{p\left(E_{t h}\right)_{a}}{\Lambda_{e t h, s s}}\left[\Phi_{\text {eth }, s s}^{*} \exp \left(-\frac{Z}{\Lambda_{f, e}}\right)\right. \\
\left.+(F \Delta \Phi)_{e t h, s s}^{*} \exp \left(-\frac{|Z|}{L_{\text {eth }, s s}}\right)\right],
\end{array}
$$


where $D_{t h, s s}$ (Equation E.29) is the diffusion coefficient for thermal neutrons; $R_{t h, s s}$ is the ratio of thermal neutron production in the rock to that in the atmosphere (Equation E.38). The term $p\left(E_{t h}\right)_{a}$ is the resonance escape probability of a neutron from the epithermal energy range in the atmosphere (Equation E.24), with the corresponding subsurface term shown in Equation E.23.

The equations described above can be solved for the thermal neutron flux using the same boundary conditions assumed in the epithermal problem. The thermal neutron flux, discounting muon-induced neutrons, is shown in Equation B.13.

$$
\begin{aligned}
\Phi_{t h, s s}=S_{T} S_{e l, s} \Phi_{t h, s s}^{*} \exp \left(-\frac{Z}{\Lambda_{f, e}}\right)+ & (\mathscr{F} \Delta \Phi)_{e t h, s s}^{*} \exp \left(-\frac{|Z|}{L_{e t h, s s}}\right) \\
& +(\mathscr{F} \Delta \Phi)_{t h, s s}^{*} \exp \left(-\frac{|Z|}{L_{t h, s s}}\right)
\end{aligned}
$$

where:

$$
\begin{gathered}
\Phi_{t h, s s}^{*}=\frac{p\left(E_{t h}\right)_{a} R_{t h, s s} \Phi_{e t h, s s}^{*}}{\Lambda_{e t h, s s}\left(\Sigma_{t h, s s}-\frac{D_{t h, s s}}{\Lambda_{e t h, s s}^{2}}\right)} \\
(\mathscr{F} \Delta \Phi)_{e t h, s s}^{*}=\frac{p\left(E_{t h}\right)_{a} R_{t h, s s}(F \Delta \Phi)_{e t h, s s}^{*}}{\Lambda_{e t h, s s}\left(\Sigma_{t h, s s}-D_{t h, s s} / L_{e t h, s s}^{2}\right)} \\
(\mathscr{F} \Delta \Phi)_{t h, s s}^{*}=\left[D_{t h, a}\left(\frac{\Phi_{t h, a}^{*}}{\Lambda_{f, e}}-\frac{(\mathscr{F} \Delta \Phi)_{e t h, a}^{*}}{L_{e t h, a}}\right)\right. \\
-D_{t h}\left(\frac{\Phi_{t h, s s}^{*}}{\Lambda_{f, e}}-\frac{(\mathscr{F} \Delta \Phi)_{e t h, s s}^{*}}{L_{e t h, s s}}\right) \\
\left.+\frac{D_{t h, a}}{L_{t h, a}}\left(\Delta \Phi_{t h, s s}^{*}+\Delta(\mathscr{F} \Delta \Phi)_{e t h, s s}^{*}\right)\right] /\left(\frac{D_{t h, s s}}{L_{t h, s s}}+\frac{D_{t h, a}}{L_{t h, a}}\right)
\end{gathered}
$$

In Equation B.16, additional parameters of $\Delta \Phi_{t h, s s}^{*}$ and $\Delta(\mathscr{F} \Delta \Phi)_{e t h, s s}^{*}$ are described in Equations E.31 and E.4, respectively. $S_{e l, s}$ is the scaling factor for spallation reactions.

\section{Appendix B.4. Muons}

Muons are unstable, charged subatomic particles with a mass of about 207 times that of an electron and a mean life of about $2.2 \mathrm{~s}$. They are produced by 
decay of charged pions and $\mathrm{K}$ mesons, which in turn result from the interaction of high-energy cosmic-ray protons with matter in the atmosphere and the solid earth (Lal \& Peters, 1967). Cosmic-ray muons possess a wide spectrum of energies and the nature of their interaction with atomic nuclei depends strongly on energy. Lower energy ("slow") muons can participate in muoncapture reactions. The muon-capture reactions can release neutrons that later participate in neutron-capture reactions. Higher energy ("fast") muons can produce nuclear transmutations through inelastic scattering reactions, including both primary scattering reactions by the muons themselves and secondary ones by hadrons and photons released as a result of the primary muon interaction. The hadrons released include neutrons, and neutrons are also produced by gamma rays from muon-induced bremsstrahlung reactions (emission of electromagnetic radiation from an atomic nucleus stimulated by deflection of an energetic charged particle passing close to the nucleus). The energetic bremsstrahlung gamma rays can produce neutrons if they participate in $(\gamma, n)$ reactions with the nuclei of other atoms. These neutrons also can later participate in neutron-absorption reactions. Muons can thus induce the production of the nuclides modeled by CRONUScalc by means of a wide variety of reactions (Charalambus, 1971; Fabryka-Martin, 1988; Gaisser, 1990; Heisinger et al., 2002a,b).

Although the cosmic-ray muon flux is larger than the hadron flux at the earth's surface, the rate of interaction is much lower. The muonic component of the cosmic radiation is thus much more penetrating than the hadronic component. The slow component of the muon flux tends to be lost more rapidly due to muon-capture reactions and thus, although the magnitude of the flux decreases with depth below the earth's surface, the average energy increases. Whereas the hadron flux is important for cosmogenic-nuclide production down to about $1,000 \mathrm{~g} \mathrm{~cm}^{-2}$, the slow-muon flux is important down to about $2,500 \mathrm{~g} \mathrm{~cm}^{-2}$ and nuclides produced by the fast-muon flux are detectable down to $10,000 \mathrm{~g} \mathrm{~cm}^{-2}$. The penetration of muons producing cosmogenic nuclides is often characterized by an attenuation length employed in an exponential depth-dependent equation (e.g., Braucher et al. 2013), but due to the continuous hardening of the muon energy spectrum with depth, the muon flux does not have an exponential dependence on depth and the apparent attenuation length will increase as the depth of the measurements increases.

Muon contributions to total production are typically small at the surface, but become predominant at depths exceeding $\sim 1,000 \mathrm{~g} \mathrm{~cm}^{-2}$. Accurate 
calculation of muogenic production is thus important for sampling sites with large erosion rates or depth profiles. Accurate muon production formulations are also necessary for depth profiles deeper than about $3 \mathrm{~m}$ (Stone et al., 1998; Granger \& Smith, 2000), where the simultaneous evaluation of spallogenic and muogenic fractions offers the opportunity to uniquely determine both age and erosion rate (Braucher et al., 2009).

The original CRONUS-Earth calculator of Balco et al. (2008) implemented the Heisinger et al. (2002a,b) muon model as an improvement over the more empirical formulation in Stone et al. (1998). However, soon after Heisinger's publications, Braucher et al. (2003) used a deep core to provide evidence that the parameters specified by Heisinger et al. (2002a,b) overestimated actual ${ }^{10} \mathrm{Be}$ production by fast muons by approximately a factor of two. This was supported by additional profile data measured by Braucher et al. (2011) and by Kim \& Englert (2004), as well as reanalysis of previously published deep profile data by Braucher et al. (2013). This result has been confirmed by a deep profile drilled in a very low-erosion environment at Beacons Hills, Antarctica, by the CRONUS-Earth Project (Fig 1 in Phillips et al., 2015). CRONUScalc employs the Heisinger formulation for calculation of the subsurface muon flux for all nuclides, but uses calibrated production parameters obtained by fitting to the Beacon Heights profile data for ${ }^{10} \mathrm{Be}$ and ${ }^{26} \mathrm{Al}$.

The muon-flux model of Sato et al. (2008), combined with the previous Heisinger muon production equations and CRONUS-Earth data, has been employed to formulate a new hybrid muon production model that combines aspects of each of these models. The CRONUScalc muon code has been constructed by N. Lifton by modifying the Heisinger muon implementation described in Balco et al. (2008) and supplemental materials. The procedure followed by the code is summarized here along with the relevant equations.

The muon flux at the surface is scaled based on the Lifton-Sato-Dunai model (Lifton et al., 2014). The scaling is done by computing the omnidirectional muon flux as a function of energy at the site and at a reference location (SLHL) and dividing the site flux by the reference flux. The CRONUScalc muon module initially calculates the omnidirectional muon flux at SLHL and at the site of interest using the PARMA-based equations (Sato et al., 2008). Energy-dependent scaling factors are then calculated as the ratio of site flux to that at SLHL for each energy interval. A single scaling factor is similarly calculated for the stopping muon flux at the surface - we define stopping muons as those that have ranges less than $10 \mathrm{~g} / \mathrm{cm}^{2}$ (equivalent to ca. 40 
MeV energy) (Groom et al., 2001). The vertical muon flux at SLHL is calculated using the equation presented in Equation 3 in Heisinger et al. (2002a) and shown here as Equation B.17.

$$
\phi_{\nu, 0}(\mathrm{Z})=\frac{a}{(\mathrm{Z}+b)\left([\mathrm{Z}+1000]^{1.66}+c\right)} e^{d \mathrm{Z}},
$$

where the coefficients are as follows: $a=5.401 \times 10^{7}, b=21000, c=$ $1.567 \times 10^{5}, d=-5.5 \times 10^{-6}$. This formulation is only valid down to 200,000 $\mathrm{g} / \mathrm{cm}^{2}$ ( $\sim 750 \mathrm{~m}$ depth) and the alternative formulation provided in Balco (2008 supplemental material - Eqns. 49-51) should be used for deeper applications.

The stopping rate of the vertically incident muons $\left(R_{\nu, 0}(Z)\right)$ is calculated by equivalence to the range spectrum of the muons at the surface. Equation B.18 shows this calculation.

$$
R_{\nu, 0}(Z)=\frac{d}{d z}\left(\phi_{\nu, 0}(Z)\right)=-5.401 \times 10^{7}\left[\frac{b c \frac{d a}{d z}-a\left(\frac{d b}{d z} c+\frac{d c}{d z} b\right)}{b^{2} c^{2}}\right]
$$

where $a=e^{-5.5 \times 10^{-6}} z ; b=(z+21000) ; c=(z+1000)^{1.66}+1.567 \times 10^{5}$; $\frac{d a}{d z}=-5.5 \times 10^{-6} e^{-5.5 \times 10^{-6} z} ; \frac{d b}{d z}=1 ; \frac{d c}{d z}=1.66(z+1000)^{0.66}$ (Balco et al., 2008; Heisinger et al., 2002b).

The vertical muon flux as a function of depth $\left(\phi_{\nu}(\mathrm{Z})\right)$ at the site is found by numerically integrating the stopping rate from infinite depth to the depth of interest (Equation B.19).

$$
\phi_{\nu}(\mathrm{Z})=\int_{\mathrm{Z}}^{\infty} R_{\nu}(x) d x
$$

The vertical muon flux is converted to total muon flux at the site following Heisinger et al. (2002b) (Equation B.20), but modified to use depth units of $\mathrm{g} / \mathrm{cm}^{2}$ by Balco et al. (2008), as shown in Equation B.21.

$$
\begin{gathered}
\phi(\mathrm{Z}, \theta)=\phi_{\nu}(\mathrm{Z}) \cos ^{n(\mathrm{Z})} \theta \\
n(\mathrm{Z})=3.21-0.297 \ln \left(\frac{\mathrm{Z}}{100}+42\right)+\mathrm{Z} * 1.21 \times 10^{-5}
\end{gathered}
$$

The total muon flux at a given depth $\left(\phi_{\mu}(\mathrm{Z})\right)$ is given by Equation B.22. 


$$
\phi_{\mu}(\mathrm{Z})=\frac{2 \pi}{n(\mathrm{Z}+\delta \mathrm{Z})+1} \phi_{\nu}(\mathrm{Z})
$$

where $\delta \mathrm{Z}$ is the difference between the site of interest and sea level in units of $\mathrm{g} \mathrm{cm}^{-2}$. The total muon stopping rate as a function of depth $(\mathrm{R}(\mathrm{Z}))$ can be calculated by Equation B.23, following Balco (2007). The total stopping rate in muons $\mathrm{g}^{-1} \mathrm{~s}^{-1}$ is converted to the negative muon stopping rate by accounting for the percentage of all stopped muons that are negative stopped muons (44\%) and then converting the units to muons $\mathrm{g}^{-1} \mathrm{yr}^{-1}$. In both flux calculations (total muon flux and stopped negative muon flux) the values are calculated so that the flux is a positive value.

$$
\begin{gathered}
R(\mathrm{Z})=\frac{2 \pi}{n(\mathrm{Z}+\delta \mathrm{Z})+1} R_{\nu}(\mathrm{Z})-\phi_{\nu}(\mathrm{Z})(-2 \pi) * \\
(n(\mathrm{Z}+\delta \mathrm{Z})+1)^{2}\left[\frac{-0.297 \times 10^{-2}}{\frac{\mathrm{Z}+\delta \mathrm{Z}}{100}+42}+1.21 \times 10^{-5}\right]
\end{gathered}
$$

\section{Appendix B.4.1. Fast Muon Production}

Production from fast muons as a function of depth is calculated using the formulas in Heisinger et al. (2002b), with the general production described by Equation B.24.

$$
P_{\mu, f a s t}=S_{T} \phi_{\mu, t o t a l}(\mathrm{Z}) \beta(Z)(\bar{E}(Z))^{\alpha} \sigma_{0} \mathrm{~N}_{t, i}
$$

Where the factor $\beta(\mathrm{Z})$ is a function of the mean total muon energy and is shown in Equation B.25 and $\bar{E}$ is defined as the mean muon energy at a given depth $\mathrm{Z}$ and is shown in Equation B.26. $\mathrm{N}_{t, i}$ is the number density of the atoms in the target element (in units of at $/ \mathrm{g}$ ). This value is a constant for each nuclide unless the composition of the target changes, as it does for ${ }^{36} \mathrm{Cl}$.

$$
\begin{gathered}
\beta(Z)=0.846-0.015 \log \left(\frac{Z}{100}+1\right)+0.003139\left(\log \left(\frac{Z}{100}+1\right)^{2}\right) \quad(\text { B. } 25) \\
\bar{E}(Z)=7.6+321.7 *\left(1-\exp \left(-8.059 \times 10^{-6} Z\right)\right)+50.7\left(1-\exp \left(-5.05 \times 10^{-7} Z\right)\right)
\end{gathered}
$$


In Heisinger et al. (2002b), the experimentally-determined value of $\sigma_{190}$ (i.e., the energy-dependent reaction cross-section measured at $190 \mathrm{GeV}$ ) was used to calculate the value for $\sigma_{0}$ (the cross-section at $1 \mathrm{GeV}$ ) using Equation B.27, which can then be used to calculate the production from muons for a particular nuclide, as shown in Equation B.24. Alpha $(\alpha)$ is an only weakly energy-dependent coefficient that parameterizes the energy dependence of the cross-section on muon energy, with low values indicating a weaker dependence and higher values a stronger dependence. Based on a survey of the literature, Heisinger et al. (2002b) adopted a value of $\alpha \approx 0.75$, but their own experimental evidence supported a value of about $0.93 .{ }^{26} \mathrm{Al} /{ }^{10} \mathrm{Be}$ ratios measured by Kim \& Englert (2004) in a profile down to $50,000 \mathrm{~g} / \mathrm{cm}^{-2}$ depth are higher than predicted by Heisinger et al. (2002b), supporting a larger value of $\alpha$. Experimental results are permissive of values between 0.75 and $>1.0$ (Heisinger et al., 2002b) so the CRONUS-Earth Project chose a value of $\alpha=1.0$. By assuming that $\alpha$ equals one, $\beta$ will also be equal to one. Heisinger et al. (2002b) reported experimentally determined values of $\sigma_{190}$ for many of the nuclides of interest including ${ }^{26} \mathrm{Al},{ }^{10} \mathrm{Be},{ }^{14} \mathrm{C}$, and ${ }^{36} \mathrm{Cl}$ from calcium. Note that there is no value for ${ }^{36} \mathrm{Cl}$ from potassium. However, application of these values in many cases produced calculated concentrations in excess of what has been measured in deep profiles (Braucher et al., 2011, 2013).

Rather than using parameters estimated from laboratory muon irradiations, the CRONUS-Earth Project has adopted values calibrated from nuclideconcentration profiles at carefully selected sites whenever possible (Fig 1 in Phillips et al., 2015; Borchers et al., 2015; Marrero, 2012). $\sigma_{0}$ was selected as the calibration parameter for the production of nuclides by muon reactions, as discussed in Marrero (2012). This was done mainly for two reasons. First, $\sigma_{0}$ is the only nuclide-dependent parameter in the fast production equation, so it is the logical choice. Second, by directly calibrating the $\sigma_{0}$ parameter, any dependence on the accuracy of the conversion from $\sigma_{190}$ to $\sigma_{0}$ is eliminated. Equation B.27 was used to calculate initial starting parameters for the $\sigma_{0}$ calibration.

$$
\sigma(E)=\sigma_{0} E^{\alpha},
$$

where $\mathrm{E}$ is the muon energy in $\mathrm{GeV}$. 


\section{Appendix B.4.2. Slow Negative Muon Capture Production}

Nuclide production by slow negative muon capture $\left(P_{\mu-}\right)$ is described by Equation B.28, originally from Charalambus (1971) and discussed in detail for ${ }^{36} \mathrm{Cl}$ by Stone et al. (1998). The production rate depends on the stopping rate of negative muons $\left(\phi_{\mu_{-}}\right)$as well as the nuclide-dependent factors $\left(f_{i, C}\right.$, $\left.f_{i, D}, f_{i}^{*}\right) . f_{i, D}$ is the fraction of muons stopped by element $\mathrm{k}$ and absorbed by the nucleus before decay of the muon. $f_{i, C}$, the compound factor, represents the fraction of the muons that are captured by a target element (as opposed to the other elements present) within the bulk rock. The formula for the compound factor is taken from Charalambus (1971) and the values are consistent with those used by Heisinger et al. (2002a). In the case of nuclides measured in a rock of uniform composition, the compound factor is a constant parameter; however, for cases where the lithology, and hence the chemical composition, is spatially variable, the compound factor will also vary. The value for $f_{i, C}$ can be calculated using the formula in Equation E.40 and the values in von Egidy \& Hartmann (1982).

$$
P_{\mu-}=S_{T} \phi_{\mu-}(Z) f_{i, C} f_{i, D} f_{i}^{*}
$$

The remaining parameter, $f_{i}^{*}$, the particle emission channel probability, is the probability that the excited nucleus of the target atom will emit the proper particle to result in transformation to the nuclide of interest. Heisinger et al. (2002a) report experimentally determined $f_{i}^{*}$ values for the production of ${ }^{26} \mathrm{Al}$ (from $\mathrm{Si}$ ), ${ }^{10} \mathrm{Be}$ and ${ }^{14} \mathrm{C}$ (from $\mathrm{O}$ ), and ${ }^{36} \mathrm{Cl}$ (from $\mathrm{K}$ and $\mathrm{Ca}$ ). As for the fast muon production reactions, the parameters of Heisinger et al. (2002a) tend to overestimate nuclide concentrations measured in depth profiles (Fig 1 in Phillips et al., 2015; Braucher et al., 2011), so $f_{i}^{*}$ for ${ }^{10} \mathrm{Be},{ }^{26} \mathrm{Al},{ }^{36} \mathrm{Cl}$ were calibrated by fitting to the measured CRONUS-Earth profiles (Phillips et al., 2015; Borchers et al., 2015; Marrero, 2012).

\section{Appendix B.4.3. Muon-induced Neutrons}

As muons react with atomic nuclei in the subsurface, neutrons are released. These can, in turn, react with other nuclei to produce cosmogenic nuclides of interest. The principal reactions responsible for the production of neutrons are muon capture and $(\gamma, \mathrm{n})$ reactions resulting from interaction of high-energy gamma from muon-induced bremsstrahlung reactions with the nuclei of atoms in the subsurface. In order to calculate the nuclide production due to these muonic neutrons, it is necessary to know the muon flux as 
a function of depth. Due to the capabilities of the muon model, the quantification of fluxes has improved and they need no longer be approximated using a simple exponential equation (Stone et al., 1998), as was previously done in most models, including CHLOE (Phillips \& Plummer, 1996) and the Schimmelpfennig et al. (2009) calculator, but instead are directly calculated using Equation B.29. The muon module, described in the previous section, is used to calculate the negative muon stopping rate $\left(\phi_{\mu-}(\mathrm{Z})\right)$ and total muon flux $\left(\phi_{\mu f}(Z)\right)$ terms at a given depth.

$$
P_{n, \mu}(\mathrm{Z})=Y_{s} \phi_{\mu-}(Z)+5.8 \times 10^{-6} \phi_{\mu f}(Z),
$$

where $Y_{s}$ is the average neutron yield per stopped negative muon (FabrykaMartin, 1988).

Near the atmosphere/subsurface interface, muon-induced low-energy neutrons are assumed to follow the same distribution as the spallation-induced neutrons. Although the muon-induced neutron flux near the surface is not in equilibrium with the production rate due to diffusion, the diffusion is occurring based on the total concentration of neutrons at the surface. The dominant source of neutrons is spallation reactions, so the muons are assumed to follow the same pattern as the spallation-induced neutrons, leading to the incorporation of the muogenic neutrons into the epithermal neutron flux as shown in Equation B.30.

$$
\begin{aligned}
\Phi_{\mathrm{eth}, \mathrm{ss}}(Z)= & S_{T} S_{e l, s} \Phi_{\mathrm{eth}, \mathrm{ss}}^{*} \exp \left(-\frac{Z}{\Lambda_{\mathrm{f}, \mathrm{e}}}\right) \\
& +\left(1+R_{\mu}(0) R_{\mathrm{eth}, \mathrm{ss}}\right)(F \Delta \Phi)_{\mathrm{eth}, \mathrm{ss}}^{*} \exp \left(-\frac{Z}{L_{\mathrm{eth}, \mathrm{ss}}}\right) \\
& +R_{\mu}(Z) \Phi_{\mathrm{eth}, \mathrm{ss}}^{*}
\end{aligned}
$$

There are two different values used in the code for the muon-induced neutron factor, $\mathrm{R}_{\mu} \cdot \mathrm{R}_{\mu}(\mathrm{Z})$ is defined in Equation B.31. In the parts of the equation dealing with epithermal neutrons, the surface production rate of the muogenic neutrons $\left(R_{\mu}(0)\right)$ is used because of the assumption that the production follows the same trend as the spallogenic neutrons. For the parts of the equation dependent on the attenuation at depth of the muon flux, the actual values for $\mathrm{R}_{\mu}(\mathrm{Z})$ are calculated from the muon module and used in the equation. 


$$
R_{\mu}(Z)=\frac{S_{e l, \mu} P_{n, \mu}(Z)}{S_{e l, e t h} P_{f}(0) R_{e t h}}
$$

The code calculates the epithermal neutron flux and the subsequent cosmogenic nuclide production by combining the muon-induced neutrons with the original epithermal neutron production equation, Equation B.8, to produce the total epithermal neutron production for nuclide $\mathrm{m}$, as shown in Equation B.32.

$$
\begin{aligned}
& P_{\text {eth,ss }, \mathrm{m}}(\mathrm{Z})=\frac{f_{\text {eth }, \mathrm{ss}} \Phi_{\text {eth,ss,total }}}{\Lambda_{\text {eth,ss }}}=\frac{f_{\text {eth,ss }}}{\Lambda_{\text {eth,ss }}}\left\{\Phi_{\text {eth,ss }}^{*} \exp \left(-\frac{\mathrm{Z}}{\Lambda_{\mathrm{f}, \mathrm{e}}}\right)\right. \\
& +\left(1+R_{\mu}(0) R_{\text {eth }, \mathrm{ss}}\right)(F \Delta \Phi)_{\mathrm{eth}, \mathrm{ss}}^{*} \exp \left(-\frac{z}{L_{\mathrm{eth}, \mathrm{ss}}}\right) \\
& \left.+R_{\mu}(\mathrm{Z}) \Phi_{\mathrm{eth}, \mathrm{ss}}^{*}\right\}
\end{aligned}
$$

Similar considerations for muon-induced neutrons must be made for the thermal energy range. Some of the epithermal-range neutrons produced by muon interactions lose enough energy to become thermal neutrons. The contribution of these muon-induced neutrons to the thermal flux is shown in Equation B.33. Once again, the muon-induced neutrons are assumed to follow the same trends as the spallogenic neutrons and are scaled appropriately using only the surface value of $R_{\mu}^{\prime}(Z)$ for the spallogenic parts of the equation. For the neutron-dependent term, the actual values for each depth are calculated. The final equation for the thermal neutron flux is shown in Equation B.34.

$$
R_{\mu}^{\prime}(Z)=\frac{p\left(E_{t h}\right)_{a}}{p\left(E_{t h}\right)} R_{\mu}(Z)
$$




$$
\left.\begin{array}{r}
\Phi_{t h, s s, t o t a l}=S_{T} S_{e l, s}\left\{\Phi_{\mathrm{th}, \mathrm{ss}}^{*} \exp \left(-\frac{\mathrm{Z}}{\Lambda_{\mathrm{f}, \mathrm{e}}}\right)+\right. \\
\left(1+R_{\mu}^{\prime}(0)\right)(\Im \Delta \Phi)_{\mathrm{eth}, \mathrm{ss}}^{*} \exp \left(-\frac{\mathrm{Z}}{L_{\mathrm{eth}, \mathrm{ss}}}\right) \\
+\left(1+R_{\mu}^{\prime}(0) R_{\mathrm{th}, \mathrm{ss}}\right)(\Im \Delta \Phi)_{\mathrm{th}, \mathrm{ss}}^{*} \exp \left(-\frac{\mathrm{Z}}{L_{\mathrm{eth}, \mathrm{ss}}}\right)+ \\
R_{\mu}^{\prime}(\mathrm{Z}) \Phi_{\mathrm{th}, \mathrm{ss}}^{*}
\end{array}\right\}
$$

The total production of cosmogenic nuclide $\mathrm{k}$ via thermal neutron pathways is described by combining Equation B.34 with Equation B.11 and yields an equation for total production with depth from thermal neutrons, shown in Equation B.35.

$$
\begin{aligned}
P_{\mathrm{th}, \mathrm{ss}, \mathrm{m}}(\mathrm{Z})= & S_{T} S_{e l, s} \frac{f_{\mathrm{th}} \Phi_{\mathrm{th}, \mathrm{ss}, \mathrm{total}}}{\Lambda_{\mathrm{th}, \mathrm{ss}}}=\frac{f_{\mathrm{th}}}{\Lambda_{\mathrm{th}, \mathrm{ss}}}\left\{\Phi_{\mathrm{th}, \mathrm{ss}}^{*} \exp \left(-\frac{\mathrm{Z}}{\Lambda_{\mathrm{f}, \mathrm{e}}}\right)\right. \\
& +\left(1+R_{\mu}^{\prime}(0)\right)(\Im \Delta \Phi)_{\mathrm{eth}, \mathrm{ss}}^{*} \exp \left(-\frac{\mathrm{Z}}{L_{\mathrm{eth}, \mathrm{ss}}}\right) \\
& +\left(1+R_{\mu}^{\prime}(0) R_{\mathrm{th}}\right)(\Im \Delta \Phi)_{\mathrm{th}, \mathrm{ss}}^{*} \exp \left(-\frac{\mathrm{Z}}{L_{\mathrm{eth}, \mathrm{ss}}}\right) \\
& \left.+R_{\mu}^{\prime}(\mathrm{Z}) \Phi_{\mathrm{th}, \mathrm{ss}}^{*}\right\}
\end{aligned}
$$

\section{Appendix B.5. Radiogenic Production}

"Radiogenic production" in this context refers to the generation of lowenergy neutrons by reactions related to the radioactive decay or spontaneous fission of $\mathrm{U}$ or $\mathrm{Th}$, and the subsequent absorption of those neutrons to produce nuclides of interest, principally ${ }^{36} \mathrm{Cl}$. The radiogenic low-energy neutron flux is assumed to be in equilibrium with the concentrations of uranium (U) and thorium (Th) in the rock. This component is quantified using measured concentrations of $\mathrm{U}$ and $\mathrm{Th}$ and the method described in Fabryka-Martin (1988), which is based on the formulations developed by Feige et al. (1968). The uranium and thorium $\alpha$-decay chain members produce alpha particles 
$(\alpha)$ as they decay. The alpha particles react with light nuclei in the rock matrix to produce low-energy neutrons. In turn, the neutrons can react with target elements in the rock in the same way that cosmogenically produced neutrons react to produce nuclides such as ${ }^{36} \mathrm{Cl}$. The equations for calculating this contribution to the total nuclide inventory within a sample are provided in detail in Fabryka-Martin (1988) and are summarized here.

The radiogenic production of nuclides is given by Equation B.36. The elements with the maximum yield of neutrons due to alpha particle reaction are $\mathrm{Be}, \mathrm{B}, \mathrm{F}$, and Li. However, due to the low concentration of these elements in most rocks, the largest concentrations of neutrons result from targets with larger matrix concentrations, such as $\mathrm{Al}, \mathrm{Si}, \mathrm{Mg}, \mathrm{O}$, and $\mathrm{Na}$. The concentrations of both $\mathrm{O}$ and $\mathrm{H}$ are calculated from the oxide measurements performed on the other elements.

$$
P_{r}=P_{e t h, r} f_{e t h}+P_{t h, r} f_{t h}
$$

where $P_{r}$ is the total radiogenic production from all mechanisms in a particular sample; $P_{e t h, r}$ is the total radiogenic epithermal neutron production (Equation B.37); $P_{t h, r}$ is the total radiogenic thermal neutron production (Equation B.38).

Although the concentrations of the largest producers of neutrons are the most important elements to quantify, the remaining rock matrix composition must still be quantified in addition to the elements listed above so that all elements can be used to calculate the stopping power of the rock. In particular, there are several elements, such as boron and gadolinium, that have large thermal neutron absorption cross-sections, meaning that they have a large probability of absorbing neutrons (from both radiogenic and cosmogenic sources) (Fabryka-Martin, 1988). This decreases the actual amount of ${ }^{36} \mathrm{Cl}$ formed within the rock because these other elements intercept the neutrons prior to formation of ${ }^{36} \mathrm{Cl}$.

$$
\begin{gathered}
P_{e t h, r}=\left(P_{n, \alpha}+P_{n, s f}\right)\left(1-p\left(E_{t h}\right)\right), \\
P_{t h, r}=\left(P_{n, \alpha}+P_{n, s f}\right)\left(p\left(E_{t h}\right)\right),
\end{gathered}
$$

where $P_{n, \alpha}$ is the production rate of neutrons from alpha particles in neutrons $\mathrm{g}^{-1} \mathrm{yr}^{-1}$ (Equation B.39). $P_{n, s f}$ is the neutron production rate due to the spontaneous fission of ${ }^{238} \mathrm{U}$ and can be calculated as $0.429[\mathrm{U}]$, where $[\mathrm{U}]$ is the concentration of uranium in ppm. 


$$
P_{n, \alpha}=X[U]+Y[T h],
$$

where $[\mathrm{Th}]$ is the thorium concentration in ppm. $\mathrm{X}$ and $\mathrm{Y}$ are neutron production factors related to the light isotope composition of the rock matrix and are described in Equations B.40 and B.41, respectively. These were originally described by Feige et al. (1968).

$$
\begin{aligned}
X & =\frac{\sum k S_{k} F_{k, \text { bulk }} Y_{n}^{U}}{\sum k S_{k} F_{k, \text { bulk }}}, \\
Y & =\frac{\sum k S_{k} F_{k, \text { bulk }} Y_{n}^{T h}}{\sum k S_{k} F_{k, \text { bulk }}},
\end{aligned}
$$

where $S_{k}$ is the mass stopping power of element k for $\alpha$-particles of a given energy; $Y_{n}^{U}$ and $Y_{n}^{T h}$ are the neutron yields of element i per ppm $\mathrm{U}$ or Th in equilibrium; $F_{k, b u l k}$ is the fractional abundance of element $\mathrm{k}$ in ppm in the bulk rock.

\section{Appendix C. Scaling}

Cosmogenic nuclide scaling applies the physics governing the modulation of the cosmic-ray flux by atmospheric mass and the terrestrial and solar magnetic fields to provide production rates as a function of location and exposure time. Numerous scaling frameworks have been proposed in order to correct for latitude, elevation, atmospheric pressure anomalies, dipole and non-dipole geomagnetic field changes, and solar modulation. For all the details of the scaling frameworks themselves, please see the original papers (cited in Table 2); for details of implementation, please see the descriptions in Balco et al. (2008) and Lifton et al. (2014).

The fundamental correction for elevation and latitude is the key part of each scaling framework. The first scaling framework to implement this was Lal (1991). Eventually, Stone (2000) reformulated the original equations to take atmospheric pressure, instead of elevation, as an input. This is still a commonly cited scaling framework. However, the original, timeindependent Lal/Stone scaling (abbreviated as St in the code) does not account for changes in production rate that we know are occurring through time due to fluctuations in the terrestrial and solar magnetic fields.

The production rates of cosmogenic nuclides are a function of the magnetic field strength. As the geomagnetic field of the earth changed in the 
past, production rates of the nuclides also changed. This fact has led to the development of scaling frameworks that incorporate the geomagnetic history of the earth. Dunai (2000, 2001a) (Du), Desilets et al. (2006b); Desilets \& Zreda (2003) (De), and Lifton et al. (2005, 2008) (Li), and Lifton-Sato-Dunai (Lifton et al., 2014) (LSD, herein labeled Sf) have all implemented different models to incorporate the changing magnetic field. Following Balco et al. (2008), we have also provided the time-dependent Lal scaling (Lm, including dipole geomagnetic effects as approximated by Nishiizumi et al. (1989)) in order to differentiate between the geomagnetic effects and other differences in the models.

In CRONUScalc, the geomagnetic history is consistent across all scaling frameworks and is summarized in Table 3. The Lifton et al. (2005) and the more recent model presented in Lifton et al. (2014) (LSD) also incorporate the effects of solar modulation into the scaling framework. For a discussion of the uncertainties associated with geomagnetic models, see Section 2.3.

In each scaling framework that incorporates geomagnetic effects, the appropriate input is cutoff rigidity. However, each scaling framework implements the rigidity cutoff calculations differently (see Schimmelpfennig (2009) for a summary of these differences). See each original scaling reference for the equations for cutoff rigidity. In the program, most of the scaling frameworks are taken directly from Balco et al. (2008) and complete descriptions can be found in the original calculator supplemental material (Balco et al., 2008). For the Sa and Sf models, see the paper by Lifton et al. (2014).

\section{Appendix D. Comparison of CRONUScalc and Analytical Solu- tions for ${ }^{3} \mathrm{He}$}

Synthetic ${ }^{3} \mathrm{He}$ concentrations were predicted using the analytical solution presented in Dunai (2010) for samples undergoing both production and erosion. The CRONUS-Earth calibrated production rate for ST scaling and the erosion rate (Table D.7, column 1) were used to predict the concentration (Table D.7, column 2). The resulting CRONUScalc ages for ST scaling are presented in Table D.7, column 4 . The differences in terms of $\%$ are provided in the final column of the table. Saturated samples were excluded from comparison. Samples were assumed to be located at SLHL, 0 degrees longitude, and have a density of $2.65 \mathrm{~g} / \mathrm{cm}^{3}$, shielding of 1 , thickness of $0.001 \mathrm{~cm}$, an effective attenuation length of $136 \mathrm{~g} / \mathrm{cm}^{2}$ and were collected in 2014 AD. 


\begin{tabular}{|c|c|c|c|c|}
\hline $\begin{array}{l}\text { Erosion rate } \\
(\mathrm{mm} / \mathrm{kyr})\end{array}$ & $\begin{array}{l}\text { Concentration } \\
\left(\text { atoms } \mathrm{g}^{-1}\right)\end{array}$ & $\begin{array}{l}\text { Actual age } \\
\text { (ka) }\end{array}$ & $\begin{array}{l}\text { Calc age } \\
(\mathrm{ka})\end{array}$ & $\begin{array}{l}\% \text { Difference } \\
(\%)\end{array}$ \\
\hline 0 & 118 & 0.001 & 0.001 & $4.6 \times 10^{-} 7$ \\
\hline 0 & 11821 & 0.1 & 0.100 & $2.0 \times 10^{-7}$ \\
\hline 0 & 1182137 & 10 & 10.000 & $-4.9 \times 10^{-} 7$ \\
\hline 0 & 5910685 & 50 & 50.000 & $5.6 \times 10^{-7}$ \\
\hline 0 & 11821370 & 100 & 100.000 & $5.6 \times 10^{-} 7$ \\
\hline 0 & 23642739 & 200 & 200.000 & $5.6 \times 10^{-} 7$ \\
\hline 0 & 47285479 & 400 & 400.000 & $5.6 \times 10^{-} 7$ \\
\hline 0 & 118213696 & 1000 & 1000.000 & $-7.5 \times 10^{-} 7$ \\
\hline 0 & 236427393 & 2000 & 2000.000 & $-7.5 \times 10^{-} 7$ \\
\hline 0 & 354641089 & 3000 & 3000.000 & $-9.9 \times 10^{-} 7$ \\
\hline 0 & 591068482 & 5000 & 5000.000 & $6.0 \times 10^{-} 7$ \\
\hline 0 & 827495875 & 7000 & 7000.000 & $8.5 \times 10^{-} 7$ \\
\hline 1 & 11820 & 0.1 & 0.100 & $2.0 \times 10^{-} 7$ \\
\hline 1 & 1170695 & 10 & 10.000 & $6.8 \times 10^{-} 7$ \\
\hline 1 & 5631906 & 50 & 50.000 & $5.6 \times 10^{-} 7$ \\
\hline 1 & 10741040 & 100 & 100.000 & $5.6 \times 10^{-} 7$ \\
\hline 1 & 19580586 & 200 & 200.000 & $5.6 \times 10^{-} 7$ \\
\hline 1 & 32842095 & 400 & 400.000 & $5.6 \times 10^{-} 7$ \\
\hline 1 & 52026941 & 1000 & 1000.000 & $7.5 \times 10^{-} 7$ \\
\hline 1 & 59441147 & 2000 & 2000.000 & $2.2 \times 10^{-} 6$ \\
\hline 1 & 60497723 & 3000 & 3000.000 & $8.9 \times 10^{-} 6$ \\
\hline 1 & 60669750 & 5000 & 5000.014 & $2.8 \times 10^{-} 4$ \\
\hline 1 & 60673244 & 7000 & 7000.662 & $9.5 \times 10^{-} 3$ \\
\hline 10 & 11810 & 0.1 & 0.100 & $11.7 \times 10^{-5}$ \\
\hline 10 & 1074104 & 10 & 10.000 & $1.7 \times 10^{-} 5$ \\
\hline 10 & 3776908 & 50 & 50.000 & $2.7 \times 10^{-} 5$ \\
\hline 10 & 5202694 & 100 & 100.000 & $4.9 \times 10^{-} 5$ \\
\hline 10 & 5944115 & 200 & 200.000 & $2.0 \times 10^{-} 4$ \\
\hline 10 & 6064829 & 400 & 400.020 & $4.9 \times 10^{-} 3$ \\
\hline
\end{tabular}

Table D.7: Summary of comparison between analytical solutions for ${ }^{3} \mathrm{He}$ and CRONUScalc results over a range of erosion rates and exposure ages. 


\section{Appendix E. Glossary of Terms and Equations}

Table E.8: Glossary of terms and equations

\begin{tabular}{|c|c|}
\hline Term & Definition \\
\hline \multicolumn{2}{|c|}{ General parameters and subscripts } \\
\hline bulk & $\begin{array}{l}\text { In reference to the bulk rock composition of the sample } \\
\text { as opposed to the target (processed) material }\end{array}$ \\
\hline$C_{k}$ & $\begin{array}{l}\text { Mass concentration of element } \mathrm{k}\left[\begin{array}{lll}(\mathrm{g} & \text { element } \mathrm{k}) & (\mathrm{g} \\
\text { material })^{-1}\end{array}\right.\end{array}$ \\
\hline eth & $\begin{array}{l}\text { Subscript used to denote the epithermal production path- } \\
\text { way, defined as neutrons with energies of } 0.5 \mathrm{eV} \text { to } 0.1 \\
\mathrm{MeV} \text {. }\end{array}$ \\
\hline $\mathrm{h}$ & Atmospheric depth $\left[\mathrm{g} \mathrm{cm}^{-2}\right]$ \\
\hline $\mathrm{k}$ & $\begin{array}{l}\text { Subscript used to denote a particular cosmogenic- } \\
\text { producing element }\end{array}$ \\
\hline $\mathrm{m}$ & Subscript used to denote a particular cosmogenic nuclide \\
\hline $\mathrm{m}$ & Molar concentration \\
\hline$\mu$ & Subscript used to denote the muon production pathway \\
\hline$\rho$ & Density $\left[\mathrm{g} \mathrm{cm}^{-3}\right]$ \\
\hline $\mathrm{s}$ & $\begin{array}{l}\text { Subscript used to denote the spallation production path- } \\
\text { way }\end{array}$ \\
\hline target & $\begin{array}{l}\text { In reference to the particular target fraction of the sam- } \\
\text { ple, specifically in the case of mineral separates }\end{array}$ \\
\hline th & $\begin{array}{l}\text { Subscript used to denote the thermal production path- } \\
\text { way, defined as neutrons with energies of }<0.5 \mathrm{eV} \text {. }\end{array}$ \\
\hline $\mathrm{Z}$ & Ordinary linear distance $[\mathrm{cm}]$ \\
\hline $\bar{Z}$ & $\begin{array}{l}\text { Mass depth below the surface }\left[\mathrm{g} \mathrm{cm}^{-2}\right] \\
\qquad Z(z)=\int_{0}^{z} \rho(z) d z\end{array}$ \\
\hline \multicolumn{2}{|c|}{ Cosmic Rays } \\
\hline$c$ & Speed of light (see eqn A.1) \\
\hline$e$ & Particle charge (see eqn A.1) \\
\hline$p$ & Particle momentum (see eqn A.1) \\
\hline
\end{tabular}


Table E.8 - continued from previous page

\begin{tabular}{|l|l|}
\hline \multicolumn{1}{|c|}{ Term } & \multicolumn{1}{c|}{ Definition } \\
\hline$R$ & Rigidity of a particle (see eqn A.1) \\
\hline$S_{e l}$ & $\begin{array}{l}\text { Latitude/Elevation scaling coefficient (see scaling scheme } \\
\text { section) [unitless] }\end{array}$ \\
\hline$S_{T}$ & $\begin{array}{l}\text { Topographic scaling coefficient describing the shielding } \\
\text { from surrounding topography [unitless] }\end{array}$ \\
\hline$\theta$ & Inclination angle from the horizontal [degrees] \\
\hline$z_{p}$ & $\begin{array}{l}\text { Vertical penetration depth }\left[\mathrm{g} \mathrm{cm}^{-2}\right] \\
\end{array}$ \\
\hline
\end{tabular}

\begin{tabular}{|l|l|}
\multicolumn{2}{l|}{ Spallation } \\
\hline \hline$I(\theta)$ & $\begin{array}{l}\text { Intensity. See eqn B.2. } I_{0} \text { is the intensity of I for a sample } \\
\text { with 0 dip. }\end{array}$ \\
\hline$\Lambda_{\mathrm{f}, \mathrm{e}}$ & $\begin{array}{l}\text { Effective attenuation length for fast neutrons. See Ap- } \\
\text { pendix B.1.1. }\end{array}$ \\
\hline$P_{s, m}$ & Production rate for spallation of nuclide m. See eqn 1. \\
\hline$P_{m, k}$ & $\begin{array}{l}\text { Production rate of nuclide m from target element k. See } \\
\text { eqn 1. }\end{array}$ \\
\hline$\theta$ & $\begin{array}{l}\text { Sample dip/inclination as measured from the horizontal. } \\
\text { See eqn B.2. }\end{array}$ \\
\hline
\end{tabular}

Epithermal Production

\begin{tabular}{|l|l|}
\hline \hline $\bar{A}_{s s}$ & $\begin{array}{l}\text { Average atomic weight of the bulk rock }\left[\mathrm{g} \mathrm{mol}{ }^{-1}\right] \\
\bar{A}_{s s}=\frac{\sum_{k} A_{k} N_{k, s s, b u l k}}{\sum_{k} N_{k, s s, b u l k}}\end{array}$ \\
\hline $\bar{A}_{a}$ & $\begin{array}{l}\text { Average atomic weight of the atmosphere; constant } \\
\left.14.5 \text { g mol }^{-1}\right] \text { (Phillips \& Plummer, 1996) }\end{array}$ \\
\hline$A_{k}$ & Atomic weight of element $\mathrm{k}[\mathrm{g}$ mol \\
\hline
\end{tabular}


Table E.8 - continued from previous page

\begin{tabular}{|c|c|}
\hline Term & Definition \\
\hline$\Delta(\mathscr{F} \Delta \Phi)_{e t h, s s}^{*}$ & $\begin{array}{l}\text { Difference between } \mathscr{F} \Delta \Phi)_{\text {eth }}^{*} \text { in the atmosphere } \\
\left.\left.(\mathscr{F} \Delta \Phi)_{\text {eth }, a}^{*}\right) \text { and the subsurface }(\mathscr{F} \Delta \Phi)_{\text {eth }, s s}^{*}\right) \\
\qquad \Delta(\mathscr{F} \Delta \Phi)_{\text {eth,ss }}^{*}=(\mathscr{F} \Delta \Phi)_{\text {eth,a }}^{*}-(\mathscr{F} \Delta \Phi)_{\text {eth,ss }}^{*} \quad \text { (E.4) }\end{array}$ \\
\hline$\Delta \Phi_{e t h, s s}^{*}$ & $\begin{array}{l}\text { Difference between the hypothetical equilibrium epither- } \\
\text { mal neutron fluxes in atmosphere and rock [neutrons } \\
\left.\mathrm{cm}^{-2} \mathrm{yr}^{-1}\right] \\
\qquad \Delta \Phi_{\text {eth,ss }}^{*}=\Phi_{\text {eth,a }}^{*}-\Phi_{\text {eth,ss }}^{*}\end{array}$ \\
\hline$\Delta \Phi_{e t h, a}^{*}$ & $\begin{array}{l}\text { Difference between the hypothetical equilibrium epither- } \\
\text { mal neutron fluxes in atmosphere and rock [neutrons } \\
\left.\mathrm{cm}^{-2} \mathrm{yr}^{-1}\right] \\
\qquad \Delta \Phi_{\text {eth,a }}^{*}=\Phi_{\text {eth,ss }}^{*}-\Phi_{\text {eth,a }}^{*}\end{array}$ \\
\hline$\Delta \Phi_{e t h, s s}^{* *}$ & $\begin{array}{l}\text { Adjusted difference between the hypothetical equilibrium } \\
\text { epithermal neutron fluxes in atmosphere and rock. [neu- } \\
\text { trons } \mathrm{cm}^{-2} \mathrm{yr}^{-1} \text { ] } \\
\qquad \Delta \Phi_{\text {eth,ss }}^{* *}=\Phi_{\text {eth,a }}^{*}-\frac{D_{\text {eth,ss }}}{D_{\text {eth,a }}} \Phi_{\text {eth,ss }}^{*}\end{array}$ \\
\hline$\Delta \Phi_{e t h, a}^{* *}$ & $\begin{array}{l}\text { Adjusted difference between the hypothetical equilibrium } \\
\text { epithermal neutron fluxes in atmosphere and rock. [neu- } \\
\left.\text { trons } \mathrm{cm}^{-2} \mathrm{yr}^{-1}\right] \\
\qquad \Delta \Phi_{\text {eth,a }}^{* *}=\Phi_{\text {eth,ss }}^{*}-\frac{D_{\text {eth,a }}}{D_{\text {eth,ss }}} \Phi_{\text {eth,a }}^{*}\end{array}$ \\
\hline & Continued on next page \\
\hline
\end{tabular}


Table E.8 - continued from previous page

\begin{tabular}{|c|c|}
\hline Term & Definition \\
\hline$D_{e t h, s s}$ & $\begin{array}{l}\text { Diffusion coefficient for epithermal neutrons in subsurface } \\
{\left[\mathrm{g} \mathrm{cm}^{-2}\right]} \\
\qquad D_{\text {eth,ss }}=\left[3 \Sigma_{s c}\left(1-\frac{2}{3 \bar{A}}\right)\right]^{-1}\end{array}$ \\
\hline$D_{e t h, a}$ & $\begin{array}{l}\text { Diffusion coefficient for epithermal neutrons in air }[\mathrm{g} \\
\left.\mathrm{cm}^{-2}\right] \text { can be calculated using values of }\left(\Sigma_{s c, a}\right)=0.3773 \\
{\left[\mathrm{~cm}^{-2} \mathrm{~g}^{-1}\right] \text { (Phillips \& Plummer, 1996). }} \\
D_{\text {eth }, a}=\left[3 \Sigma_{s c, a}\left(1-\frac{2}{3 \bar{A}}\right)\right]^{-1}\end{array}$ \\
\hline$(F \Delta \Phi)_{e t h, s s}^{*}$ & $\begin{array}{l}\text { Difference between the epithermal neutron flux if there } \\
\text { was no boundary }\left(\Phi_{\text {eth,ss }}^{*}\right) \text { and the actual epithermal neu- } \\
\text { tron flux at the atmosphere/subsurface interface (see } \\
\left.\text { equation B.9) [neutrons } \mathrm{cm}^{-2} \mathrm{yr}^{-1}\right] \\
(F \Delta \Phi)_{\text {eth }, s s}^{*}=\frac{\Delta \Phi_{\text {eth }, s s}^{*} D_{e t h, a} / L_{e t h, a}-\Delta \Phi_{e t h, a}^{* *} D_{e t h, s s} / \Lambda_{f, e}}{D_{e t h, a} / L_{e t h, a}+D_{e t h, s s} / L_{e t h, s s}} \\
\text { (E.11) }\end{array}$ \\
\hline$(F \Delta \Phi)_{e t h, a}^{*}$ & 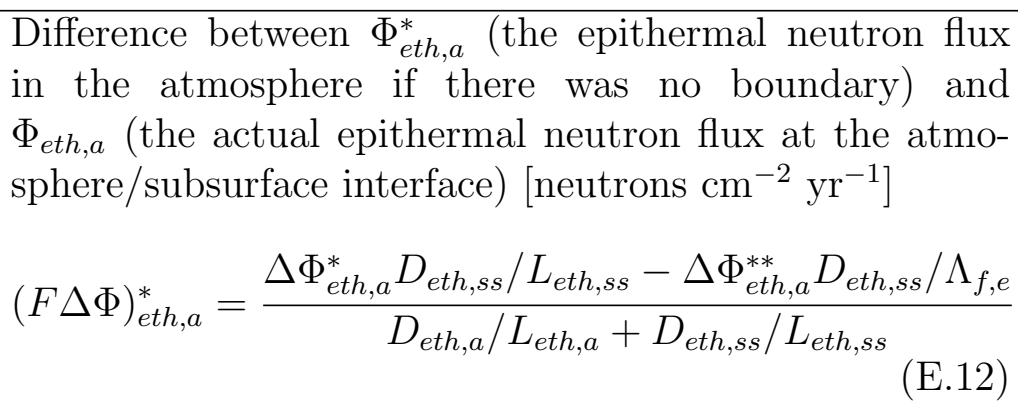 \\
\hline
\end{tabular}


Table E.8 - continued from previous page

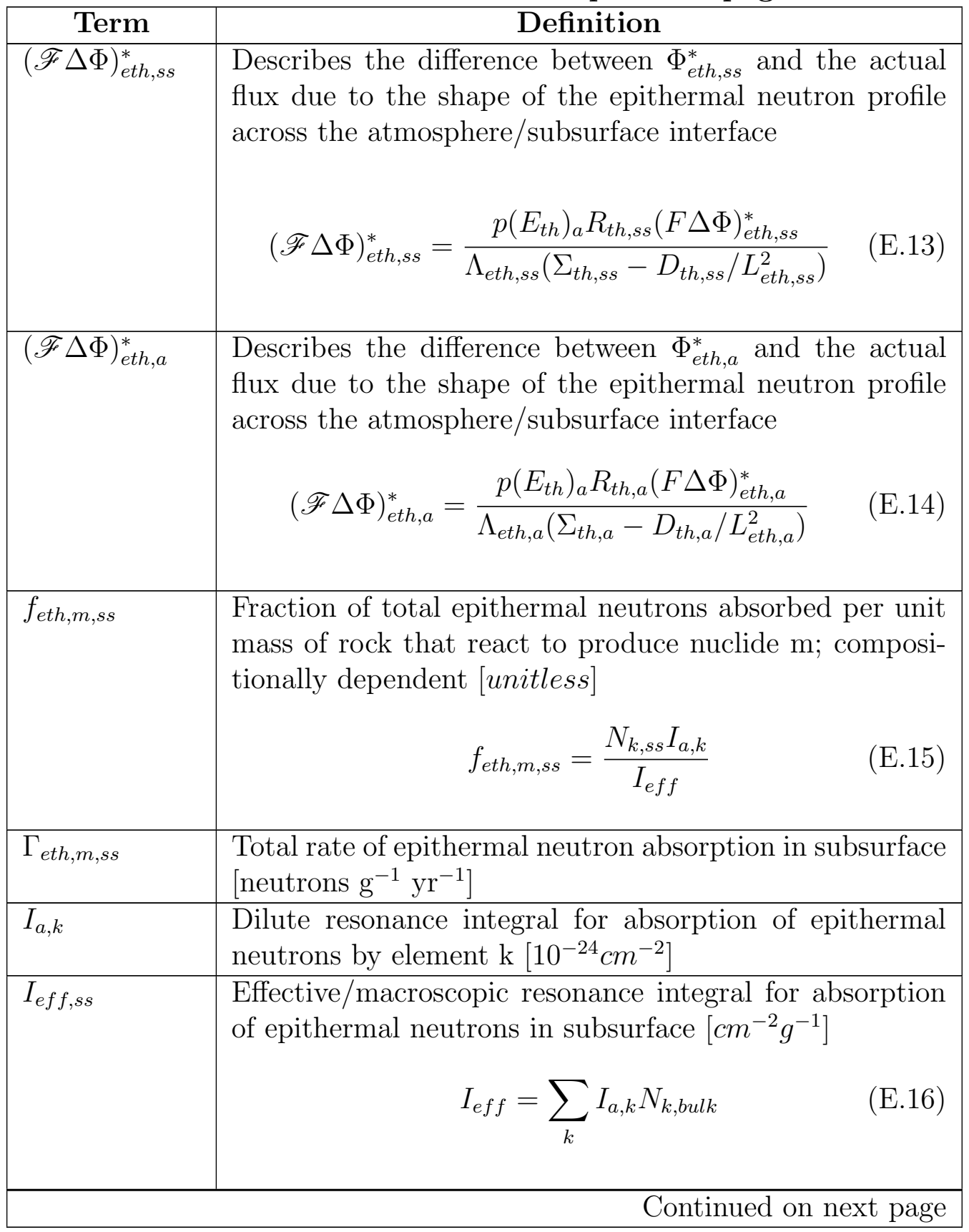


Table E.8 - continued from previous page

\begin{tabular}{|c|c|}
\hline Term & Definition \\
\hline$\Lambda_{e t h, s s}$ & $\begin{array}{l}\text { Effective epithermal neutron attenuation length in sub- } \\
\text { surface, accounting for both absorption and moderation } \\
{\left[\mathrm{g} \mathrm{cm}^{-2}\right]} \\
\qquad \Lambda_{\text {eth,ss }}=\left[\xi\left(I_{e f f, s s}+\Sigma_{s c, s s}\right)\right]^{-1}=\Sigma_{\text {eth,ss }}^{-1}\end{array}$ \\
\hline$\Lambda_{e t h, a}$ & $\begin{array}{l}\text { Effective epithermal neutron attenuation length in the } \\
\text { atmosphere, accounting for both absorption and moder- } \\
\text { ation }\left[\mathrm{g} \mathrm{cm}^{-2}\right] \\
\qquad \Lambda_{\text {eth,a}}=\left[\xi\left(I_{e f f, a}+\Sigma_{s c, a}\right)\right]^{-1}=\Sigma_{e t h, a}^{-1}\end{array}$ \\
\hline$L_{e t h, s s}$ & $\begin{array}{l}\text { Diffusion length for epithermal neutrons in the subsurface } \\
{\left[\mathrm{g} \mathrm{cm}^{-2}\right]} \\
\qquad L_{e t h, s s}=\left(\sqrt{3 \Sigma_{s c, s s} \Sigma_{e t h, s s}}\right)^{-1}\end{array}$ \\
\hline$\overline{L_{e t h, a}}$ & $\begin{array}{l}\text { Diffusion length for epithermal neutrons in the air }[\mathrm{g} \\
\left.\mathrm{cm}^{-2}\right] \\
\qquad L_{e t h, a}=\left(\sqrt{3 \Sigma_{s c, a} \Sigma_{e t h, a}}\right)^{-1}\end{array}$ \\
\hline$N_{k, \text { ss,bulk/target }}$ & $\begin{array}{l}\text { Atomic concentration of element } \mathrm{k} \text { in subsurface (target } \\
\text { or bulk specified as additional subscript) }[a t / g]\end{array}$ \\
\hline$N_{k, a}$ & Atomic concentration of element $\mathrm{k}$ in air $[a t / g]$ \\
\hline$P_{\text {eth }, m}$ & $\begin{array}{l}\text { Production rate for epithermal production of nuclide } \mathrm{m} \text {. } \\
\text { See eqn B. } 28 \text {. }\end{array}$ \\
\hline$\Phi_{\text {eth }, s s}(z)$ & $\begin{array}{l}\text { Epithermal neutron flux in subsurface [neutrons } \mathrm{cm}^{-2} \\
\mathrm{yr}^{-1} \text { ] }\end{array}$ \\
\hline & Continued on next page \\
\hline
\end{tabular}


Table E.8 - continued from previous page

\begin{tabular}{|c|c|}
\hline Term & Definition \\
\hline$\Phi_{\text {eth }, s s}^{*}$ & $\begin{array}{l}\text { Epithermal neutron flux that would be observed at the } \\
\text { land surface if the properties of the medium did not } \\
\text { change (e.g. identical to the subsurface).) [neutrons } \\
\left.\mathrm{cm}^{-2} \mathrm{yr}^{-1}\right] \text { (See equation B.6) } \\
\qquad \Phi_{\text {eth,ss }}^{*}=\mathrm{P}_{f}(0) \frac{R_{e t h, s s}}{\Sigma_{e t h, s s}-\frac{D_{e t h, s s}}{\Lambda_{f, e}^{2}}} \quad \text { (E.21) }\end{array}$ \\
\hline$\Phi_{\text {eth,a }}^{*}$ & $\begin{array}{l}\text { Epithermal neutron flux that would be observed at the } \\
\text { land surface if the properties of the medium did not } \\
\text { change (e.g. atmosphere identical to the air).) [neutrons } \\
\left.\mathrm{cm}^{-2} \mathrm{yr}^{-1}\right] \\
\qquad \Phi_{\text {eth,a }}^{*}=\mathrm{P}_{f}(0) \frac{R_{\text {eth }, a}}{\sum_{\text {eth,a}}-\frac{D_{\text {eth,a }}}{\Lambda_{f, e}^{2}}}\end{array}$ \\
\hline$P_{f}(Z)$ & $\begin{array}{l}\text { Production rate of epithermal neutrons from fast sec- } \\
\text { ondary cosmogenic neutrons as a function of depth. [neu- } \\
\left.\text { trons }(\mathrm{g} \text { air })^{-1} \mathrm{yr}^{-1}\right]\end{array}$ \\
\hline$P_{f}(0)$ & $\begin{array}{l}\text { is } P_{f} \text { at depth equal to } 0 \text { and is a calibrated production } \\
\text { rate parameter. [neutrons (g air })^{-1} \mathrm{yr}^{-1} \text { ] }\end{array}$ \\
\hline$p\left(E_{t h}\right)_{s s}$ & $\begin{array}{l}\text { Resonance escape probability in the subsurface - proba- } \\
\text { bility that a neutron will pass through the epithermal en- } \\
\text { ergy range to the thermal range without being absorbed } \\
\text { [unitless] } \\
\qquad p\left(E_{t h}\right)=\exp \left[-\frac{I_{e f f}}{\sum_{k} \xi_{k} N_{k, b u l k} \sigma_{s c, k}}\right]\end{array}$ \\
\hline & Continued on next page \\
\hline
\end{tabular}


Table E.8 - continued from previous page

\begin{tabular}{|c|c|}
\hline Term & Definition \\
\hline$p\left(E_{t h}\right)_{a}$ & $\begin{array}{l}\text { Resonance escape probability in the air - probability that } \\
\text { a neutron will pass through the epithermal energy range } \\
\text { to the thermal range without being absorbed [unitless]. } \\
\text { Value according to Phillips \& Plummer (1996). } \\
\qquad p\left(E_{t h}\right)_{a}=0.56\end{array}$ \\
\hline$R_{e t h, s s}$ & $\begin{array}{l}\text { Ratio of epithermal neutron production in the rock to } \\
\text { that of the atmosphere [unitless] } \\
\qquad R_{e t h, s s}=\sqrt{\frac{\bar{A}_{s s}}{A_{a}}}\end{array}$ \\
\hline$R_{e t h, a}$ & $\begin{array}{l}\text { Ratio of epithermal neutron production in the atmo- } \\
\text { sphere to that of the atmosphere [unitless]. } \\
\qquad R_{e t h, a}=\sqrt{\frac{\bar{A}_{a}}{A_{a}}}=1\end{array}$ \\
\hline$\Sigma_{e t h, s s}$ & $\begin{array}{l}\text { Effective epithermal loss cross-section in subsurface, by } \\
\text { both absorption and energy moderation }\left[\mathrm{cm}^{2} \mathrm{~g}^{-1}\right]\end{array}$ \\
\hline$\Sigma_{e t h, a}$ & $\begin{array}{l}\text { Effective epithermal loss cross-section in air, by both ab- } \\
\text { sorption and energy moderation }\left[\mathrm{cm}^{2} \mathrm{~g}^{-1}\right]\end{array}$ \\
\hline$\Sigma_{s c, s s}$ & $\begin{array}{l}\text { Macroscopic neutron scattering cross-section in subsur- } \\
\text { face }\left[\mathrm{cm}^{2} \mathrm{~g}^{-1}\right] \\
\qquad \Sigma_{s c, s s}=\sum_{k} N_{k, b u l k} \sigma_{s c, k}\end{array}$ \\
\hline$\Sigma_{s c, a}$ & $\begin{array}{l}\text { Macroscopic neutron scattering cross-section in air. Con- } \\
\text { stant }=0.3773\left[\mathrm{~cm}^{2} \mathrm{~g}^{-1}\right]\end{array}$ \\
\hline
\end{tabular}


Table E.8 - continued from previous page

\begin{tabular}{|l|l|}
\hline \multicolumn{1}{|c|}{ Term } & \multicolumn{1}{c|}{ Definition } \\
\hline$\sigma_{s c, k}$ & $\begin{array}{l}\text { Neutron scattering cross-section for element } \mathrm{k}\left[1 \times 10^{-24}\right. \\
\left.\mathrm{cm}{ }^{2}\right]\end{array}$ \\
\hline$\xi_{\text {bulk }}$ & $\begin{array}{l}\text { Macroscopic average log decrement neutron energy loss } \\
\text { per collision for the bulk rock }\end{array}$ \\
$\qquad \bar{\xi}_{b u l k}=\frac{\sum_{k} \xi_{k} \sigma_{s c, k} N_{k, s s, b u l k}}{\sum_{k} \sigma_{s c, k} N_{k, s s, b u l k}}$ \\
\hline$\xi_{k}$ & Average log decrement of energy loss for element k \\
\hline
\end{tabular}

Thermal Production

\begin{tabular}{|c|c|}
\hline$\overline{D_{t h, s s}}$ & $\begin{array}{l}\text { Diffusion coefficient for thermal neutrons in the subsur- } \\
\text { face [unitless] } \\
\qquad D_{t h, s s}=\left[3 \Sigma_{s c, s s}\left(1-\frac{2}{3 A_{s} s}\right)\right]^{-1}\end{array}$ \\
\hline$D_{t h, a}$ & $\begin{array}{l}\text { Diffusion coefficient for thermal neutrons in the atmo- } \\
\text { sphere }[\text { unitless }] \\
\qquad D_{t h, a}=\left[3 \Sigma_{s c, a}\left(1-\frac{2}{3 A_{a}}\right)\right]^{-1}\end{array}$ \\
\hline$\Delta \Phi_{t h, s s}^{*}$ & $\begin{array}{l}\text { Describes the difference between the hypothetical equi- } \\
\text { librium thermal neutron flux in the air and the subsurface } \\
\left.\text { [neutrons } \mathrm{cm}^{-2} \mathrm{yr}^{-1}\right] \\
\qquad \Delta \Phi_{t h, s s}^{*}=\Phi_{t h, a}^{*}-\Phi_{t h, s s}^{*}\end{array}$ \\
\hline & Continued on next page \\
\hline
\end{tabular}


Table E.8 - continued from previous page

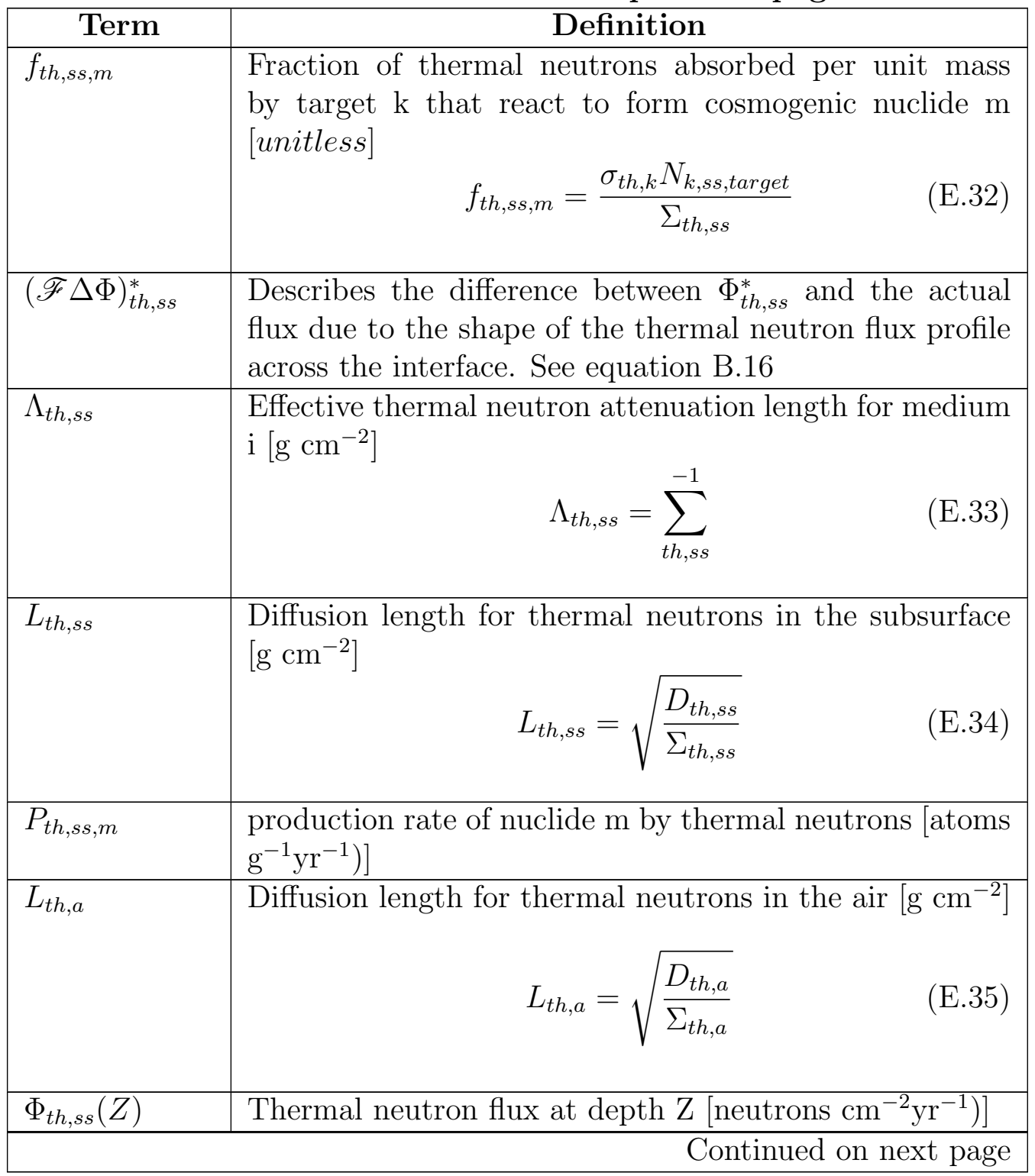


Table E.8 - continued from previous page

\begin{tabular}{|c|c|}
\hline Term & Definition \\
\hline$\Phi_{t h, s s}^{*}$ & $\begin{array}{l}\text { Thermal neutron flux that would be observed at the land } \\
\text { surface if the properties of the atmosphere and subsurface } \\
\text { were identical [neutrons } \mathrm{cm}^{-2} \mathrm{yr}^{-1} \text { ] } \\
\qquad \Phi_{t h, s s}^{*}=\frac{p\left(E_{t h}\right)_{a} R_{t h, s s} \Phi_{e t h, s s}^{*}}{\Lambda_{e t h, s s}\left(\Sigma_{t h, s s}-\frac{D_{t h, s s}}{\Lambda_{e t h, s s}^{2}}\right)}\end{array}$ \\
\hline$\overline{\Phi_{t h, a}^{*}}$ & $\begin{array}{l}\text { Thermal neutron flux that would be observed at the land } \\
\text { surface if the properties of the medium did not change } \\
\text { and were identical to the atmosphere [neutrons } \mathrm{cm}^{-2} \\
\left.\mathrm{yr}^{-1}\right] \\
\qquad \Phi_{t h, a}^{*}=\frac{p\left(E_{t h}\right)_{a} R_{t h, a} \Phi_{\text {eth,a}}^{*}}{\Lambda_{\text {eth,a}}\left(\Sigma_{t h, a}-\frac{D_{t h, a}}{\Lambda_{\text {eth,a }}^{2}}\right)}\end{array}$ \\
\hline$R_{t h, s s}$ & $\begin{array}{l}\text { Ratio of thermal neutron production in the rock to that } \\
\text { in the atmosphere [unitless] } \\
\qquad R_{t h, s s}=\frac{p\left(E_{t h, s s}\right)}{p\left(E_{t h, a}\right)}\end{array}$ \\
\hline$\sigma_{t h, s s, k}$ & $\begin{array}{l}\text { Elemental thermal neutron cross-section for the subsur- } \\
\text { face [barns] } 1 \text { barn }=10^{-24} \mathrm{~cm}^{2}\end{array}$ \\
\hline$\sigma_{t h, a, k}$ & $\begin{array}{l}\text { Elemental thermal neutron cross-section for the air } \\
\text { [barns] } 1 \text { barn }=10^{-24} \mathrm{~cm}^{2}\end{array}$ \\
\hline$\Sigma_{t h, s s}$ & $\begin{array}{l}\text { Macroscopic neutron absorption cross section }\left[\mathrm{cm}^{2} \mathrm{~g}^{-1}\right] \\
\qquad \Sigma_{t h, s s}=\sum_{k} \sigma_{t h, k} N_{k, s s, b u l k}=\Lambda_{t h, s s}^{-1}\end{array}$ \\
\hline$\overline{\Gamma_{t h, s s, m}}$ & $\begin{array}{l}\text { Total rate of thermal neutron absorption [neutrons } \\
\left.\left.\mathrm{g}^{-1} \mathrm{yr}^{-1}\right)\right]\end{array}$ \\
\hline Muons & \\
\hline
\end{tabular}


Table E.8 - continued from previous page

\begin{tabular}{|c|c|}
\hline Term & Definition \\
\hline$f_{i}^{*}$ & $\begin{array}{l}\text { Probability for particle emission to the radionuclide. See } \\
\text { Heisinger et al. (2002a). }\end{array}$ \\
\hline$f_{i, D}$ & $\begin{array}{l}\text { Fraction of muons stopped by element k and absorbed by } \\
\text { the nucleus before decay of the muon (Fabryka-Martin, } \\
\text { 1988) [unitless] }\end{array}$ \\
\hline \multirow[t]{2}{*}{$f_{i, C}$} & $\begin{array}{l}\text { Chemical compound factor [unitless] Chemical com- } \\
\text { pound factor (for Be, Al, C, see Heisinger et al. (2002a); } \\
\text { values computed on a sample by sample basis for }{ }^{36} \mathrm{Cl} \\
\text { due to variations in composition using values from von } \\
\text { Egidy \& Hartmann (1982). }\end{array}$ \\
\hline & $f_{i, C}=\frac{M_{k, b u l k} \Omega_{k}}{\sum j M_{j, b u l k} \Omega_{j}}$ \\
\hline $\mathrm{N}_{\text {atoms }}$ & Atom number density of the target atom $\left[\right.$ atoms $\left.\mathrm{g}^{-1}\right]$ \\
\hline$\Omega$ & $\begin{array}{l}\text { Atomic number of the element. Subscript k refers to the } \\
\text { target element and j refers to all elements in the rock. }\end{array}$ \\
\hline$\overline{\mathrm{P}}$ & $\begin{array}{l}\text { Average probability of muon capture by a nucleus rela- } \\
\text { tive to that of oxygen (von Egidy \& Hartmann, 1982) } \\
\text { [unitless] }\end{array}$ \\
\hline$P_{\mu-, m}$ & $\begin{array}{l}\text { Production rate for negative muon production of nuclide } \\
\text { m. See eqns B.3 and B.32. }\end{array}$ \\
\hline$P_{\mu, f a s t, m}$ & $\begin{array}{l}\text { Production rate for fast muon production of nuclide } \mathrm{m} \text {. } \\
\text { See eqn B. } 24 \text {. }\end{array}$ \\
\hline$P_{n, \mu}$ & $\begin{array}{l}\text { Production rate for muon-induced neutrons. See eqn } \\
\text { B. } 29 \text {. }\end{array}$ \\
\hline$P_{n, \mu}(Z)$ & $\begin{array}{l}\text { Total muon-induced neutron production at depth } \mathrm{Z} \text { [neu- } \\
\left.\text { trons } \mathrm{cm}^{-2} \mathrm{yr}^{-1}\right] \text {; value at surface is } P_{n, \mu}(0) \\
\qquad P_{n, \mu}(Z)=Y_{s} \Psi_{\mu}(Z)+5.8 \times 10^{-6} \Phi_{\mu f}(Z)\end{array}$ \\
\hline & Continued on next page \\
\hline
\end{tabular}


Table E.8 - continued from previous page

\begin{tabular}{|c|c|}
\hline Term & Definition \\
\hline$\Phi_{\nu, 0}$ & $\begin{array}{l}\text { Vertical muon flux at SLHL as a function of depth. Only } \\
\text { valid for depths of }<200,000 \mathrm{~g} / \mathrm{cm}^{2} \text {. See equation B.17. } \\
{\left[\mathrm{cm}^{-2} \mathrm{~s}^{-1} \mathrm{sr}^{-1}\right]}\end{array}$ \\
\hline$\phi_{\mu f}(Z, \theta)$ & $\begin{array}{l}\text { Fast muon flux at depth } \mathrm{Z}\left[\text { muons } \mathrm{g}^{-1} \mathrm{yr}^{-1}\right] \text {; calculated } \\
\text { from the muon code }\end{array}$ \\
\hline$\Psi_{\mu-}(Z)$ & $\begin{array}{l}\text { Slow negative muon stopping rate at depth } \mathrm{Z}\left[\mathrm{muons} \mathrm{g}^{-1}\right. \\
\left.\mathrm{yr}^{-1}\right] \text {; calculated from the muon code }\end{array}$ \\
\hline$R_{\mu-}(h)$ & $\begin{array}{l}\text { Rate of negative muons stopping at an atmospheric depth } \\
\text { of } h\end{array}$ \\
\hline$R_{\mu}(Z)$ & $\begin{array}{l}\text { Ratio of muon production to epithermal neutron produc- } \\
\text { tion [unitless] } \\
\qquad R_{\mu}(Z)=\frac{S_{e l, \mu} P_{n, \mu}(Z)}{S_{e l} P_{f}(0) R_{e t h}}\end{array}$ \\
\hline$R_{\mu}^{\prime}$ & $\begin{array}{l}\text { Ratio of the muon production rate to the production rate } \\
\text { for thermal neutrons. [unitless] See eqn B.33. } \\
\qquad R_{\mu}^{\prime}=\frac{p\left(E_{t h}\right)_{a}}{p\left(E_{t h}\right)} R_{\mu}\end{array}$ \\
\hline$\sigma_{190}$ & $\begin{array}{l}\text { Cross-section for fast muon production at } 190 \mathrm{GeV}[\mathrm{mb}] \text {. } \\
\text { Note: } 1 \text { barn }=1 \times 10^{-24} \mathrm{~cm}^{2}\end{array}$ \\
\hline$Y_{s}$ & $\begin{array}{l}\text { Average neutron yield per stopped negative muon [neu- } \\
\text { trons/(stopped negative muon)] } \\
\qquad Y_{s}=\sum_{k} f_{c, k, b u l k} f_{d, k} Y_{n, k}\end{array}$ \\
\hline$Y_{n, k}$ & $\begin{array}{l}\text { Average neutron yield per captured muon for element k } \\
\text { - (Fabryka-Martin, 1988) }\end{array}$ \\
\hline \multicolumn{2}{|c|}{ Radiogenic Production } \\
\hline$\overline{F_{k, b u l k}}$ & $\begin{array}{l}\text { Fractional abundance of element } \mathrm{k} \text { in } \mathrm{ppm} \text { in the bulk } \\
\text { rock }\end{array}$ \\
\hline & Continued on next page \\
\hline
\end{tabular}


Table E.8 - continued from previous page

\begin{tabular}{|l|l|}
\hline \multicolumn{1}{|c|}{ Term } & \multicolumn{1}{c|}{ Definition } \\
\hline$P_{r}$ & $\begin{array}{l}\text { Total radiogenic production from all mechanisms in a } \\
\text { particular sample. (equation B.37) }\end{array}$ \\
\hline$P_{n, \alpha}$ & $\begin{array}{l}\text { Production rate of neutrons from alpha particles in neu- } \\
\text { trons/g/yr }\end{array}$ \\
\hline$P_{n, s f}$ & $\begin{array}{l}\text { Neutron production rate due to the spontaneous fission } \\
\text { of }{ }^{238} \mathrm{U}\end{array}$ \\
\hline$S_{k}$ & $\begin{array}{l}\text { Mass stopping power of element } \mathrm{k} \text { for } \alpha \text {-particles of a } \\
\text { given energy }\end{array}$ \\
\hline $\mathrm{X}$ & $\begin{array}{l}\text { Neutron production factors related to the light isotope } \\
\text { composition of the rock matrix. See equation B.40. }\end{array}$ \\
\hline $\mathrm{Y}$ & $\begin{array}{l}\text { Neutron production factors related to the light isotope } \\
\text { composition of the rock matrix. See equation B.41. }\end{array}$ \\
\hline$Y_{n}^{U}$ & Neutron yields of element i per ppm $\mathrm{U}$ in equilibrium \\
\hline$Y_{n}^{T h}$ & Neutron yields of element i per ppm Th in equilibrium \\
\hline Accumulation &
\end{tabular}

\begin{tabular}{|c|c|}
\hline$D$ & $\begin{array}{l}\text { Depth of the sample with 'old' representing the original } \\
\text { sample depth and 'new' is the updated sample depth, } \\
\text { accounting for erosion during the time period }\end{array}$ \\
\hline$\Delta \mathrm{t}$ & Time step in the CRONUScalc program. \\
\hline$\epsilon$ & Erosion rate $\left[\mathrm{g} / \mathrm{cm}^{2}\right]$ \\
\hline$f_{\text {decay }}$ & $\begin{array}{l}\text { Decay factor that accounts for the fact that some of the } \\
\text { nuclides produced at the beginning of the time period } \\
\text { will have decayed by the end of the period. (equation } 8 \text { ) }\end{array}$ \\
\hline$\lambda$ & Decay constant for the nuclide \\
\hline$N_{t o t}$ & Total inventory in the sample up to the current time step \\
\hline$N_{\text {prev }}$ & Inventory from all previous time steps. \\
\hline$P_{t o t}$ & $\begin{array}{l}\text { Instantaneous production rate of the nuclide from all } \\
\text { mechanisms and is the sum of production from all other } \\
\text { mechanisms. }\end{array}$ \\
\hline
\end{tabular}




\section{References}

Amidon, W. H., \& Farley, K. A. (2010). Mass spectrometric He-3 measurement in He-4-rich phases: Techniques and limitations for cosmogenic He-3 dating of zircon, apatite, and titanite. Geochemistry Geophysics Geosystems, 11 .

Amidon, W. H., \& Farley, K. A. (2012). Cosmogenic He-3 and Ne-21 dating of biotite and hornblende. Earth and Planetary Science Letters, 313, 8694.

Amidon, W. H., Farley, K. A., Burbank, D. W., \& Pratt-Sitaula, B. (2008). Anomalous cosmogenic (3)He production and elevation scaling in the high Himalaya. Earth and Planetary Science Letters, 265, 287-301.

Amidon, W. H., Rood, D. H., \& Farley, K. A. (2009). Cosmogenic He-3 and Ne-21 production rates calibrated against Be-10 in minerals from the Coso volcanic field. Earth and Planetary Science Letters, 280, 194-204.

Argento, D. C., Stone, J. O., Reedy, R. C., \& O’Brien, K. (2014). Physics-based modeling of cosmogenic nuclides part II - Key aspects of in-situ cosmogenic nuclide production. Quaternary Geochronology, (p. doi:10.1016/j.quageo.2014.09.005).

Aumer, R. A. (2010). Calibration of low energy production of ${ }^{36} \mathrm{Cl}$ and the creation of an exposure age calculator. M.S. Thesis New Mexico Tech.

Balco, G., Stone, J. O., Lifton, N., \& Dunai, T. J. (2008). A complete and easily accessibly means of calculating surface exposure ages or erosion rates from ${ }^{10} \mathrm{Be}$ and ${ }^{26} \mathrm{Al}$ measurements. Quaternary Geochronology, 3, 174-195.

Bevington, P. R., \& Robinson, D. K. (1992). Data Reduction and Error Analysis for the Physical Sciences. (2nd ed.). McGraw-Hill, Inc.

Bierman, P. R. (1994). Using in situ produced cosmogenic isotopes to estimate rates of landscape evolution: A review from the geomorphic perspective. Journal of Geophysical Research, 99, 13885-13896.

Blard, P.-H., Balco, G., Burnard, P., Farley, K., Fenton, C., Friedrich, R., Jull, A., Niedermann, S., Pik, R., Schaefer, J. M., Scott, E., Shuster, D., Stuart, F., Tibari, B., Winckler, G., \& Zimmermann, L. (2014). An 
inter-laboratory comparison of cosmogenic ${ }^{3} \mathrm{He}$ and ${ }^{4} \mathrm{He}$ in the CRONUSP pyroxene standard. Quaternary Geochronology, CRONUS-Earth Special Volume, doi:10.1016/j.quageo.2014.08.004.

Blard, P.-H., \& Farley, K. (2008). The influence of radiogenic ${ }^{4} \mathrm{He}$ on cosmogenic ${ }^{3} \mathrm{He}$ determinations in volcanic olivine and pyroxene. Earth and Planetary Science Letters, 276, 20-29.

Blard, P.-H., \& Pik, R. (2008). An alternative isochron method for measuring cosmogenic ${ }^{3} \mathrm{He}$ in lava flows. Chemical Geology, 251, 20-32.

Borchers, B., Marrero, S. M., Balco, G., Caffee, M., Goehring, B., Gosse, J., Lifton, N., Nishiizumi, K., Phillips, F. M., Schaefer, J., \& Stone, J. O. (2015). Geological calibration of spallation production rates in the CRONUS-Earth project. Quaternary Geochronology, CRONUS-Earth special volume, doi:10.1016/j.quageo.2015.01.009.

Braucher, R., Bourles, D., Merchel, S., Vidani Romani, J., FernadezMosquera, D., Marti, K., Leanni, L., Chauvet, F., Arnold, M., Aumaitre, G., \& Keddadouche, K. (2013). Determination of muon attenuation lengths in depth profiles from in situ produced cosmogenic nuclides. Nuclear Instruments 83 Methods in Physics Research Section B - Beam Interactions with Materials and Atoms, 294, 484-490.

Braucher, R., Brown, E. T., Bourles, D., \& Colin, F. (2003). In situ produced ${ }^{10} \mathrm{Be}$ measurements at great depths: implications for production rates by fast muons. Earth and Planetary Science Letters, 211, 251-258.

Braucher, R., Del Castillo, P., Siame, L., Hidy, A. J., \& Bourles, D. L. (2009). Determination of both exposure time and denudation rate from an in situproduced ${ }^{10} \mathrm{Be}$ depth profile: A mathematical proof of uniqueness. model sensitivity and applications to natural cases:. Quaternary Geochronology, 4, 56-57.

Braucher, R., Merchel, S., Borgomano, J., \& Bourles, D. L. (2011). Production of cosmogenic nuclides at great depth: A multi element approach. Earth and Planetary Science Letters, 309, 1-9.

Cerling, T. E. (1990). Dating Geomorphic Surfaces Using Cosmogenic ${ }^{3} \mathrm{He}$. Quaternary Research, 33, 148-156. 
Charalambus, S. (1971). Nuclear transmutation by negative stopped muons and the activity induced by the Cosmic-Ray muons. Nuclear Physics, A166, 145-161.

Chmeleff, J., von Blankenburg, F., Kossert, K., \& Jakob, D. (2010). Determination of the ${ }^{10} \mathrm{Be}$ half-life by multicollector ICP-MS and liquid scintillation counting. Nuclear Instruments and Methods in Physics Research Section B - Beam Interactions with Materials and Atoms, 268, 192-199.

Dep, L., Elmore, D., Lipshutz, M., Vogt, S., Phillips, F., \& Zreda, M. G. (1994). Depth dependence of cosmogenic neutron-captured-produced ${ }^{36} \mathrm{Cl}$ in a terrestrial rock. Nuclear Instruments and Methods in Physics Research B, 92, 301-307.

Desilets, D., \& Zreda, M. G. (2003). Spatial and temporal distribution of secondary cosmic-ray nucleon intensities and applications to in situ cosmogenic dating. Earth and Planetary Science Letters, 206, 21-42.

Desilets, D., Zreda, M. G., Almasi, P. F., \& Elmore, D. (2006a). Determination of cosmogenic ${ }^{36} \mathrm{Cl}$ in rocks by isotope dilution: innovations, validation and error propagation. Chemical Geology, 233, 185-195.

Desilets, D., Zreda, M. G., \& Prabu, T. (2006b). Extended scaling factors for in situ cosmogenic nuclides: New measurements at low latitude. Earth and Planetary Science Letters, 246, 265-276.

Dorman, L. I., Valdes-Galicia, J. F., \& Dorman, I. V. (1999). Numerical simulation and analytical description of solar neutron transport in the Earth's atmosphere. Journal of Geophysical Research1, 104, 22417-22426.

Dunai, T. (2001a). Influence of secular variation of the geomagnetic field on production rates of in situ produced cosmogenic nuclides. Earth and Planetary Science Letters, 193, 197-212.

Dunai, T., Binnie, S. A., Hein, A. S., \& Paling, S. M. (2014). The effects of a hydrogen-rich ground cover on cosmogenic thermal neutrons: Implications for exposure dating. Quaternary Geochronology, 22, 183-191.

Dunai, T. J. (2000). Scaling factors for production rates of in situ produced cosmogenic nuclides: a critical reevaluation. Earth and Planetary Science Letters, $176,157-169$. 
Dunai, T. J. (2001b). Reply to comment on 'Scaling factors for production rates of in situ produced cosmogenic nuclides: a critical reevaluation' by Darin Desilets, Marek Zreda, and Nathaniel Lifton. Earth and Planetary Science Letters, 188, 289-298.

Dunai, T. J. (2010). Cosmogenic Nuclides: Principles, Concepts and Applications in the Earth Surface Sciences. Cambridge University Press.

Dunai, T. J., Stuart, F. M., Pik, R. I., Burnard, P., \& Gayer, E. (2007). Production of $3 \mathrm{He}$ in crustal rocks by cosmogenic thermal neutrons. Earth and Planetary Science Letters, 258, 228-236.

Dunne, J., Elmore, D., \& Muzikar, P. (1999). Scaling factors for the rates of production of cosmogenic nuclides for geometric shielding and attenuation at depth on sloped surfaces. Geomorphology, 27, 3-11.

von Egidy, T., \& Hartmann, F. J. (1982). Average muonic coulomb capture probabilities for 65 elements. Physical Review A, 26, 2355-2360.

Eidelman, S. (2004). Review of Particle Physics*1. Physics Letters B, 592, $1-5$.

Evans, J. M. (2001). Calibration of the production rates of cosmogenic 36Cl from potassium. Ph.D. thesis The Australian National University, Canberra. Doctorate of Philosophy.

Fabryka-Martin, J. (1988). Production of radionuclides in the earth and their hydrogeologic significance, with emphasis on chlorine-36 and iodine129. Ph.D. thesis University of Arizona, Hydrology and Water Resources, Tucson. Doctor of Philosphy with a major in Hydrology.

Farber, D. L., Mériaux, A.-S., \& Finkel, R. C. (2008). Attenuation length for fast nucleon production of ${ }^{10} \mathrm{Be}$ derived from near-surface production profiles. Earth and Planetary Science Letters, 274, 295-300.

Farley, K. A., Libarkin, J., Mukhopadhyay, S., \& Amidon, W. (2006). Cosmogenic and nucleogenic He-3 in apatite, titanite, and zircon. Earth and Planetary Science Letters, 248, 451-461.

Feige, Y., Oltman, B. G., \& Kastner, J. (1968). Production Rates of Neutrons in Soils Due to Natural Radioactivity. Journal of Geophysical Research, 73, 3135-3142. 
Friedlander, G., Kennedy, J. W., Macias, E. S., \& Miller, J. M. (1981). Nuclear and Radiochemistry. (2nd ed.). John Wiley \& Sons, Inc.

Gaisser, T. K. (1990). Cosmic Rays and Particle Physics. Cambridge: Cambridge University Press.

Goehring, B. M., Kelly, M. A., Schaefer, J. M., Finkel, R., \& Lowell, T. V. (2010a). Dating of raised marine and lacustrine deposits in east Greenland using beryllium-10 depth profiles and implications for estimates of subglacial erosion. Journal of Quaternary Science, 26, 865-874.

Goehring, B. M., Kurz, M. D., Balco, G., Schaefer, J. M., Licciardi, J., \& Lifton, N. (2010b). A reevaluation of in situ cosmogenic ${ }^{3}$ He production rates. Quaternary Geochronology, 5, 410-418.

Goehring, B. M., Schimmelpfennig, I., \& Schaefer, J. M. (2014). Capabilities of the lamont-doherty earth observatory in situ ${ }^{14} \mathrm{C}$ extraction laboratory updated. Quaternary Geochronology, 19, 194-197.

Goldhagen, P., Reginatto, M., Kniss, T., Wilson, J. W., Singleterry, R. C., Jones, I. W., \& Steveninck, W. V. (2002). Measurement of the energy spectrum of cosmic-ray induced neutrons aboard an ER-2 high-altitude airplane. Nuclear Instruments and Methods in Physics Research A, 476, $42-51$.

Gosse, J. C., \& Phillips, F. M. (2001). Terrestrial in situ cosmogenic nuclides: theory and application. Quaternary Science Reviews, 20, 1475-1560.

Granger, D., \& Muzikar, P. (2001). Dating sediment burial with in situproduced cosmogenic nuclides: theory, techniques, and limitations. Earth and Planetary Science Letters, 188, 269-281.

Granger, D. E. (2006). A review of burial dating methods using ${ }^{26} \mathrm{Al}$ and ${ }^{10}$ Be. In L. Siame, D. L. Bourles, \& E. T. Brown (Eds.), In situ-produced cosmogenic nuclides and quantification of geological processes (pp. 1-16). volume 415 of Geological Society of America Special Papers.

Granger, D. E., \& Smith, A. L. (2000). Dating buried sediments using radioactive decay and muogenic production of Al-26 and Be-10. Nuclear Instruments \& Methods in Physics Research, B126, 822-826. 
Groom, D., Mokhov, N., \& Striganov, S. (2001). Muon stopping power and range tables $10 \mathrm{MeV}-100 \mathrm{TeV}$. Atomic Data and Nuclear Data Tables, 78 , $183-356$.

Handwerger, D. A., Cerling, T. E., \& Bruhn, R. L. (1999). Cosmogenic ${ }^{14} \mathrm{C}$ in carbonate rocks. Geomorphology, 27, 13-24.

Hein, A. S., Hulton, N. R., Dunai, T. J., Schnabel, C., Kaplan, M. R., Naylor, M., \& Xu, S. (2009). Middle Pleistocene glaciation in Patagonia dated by cosmogenic-nuclide measurements on outwash gravels. Earth, 286, 184-197.

Heisinger, B., Lal, D., Jull, A. J. T., Kubik, P., Ivy-Ochs, S., Knie, K., \& Nolte, E. (2002a). Production of selected cosmogenic radionuclides by muons: 2. Capture of negative muons. Earth and Planetary Science Letters, 200, 357-369.

Heisinger, B., Lal, D., Jull, A. J. T., Kubik, P., Ivy-Ochs, S., Neumaier, S., Knie, K., Lazarev, V., \& Nolte, E. (2002b). Production of selected cosmogenic radionuclides by muons: 1. Fast muons. Earth and Planetary Science Letters, 200, 345-355.

Hidy, A. J., Gosse, J. C., Pederson, J. L., Mattern, J. P., \& Finkel, R. C. (2010). A geologically constrained Monte Carlo approach to modeling exposure ages from profiles of cosmogenic nuclides: An example from Lees Ferry, Arizona. Geochemistry Geophysics Geosystems, 11, doi: 10.1029/2010GC003084.

Hillas, A. M. (1972). Cosmic Rays. Oxford: Pergamon Press.

Jull, A., Scott, E., \& Bierman, P. (2013). The CRONUS-Earth intercomparison for cosmogenic isotope analysis. Quaternary Geochronology, CRONUS-Earth Special Volume, doi:10.1016/j.quageo.2013.09.003.

Jull, A., Scott, E., \& Marrero, S. (2011). The CRONUS-Earth intercomparison for cosmogenic isotope analysis. In The Twelfth International Conference on Accelerator Mass Spectrometry (p. 242).

Kim, K. J., \& Englert, P. A. J. (2004). Profiles of in situ ${ }^{10} \mathrm{Be}$ and ${ }^{26} \mathrm{Al}$ at great depths at the Macraes Flat, East Otago. Earth and Planetary Science Letters, 223, 113-126. 
Kim, K. J., Lal, D., Englert, P. A. J., \& Southon, J. (2007). In situ ${ }^{14}$ C depth profile of subsurface vein quartz samples from Macraes Flat New Zealand. Nuclear Instruments and Methods in Physics Research Section B - Beam Interactions with Materials and Atoms, 259, 632-636.

Korschinek, G., Bergmaier, A., Faestermann, T., Gerstmann, U. C., Knie, K., Rugel, G., Wallner, A., Dillmann, I., Dollinger, G., Lierse von Gostomski, C., Kossert, K., Maiti, M., Poutivtsec, M., \& Remmert, A. (2010). A new value for the half-life of ${ }^{10} \mathrm{Be}$ by heavy-ion elastic recoil detection and liquid scintillation counting. Nuclear Instruments and Methods in Physics Research Section B - Beam Interactions with Materials and Atoms, B268, 187-191.

Korte, M., \& Constable, C. G. (2005). Continuous geomagnetic field models for the past 7 millennia: 2. CALS7K. Geochemistry, Geophysics, Geosystems, 6, Q02H16.

Kurz, M. D. (1986). Cosmogenic helium in a terrestrial igneous rock. Nature, 320, 435-439.

Laj, C., Kissel, C., Beer, J., Channell, J., Kent, D., Lowrie, W., \& Meert, J. (2004). High resolution global paleointensity stack since 75 kyr (GLOPIS75) calibrated to absolute values. Timescales of the Geomagnetic Field, (pp. 255-265).

Lal, D. (1958). Investigations of Nuclear Interactions Produced by Cosmic Rays. Phd Bombay University.

Lal, D. (1987). Production of ${ }^{3}$ he in terrestrial rocks. Chemical Geology, 66 , 89-98.

Lal, D. (1988). In Situ-Produced Cosmogenic Isotopes in Terrestrial Rocks. Ann. Rev. Earth Planet. Sci, 16, 355-388.

Lal, D. (1991). Cosmic ray labeling of erosion surfaces: In situ nuclide production rates and erosion models. Earth and Planetary Science Letters, $104,424-439$.

Lal, D., \& Peters, B. (1967). Cosmic ray produced radioactivity on the earth. In K. Sitte (Ed.), Hanbuch der Physik (pp. 551-612). Berlin: Springer. 
Lifton, N., Sato, T., \& Dunai, T. J. (2014). Scaling in situ cosmogenic nuclide production rates using analytical approximations to atmospheric cosmic-ray fluxes. Earth and Planetary Science Letters, 386, 149-160.

Lifton, N., Smart, D. F., \& Shea, M. A. (2008). Scaling time-integrated in situ cosmogenic nuclide production rates using a continuous geomagnetic model. Earth and Planetary Science Letters, 268, 190-201.

Lifton, N. A., Bieber, J. W., Clem, J. M., Duldig, M. L., Evenson, P., Humble, J. E., \& Pyle, R. (2005). Addressing solar modulation and long-term uncertainties in scaling in situ cosmogenic nuclide production rates. Earth and Planetary Science Letters, 239, 140-161.

Lifton, N. A., Jull, A. J. T., \& Quade, J. (2001). A new extraction technique and production rate estimate for in situ cosmogenic ${ }^{14} \mathrm{C}$ in quartz. Geochimica et Cosmochimica Acta, 65, 1953-1969.

Lupker, M., Hippe, K., Kober, F., Wacker, L., Braucher, R., Bourles, D. L., Vidal Romani, J., \& Weiler, R. (2013). Depth-dependence of the production rate of in-situ ${ }^{14} \mathrm{C}$ in quartz. American Geophysical Union Fall Meeting, Poster EP13C-0849.

Lupker, M., Hippe, K., Wacker, L., Kober, F., Maden, C., Braucher, R., Bourles, D., Vidal Romani, J., \& Wieler, R. (2015). Depth-dependence of the production rate of in-situ ${ }^{14} \mathrm{c}$ in quartz from the Leymon High core, Spain. Quaternary Geochronology, 28, 80-87.

Marrero, S., Phillips, F., Caffee, M., \& Gosse, J. (2015). CRONUS-Earth cosmogenic ${ }^{36} \mathrm{Cl}$ calibration. Quaternary Geochronology, CRONUS-Earth Special Volume, submitted.

Marrero, S. M. (2012). Calibration of Cosmogenic Chlorine-36. Doctorate New Mexico Tech, Dept of Earth \& Environmental Science.

Marrero, S. M., Phillips, F. M., Caffee, M., Stone, J. O., Swanson, T., \& Hinz, M. (this volume, submitted). Resampling of puget lowlands yields lower discrepancy in cosmogenic chlorine-36 production rates. Quaternary Geochronology, CRONUS Special Volume.

Masarik, J., Kollar, D., \& Vanya, S. (2000). Numerical simulation of in situ production of cosmogenic nuclides: Effects of irradiation geometry. 
Nuclear Instruments and Methods in Physics Research Section B: Beam Interactions with Materials and Atoms, 172, 786-789.

Mughabghab, S. (2006). Atlas of Neutron Resonances: Resonance parameters and thermal cross-sections $Z=1-100$. Elsevier Science Ltd.

Nishiizumi, K., Imamura, M., Caffee, M. W., Southon, J. R., Finkel, R. C., \& McAninch, J. (2007). Absolute calibration of 10Be AMS standards. Nuclear Instruments and Methods in Physics Research Section B - Beam Interactions with Materials and Atoms, 258, 403-413.

Nishiizumi, K., Winterer, E. L., Kohl, C. P., Klein, J., Middleton, R., Lal, D., \& Arnold, J. R. (1989). Cosmic ray production rates of ${ }^{10} \mathrm{Be}$ and ${ }^{26} \mathrm{Al}$ in quartz from glacially polished rocks. Journal of Geophysical Research, 94,9 .

Phillips, F., Stone, W. D., \& Fabryka-Martin, J. (2001). An improved approach to calculating low-energy cosmic-ray neutron fluxes near the land/atmosphere interface. Chemical Geology, 175, 689-701.

Phillips, F. M., Argento, D. C., Balco, G., Caffee, M. W., Clem, J., Dunai, T., Finkel, R., Goehring, B., Gosse, J. C., Hudson, A., Jull, T. A., Kelly, M., Kurz, M., Lal, D., Lifton, N., Marrero, S. M., Nishiizumi, K., Reedy, R., Schaefer, J., Stone, J. O., Swanson, T., \& Zreda, M. G. (2015). The cronus-earth project: A synthesis. Quaternary Geochronology, CRONUSEarth, submitted.

Phillips, F. M., \& Plummer, M. A. (1996). CHLOE: a program for interpreting in-situ cosmogenic nuclide data for surface exposure dating and erosion studies. Radiocarbon (Abstr. 7th Int. Conf. Accelerator Mass Spectrometry), 38, 98-99.

Pigati, J., Lifton, N., Jull, A., \& Quade, J. (2010). A simplified in situ cosmogenic ${ }^{14} \mathrm{C}$ extraction system. Radiocarbon, 52, 1236-1243.

Pigati, J. S., \& Lifton, N. (2004). Geomagnetic effects on time-integrated cosmogenic nuclide production with emphasis on in situ ${ }^{14} \mathrm{C}$ and ${ }^{10} \mathrm{Be}$. Earth and Planetary Science Letters, 226, 193-205. 
Reedy, R. C. (2013). Cosmogenic nuclide production rates: Reaction cross section update. Nuclear Instruments and Methods in Physics Research Section B - Beam Interactions with Materials and Atoms, 294, 470-474.

Sato, T., Yasuda, H., Niita, K., Endo, A., \& Sihver, L. (2008). Development of PARMA: PHITS-based analytical radiation model in the atmosphere. Radiation Research, 170, 244-259.

Schaefer, J. M., Denton, G. H., Kaplan, M. R., Putnam, A. E., Finkel, R., Barrell, D. J. A., Andersen, B. G., Schwartz, R., Mackintosh, A., Chinn, T., \& Schluchter, C. (2009). High-frequency holocene glacier fluctuations in new zealand differ from the northern signature. Science, 324, 622-625.

Schaefer, J. M., Winckler, G., Blard, P.-H., Balco, G., Shuster, D., Friedrich, R., \& Schluechter, C. (2014). Performance of CRONUS-P: a pyroxene reference material for helium isotope analysis. Quaternary Geochronology, CRONUS-Earth Special Volume, doi:10.1016/j.quageo.2013.09.003.

Schaller, M., Ehlers, T., Blum, J., \& Kallenberg, M. (2009). Quantifying glacial moraine age, denudation, and soil mixing with cosmogenic nuclide depth profiles. Journal of Geophysical Research, 114, doi: 10.1029/2007/JF000921.

Schimmelpfennig, I. (2009). Cosmogenic ${ }^{36} \mathrm{Cl}$ in $\mathrm{Ca}$ and $\mathrm{K}$ rich minerals: analytical developments, production rate calibrations and cross calibration with ${ }^{3} \mathrm{He}$ and ${ }^{21} \mathrm{Ne}$. Doctorale Universite Paul Cezanne Aix-Marseille III Cerege.

Schimmelpfennig, I., Benedetti, L., Finkel, R., Pik, R., Blard, P.-H., Bourlès, D., Burnard, P., \& Williams, A. (2009). Sources of in-situ ${ }^{36} \mathrm{Cl}$ in basaltic rocks. Implications for calibration of production rates. Quaternary Geochronology, (pp. 441-461).

Schimmelpfennig, I., Benedetti, L., Pik, R., Burnard, P., Blard, P., Dunai, T. J., \& Bourles, D. L. (2008). In situ cosmogenic ${ }^{36} \mathrm{Cl}$ production rate calibration from $\mathrm{Ca}$ and $\mathrm{K}$ in lava flows. Goldschmidt Abstracts, .

Shea, M. A., \& Smart, D. F. (1983). A world grid of calculated cosmic ray vertical cutoff rigidities for 1980. Proceedings from the 18th International Cosmic Ray Conference, 3, 415-418. 
Stone, J. (2000). Air pressure and cosmogenic isotope production. Journal of Geophysical Research, 105, 23753-23760.

Stone, J. O. H., Evans, J. M., Fifield, L. K., Allan, G. L., \& Cresswell, R. G. (1998). Cosmogenic chlorine-36 production in calcite by muons. Geochimica et Cosmochimica Acta, 62, 433-454.

Uppala, S., Kallberg, P., Simmons, A., Andrae, U., Bechtold, V., Fiorino, M., Gibson, J., Haseler, J., Hernandez, A., Kelly, G., Li, X., Onogi, K., Saarinen, S., Sokka, N., Allan, R., Andersson, E., Arpe, K., Balmaseda, M., Beljaars, A., Berg, L., Bidlot, J., Bormann, N., Caires, S., Chevallier, F., Dethof, A., Dragosavac, M., Fisher, M., Fuentes, M., Hagermann, S., Holm, E., Hoskins, B., Isaksen, L., Janssen, P., Jenne, R., Mcnally, A., Mahfouf, J., Morcrette, J., Rayner, N., Saunders, R., Simon, P., Sterl, A., Trenberth, K., Untch, A., Vasiljevic, D., Viterbo, P., \& Woollen, J. (2005). The ERA-40 reanalysis. Quarterly Journal of the Royal Meteorological Society, 131, 2961-3012.

Vermeesch, P., Balco, G., Blard, P.-H., Dunai, T. J., Kober, F., Niedermann, S., Shuster, D., Strasky, S., Stuart, F., Wieler, R., \& Zimmerman, L. (2012). Interlaboratory comparison of cosmogenic $21 \mathrm{Ne}$ in quartz. Quaternary Geochronology, http://dx.doi.org/10.1016/j.quageo.2012.11.009, CRONUS-Earth Special Volume.

Wieler, R., Beer, J., \& Leya, I. (2013). The Galactic Cosmic Ray Intensity over the Past $10^{6}-10^{9}$ Years as Recorded by Cosmogenic Nuclides in Meteorites and Terrestrial Samples. Space Science Reviews, 176, $351-$ 363.

Williams, A., Stuart, F., Day, S., \& Phillips, W. (2005). Using pyroxene microphenocrysts to determine cosmogenic $3 \mathrm{He}$ concentrations in old volcanic rocks: an example of landscape development in central gran canaria. Quaternary Science Reviews, 24, 211-222.

Ziegler, L. B., Constable, C. G., Johnson, C. L., \& Tauxe, L. (2011). PADM2M: a penalized maximum likelihood model of the 0-2 Ma paleomagnetic axial diple moment. Geophys. J. Int., doi: 10.1111/j.1365246X.2010.04905.x, . 
${ }_{2146}$ Zreda, M., Desilets, D., Ferre, T. P. A., \& Scott, R. L. (2008). Measuring soil 2147 moisture content non-invasively at intermediate spatial scale using cosmicray neutrons. Geophysical Research Letters, 35. 